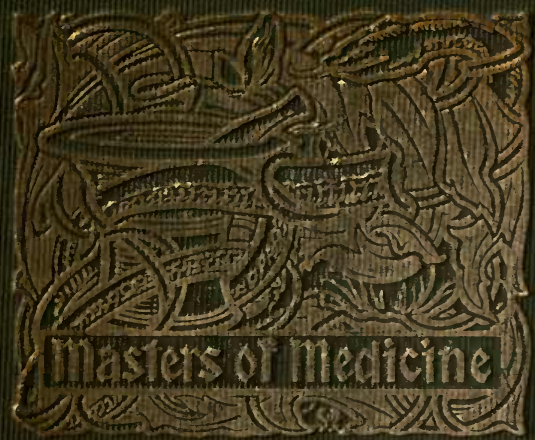

hermain won helmbolt? by Jokn G. Me Kendrick 


\section{UBRARY \\ UATVESITY OF CALIFORNU RIVERSIDE}

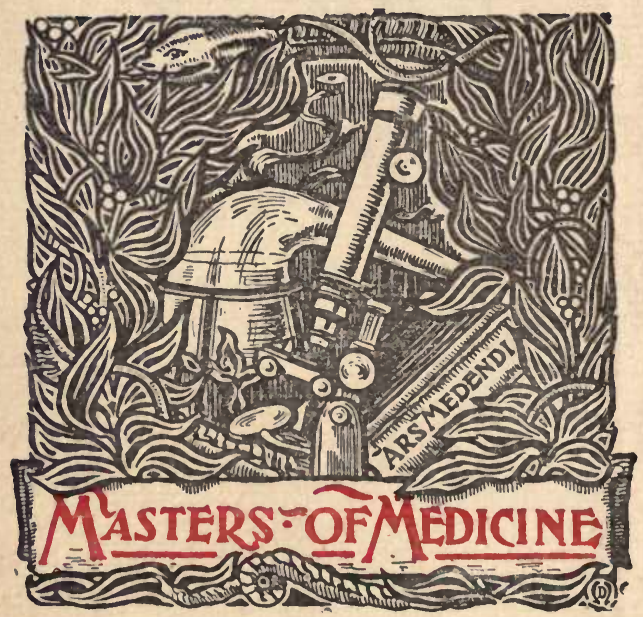




MeASTERS OF MEDICIאE

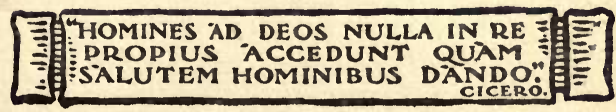




\section{Masters of Medicine}

Title

John Hunter. - . - Stephen Paget

William Harvey . . . D'Arcy Power

Sir James Young Simpson • H. Laing Gordon William Stokes . . . Sir William Stokes

Sir Benjamin Brodie . Timothy Holmes

Claude Bernard . . . Sir Michael Foster

Hermann L. F. von Helmholtz F. G. M`Kendrick

\section{In Preparation}

Thomas Sydenham ․ $\quad \mathcal{F}$. F. Payne

Andreas Vesalius . . . C. Louis Taylor 


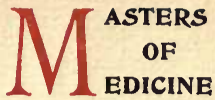

H. L. F. VON HELMHOLTZ 


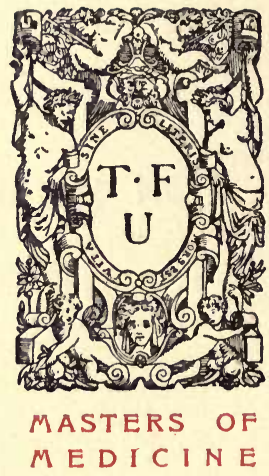





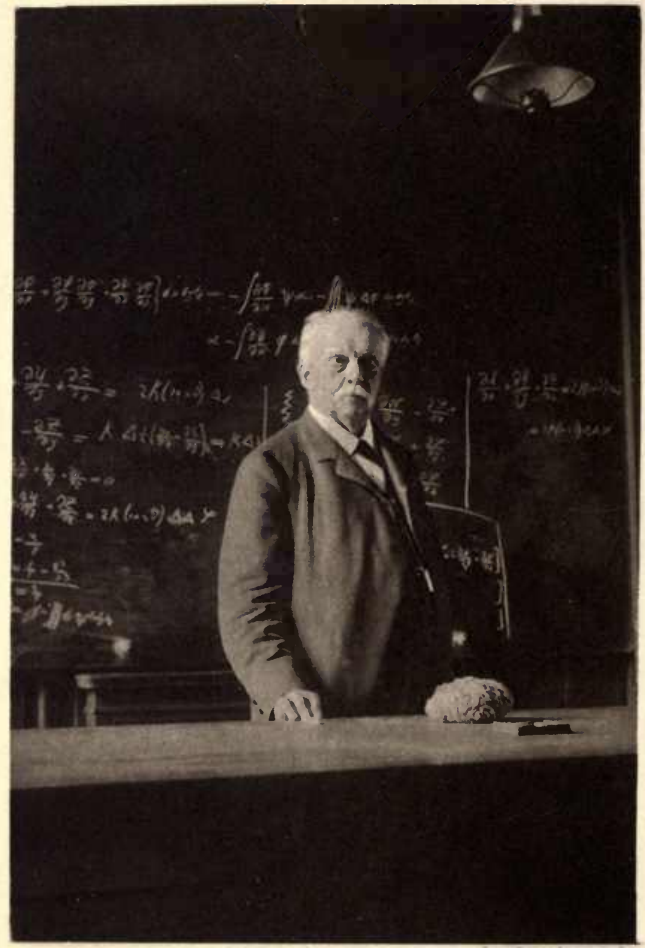

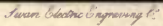

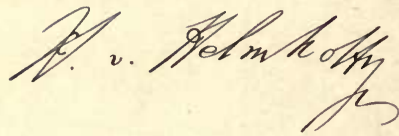




\section{Hermann Ludwig}

Ferdinand von Helmhole

MY

\section{John Gray M'Kendrick}

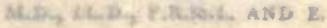

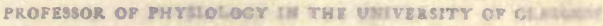

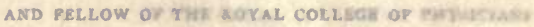
OF ISDINBUROH

\section{$\angle O N D O N$}

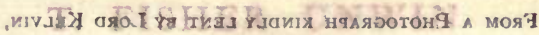

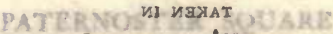

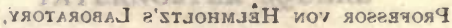

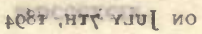




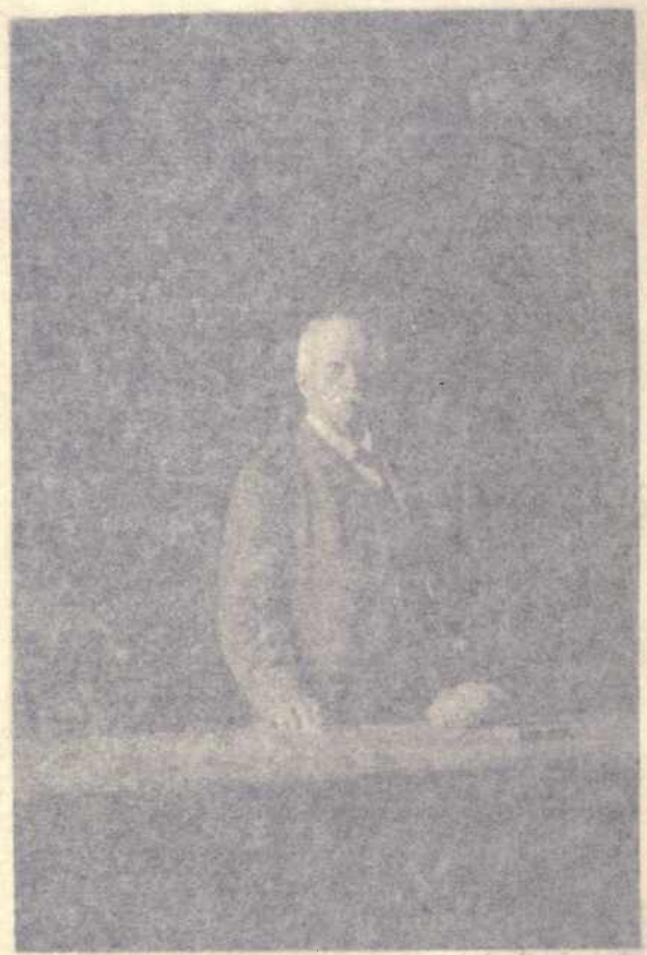

From a Photograph kindly lent by I lord Kelvin, TAKEN IN

Profrssor, von Hélimoltz's l,aboratory, ON JULY 7 TH, 1894 


\section{Hermann Ludwig}

\section{Ferdinand von Helmholtz}

BY

\section{John Gray M'Kendrick 111 M.D., LL.D., F.R.SS.L. AND E.}

PROFESSOR OF PHYSIOLOGY IN THE UNIVERSTTY OF GLASGOW AND FELLOW OF THE ROYAL COLLEGE OF PHYSICIANS OF EDINBURGH

$L O N D O N$

T. FISHER UNWIN

PATERNOSTER SQUARE 


\section{$Q 143$ \\ $15 \mathrm{MH4}$}

Copyright by $\mathcal{T}$. Fisher Unwin, 1899, for Great Britain and Longmans, Green छ Co. for the United States of America 
TO MY FRIEND

JAMES DEWAR

IN MEMORY OF OLD DAYS OF

MUTUAL WORK AND

ENCOURAGEMENT 



\section{PREFACE}

\section{林}

$\mathrm{T}_{\mathrm{H}}$ Is work is a record of the achievements in scientific discovery and invention of one of the greatest minds of the nineteenth century. Helmholtz was one whose private life was known only to a few, and he would have instinctively recoiled from biographical revelations of a purely personal character. At the same time, I have endeavoured to give the reader some idea of the man-calm, placid, reserved, thoughtful-whose love of truth, yearning spirit of inquiry, and great intellectual powers give him a place in the front ranks of the interpreters of Nature. A life full of intellectual activity, creative, ever productive, could not contain much in the way of trivial incident. I have also tried, by following a historical method, to trace the history of any branch of inquiry up to the 
xiv

point when it came under the survey of Helmholtz, and then I have given an account of the contributions made by himself. Few are able to tread in the footsteps of Helmholtz, even although these are carefully pointed out by a competent guide; but this volume may at all events give an outline of the paths along which he trod.

The proofs have been read by $\mathrm{Mr}$ J. L. Galbraith, of the Library of the University of Glasgow, to whom I owe my thanks; and I have gratefully to acknowledge much valuable assistance and friendly criticism from Dr Cargill G. Knott, Lecturer on Mathematical Physics in the University of Edinburgh.

The characteristic portrait was most kindly lent by Lord Kelvin. It was taken by $\mathrm{Mr}$ Henderson, a student of physics at that time, and it represents Helmholtz at his lecture table on July 7,1894 , a few days before his final illness:

JOHN G. M'KENDRICK.

University of Glasgow,

September, 1899. 


\section{CONTENTS}

\section{प्रत्र}

CHAP.

I. Childhood and Early Life . . I

II. Student Life and Early Manhood - 8

1II. Science in Grrmany in the Eighteenth and Early Part of the Nineteenth Centuries . . . . $\quad 18$

IV. Helmholtz in Berlin-Fermentation -Animal Heat . . . 25

V. Helmholtz in Berlin-The ConservaTION OF ENERGY • • • • 39

VI. Helmholtz in Königsberg-MeasureMENT OF THE RAPIDITY OF THE Nervous Impulse . $\quad . \quad .58$

VII. Helmholtz in Königsberg-The OPhTHALMOSCOPE • • • • • 7 I

VIII. Helmholtz in Königsberg-The MeCHANISM OF ACCOMMODATION-FIRST VISIT TO ENGLAND . . . . 88 
CHAP.

IX. Helmholtz in Königsberg-Animal Electricity . • • . 104

X. Helmholtz in Königsberg-Studies in Colour $\quad$. $\quad . \quad$.

XI. Helmholtz in Bonn and Heidelberg -Sensations of Tone . . 129

XII. Helmholtz in Bonn and Heidelberg -Sensations of Tone Continued. 145

XiII. Helmholtz in Heidelberg - Minor Physiological Researches • . 169

XIV. Helmholtz in Berlin-Physical ReSEARCHES

XV. Helmholtz in Berlin-Physical ReSearches Continued . . . 201

XVi. Helmholtz in Berlin-Physical Researches Continued . . . 233

XVII. The Philosophical Position of HelmHOLTZ . . . . . 250

XVIII. Helmholtz on Esthetics • • . 268 XIX. Helmholtz as a Lecturer • • 273 XX. Helmholtz in Berlin-Closing Years and Personal Characteristics 279 Poem-Hermann von Helmholtz 289 Biblography . . . . . 291 INDEX . . . . . . . 295 


\title{
Hermann von Helmholtz
}

\author{
CHAPTER I \\ CHILDHOOD AND EARLY LIFE
}

\section{UERMANN LUDWIG FERDINAND \\ 1 von HELMHOLTZ was born on August} 3Ist, I82I, at Potsdam, near Berlin. He was the son of Ferdinand Helmholtz, a teacher of philology and philosophy in the Gymnasium, a man of high culture and of great general intelligence, who was much respected for the thorough way in which he performed the duties of his position, and for the integrity of his character. His mother was the daughter of a Hanoverian artillery officer of the name of Penne, a lineal descendant of William Penn, the great Quaker who founded Pennsylvania ; while the grandmother, on his mother's side, sprang from a family of French refugees, of the name of Sauvage. Thus Helmholtz had German, English and French blood in his veins. We are free to speculate as to the origin of his great 


\section{HERMANN VON HELMHOLTZ}

talents, and as to his dignified presence in mature years. It is possible that something of his calm, reserved, selfpossessed manner may have come through the maternal line from the old Quaker statesman who made his mark on the new world. There is no trace of any hereditary aptitude for mathematics, and it must be said that the atmosphere of his father's home was not favourable to the development of any latent faculties in that direction.

The little we know of his early life was revealed by Helmholtz himself in a speech delivered in $189 \mathrm{I}$, in reply to the toast of his health at a banquet given in honour of his seventieth birthday. For the first seven years of his life he was a weakly boy, confined for long periods to his room, and frequently to his bed; but he was fond of such amusements as were possible, and he showed great activity of mind. His parents gave him much of their time and attention. Picture books amused him, and at an early age he read widely. A collection of wooden blocks he specially mentioned as a favourite plaything, and while he wiled away the time with these blocks, he formed from them some geometric conceptions that were the first indications of mathematical genius.

By-and-by he was able to go to school, where he passed through the usual routine of a good general education. No doubt his father's influence encouraged him to the study of languages, of literature, and of philosophy. The quality of his mind, however, did 


\section{CHILDHOOD AND EARLY LIFE}

not fit him for following in his father's footsteps. $\mathrm{He}$ had difficulty in acquiring languages, finding it hard to remember words, idiomatic expressions, and irregular grammatical forms. To have to commit prose to memory was torture, but he found it easy to store up passages of poetry, when he was helped by rhythm and rhyme. His father observed this peculiarity, and being himself an enthusiastic student of poetical literature, he introduced his boy to this golden storehouse, and not only read widely with him, but encouraged him to commit to memory poems and ballads from German literature. They read Homer together, and it is a remarkable indication of the breadth of his early education, that he was able to read the fables of Lökman in the original Arabic when he was twelve years of age. His father also exercised him in the composition of essays and even of verses, and Helmholtz remarks that although the verses showed that he was a poor poet, the practice was invaluable in the way of training him to the proper use of forms of expression. No doubt the home, if not scientific, was intellectual. He mentions that he frequently listened to philosophical discussions between his father and his friends, and thus he early became acquainted with some of the problems of metaphysics, as enunciated by Kant and Fichte.

The mind of Helmholtz opened up, becoming more receptive and retentive when the world of nature was placed before him, and when he was introduced to 


\section{HERMANN vON HELMHOLTZ}

phenomena. Already his wooden bricks had taught him much as to geometrical relationships. The mind became familiar with ideas as to spacial relations, and as to the adjustment of various forms, while he placed his bricks now in this position, now in that, so that when he began the systematic study of geometry at the Normal School of Potsdam in his eighth year, he astonished his teachers by his knowledge of many fundamental truths. He was already beginning to try his wings.

As he became stronger in body, he was able to ramble with his father in the beautiful country around Potsdam, with its palaces and gardens, and he began to look at nature with his own eyes. Not only was the love of the beautiful in nature encouraged, but also the sense that all her operations were ruled by law. $\mathrm{He}$ was now attracted to physical phenomena more than to the abstract ideas of algebra and geometry, and he early realised that a knowledge of natural events and of the laws that regulate them was, as he says, the ' enchanted key' that places the powers of nature in the hands of its possessor. Antiquated text-books of physical science found on the bookshelves of his father were eagerly read. His enthusiasm also found vent in attempts at experiment, to the detriment, he said, of his mother's furniture and linen. He constructed optical apparatus with a few spectacle glasses and a small botanical lens belonging to his father. While the class in the Gymnasium were reading Cicero 


\section{CHILDHOOD AND EARLY LIFE}

or Virgil, most of which was tiresome to young Helmholtz, he was endeavouring, below the table, to work out problems and draw diagrams relating to the passage of rays of light through a telescope. Even then he worked out for himself some optical principles, not expounded in ordinary text-books, which were of use to him in later years, in the construction of the ophthalmoscope. This was his apprenticeship in the art of experimenting, in which he afterwards became so proficient a master. He learned how to think out the conditions of an experiment, turning the question round and round, so that he might view it on all sides, pondering over the possible ways of achieving the solution of the mechanical or optical problem before him, until he got a clear idea of what had to be done. He also developed a passionate zeal to find out the realities of things, a zeal that continued throughout life, and appeared to grow in intensity as the years flew onwards. He was never satisfied with the apparent solution of a problem, if there were still doubtful points in it, and these he invariably attempted to clear up by bringing them fairly before his own mind.

It has been said by one who knew him well at this early period of his life, that he was faithful to his duties in great as well as in small matters. He was zealous in his studies; and in the autumn of I838, after the abiturienten examination, he left the Potsdam Gymnasium for the University with the following certificate from his Rector:- 


\section{HERMANN vON HELMHOLTZ}

' His exceptionally calm and reserved disposition is combined with great intellectual enthusiasm. In it we recognise an excellent combination of clear and prudent understanding and deep good nature. His manners bear witness to a carefully preserved, exceptionally pure, and genuine childlike innocence. These peculiarities, along with the richness and power of his mental development, give an agreeable and captivating impression, and justify the hope that such a ground-soil of intellectual life will only bring forth the best of fruits.' This testamur and prophecy were amply justified in after life.

It is remarkable that his mathematical talents were developed without the aid of an eminent teacher. He had no training in mathematics such as has been given to the great majority of physicists who have attained eminence. His talent was not fostered by the mathematical atmosphere of a great university like that of Cambridge, nor did he start life among his comrades with the blue ribbon of a high wranglership. His mathematical development was silently carried on, so that some of his early friends, such as Brücke and Du Bois Reymond, both afterwards physiologists of the first rank, who were his fellowstudents at the Gymnasium, were not aware, even when they were all engaged in the problems of analytical geometry, how transcendent were his latent mathematical powers.

Such was his early training. Throughout life 


\section{CHILDHOOD AND EARLY LIFE}

Helmholtz manifested the same mental characteristics as were shown in his early years. The same love of nature, the same desire to penetrate her secrets, the same determination to compel nature to explain herself. As is the case with most men of genius, he awakened early to his vocation. This awakening of a young spirit may come in many ways, and the time of its occurrence is always of the deepest interest. The youthful artist then recognises the beautiful, he clothes it with an ideal which is the product of his own mind, and to give to the ideal expression in form and colour is for ever the aim of his life. In like manner the young naturalist opens his eyes to the order of the universe, he is impressed by the majesty of law, he feels the first thrill of a desire to understand the method of nature's working, and for him, in all his future life, the driving power of all his faculties and the satisfaction of all his ideals, is the pursuit of truth. 


\section{CHAPTER II}

\section{STUDENT LIFE AND EARLY MANHOOD}

T $\mathrm{T}$ was the desire of Helmholtz to devote his life to I the study of physics, but his father, who had, out of his limited means, to maintain a family of four children, showed him that it would be almost impossible to earn a livelihood by cultivating or teaching pure science, and he wisely counselled his son to study medicine in the first instance. This advice was supported by the practical assistance of a relative, Surgeon-General Mursinna, who obtained for Helmholtz admission in 1838 as a bursar into the Royal Medico-Chirurgical Friedrich-Wilhelm Institute in Berlin, an academy for the medical education of youths of promise, given freely on the condition that they afterwards become surgeons in the Prussian army. The students of this institution attended the usual courses of instruction in the medical department of the University, and were afterwards attached for a time to the Charité Hospital. 'Thus Helmholtz was, by force of circumstances, led to enter the medical profession, and in due time he obtained his diploma and became an army surgeon.

In after life Helmholtz often referred to the great 8 


\section{STUDENT LIFE AND EARLY MANHOOD}

advantage he gained by being obliged to pass through the curriculum of medical study. In a famous lecture on Thought in Medicine, delivered in 1877 , he remarked, 'My own original inclination was towards physics; external circumstances obliged me to commence the study of medicine. It had, however, been the custom of a former time to combine the study of medicine with that of the natural sciences, and whatever in this was compulsory I must consider fortunate; not merely that I entered medicine at a time in which any one who was even moderately at home in physical considerations found a virgin field for cultivation, but I consider the study of medicine to have been that training which preached more impressively and more convincingly than any other could have done, the everlasting principles of all scientific work; principles which are so simple and yet are ever forgotten again; so clear and yet always so hidden by a deceptive veil.' ${ }^{1}$

The practical side of the medical art also appealed to his kindly nature. In the same lecture he remarks : 'Perhaps only he can appreciate the immense importance and the frightful practical scope of the problems of medical theory, who has watched the fading eye of approaching death, and witnessed the distracted grief of affection, and who has asked himself the solemn questions, Has all been done which could be done to ward off the dread event?

x Popular Lectures, I881, p. 202. 


\section{HERMANN VON HELMHOLTZ}

Have all the resources and all the means which science has accumulated become exhausted?'I

About this time there was a distinguished band of youthful students at the University of Berlin, who all ultimately became men of scientific eminence, and who made their mark on the learning of the following thirty or forty years. Here Helmholtz met $\mathrm{Du}$ Bois Reymond (a friend of his school days), who afterwards became Professor of Physiology in the University of Berlin, and who systematised and developed the department of electro-physiology; Brücke, who in due time was elected to the Chair of Physiology in Vienna; Virchow, the greatest of living pathologists, who still holds the Chair of Pathology in Berlin, while he is a power in science and also in the state; and many others. These all clustered round the feet of the greatest physiologist of the time, Johannes Müller, who taught anatomy and physiology in the university. It so happened also that Gustav Magnus filled the Chair of Physics. These two distinguished men represented a new school of thought, then arising in Germany, that which rebelled against the older metaphysical school, and craved for the investigation of natural phenomena. They attracted many disciples, and an alliance was established between the physicists and chemists on the one hand, and the physiologists on the other. Thus Gustav Karsten, Heintz, Knoblauch, Clausius, Kirchhoff, Quincke,

I Popular Lectures, op. cit., p. 203. 


\section{STUDEN'T LIFE AND EARLY MANHOOD}

Werner Siemens, Tyndall and Wiedemann, who all became remarkable in chemistry or physics, joined Du Bois Reymond, Helmholtz, Brücke, and others, who represented the physiological school, in founding the Physical Society, a society in which they met on equal terms and freely discussed papers dealing with scientific questions. ${ }^{\mathrm{I}}$ It is impossible not to notice the great preponderance of physicists in the little band; indeed it may be said they were all physicists, as $\mathrm{Du}$ Bois Reymond and Helmholtz, and even Brücke, approached physiological problems from the physical side. It was an epoch in the history of science, as not a little of the outcome of modern science, and, in particular, its methods, may be traced to that group of brilliant young men.

There can be little doubt that Johannes Müller was the greatest living force in the University of Berlin at that time. A man of indefatigable industry and perseverance, with an energy that overflowed into many sciences, a man of worthy aims and clear insight, who had the power of inspiring the youths who hung upon his words, a man who had in his great text-book collated and discussed the facts of

I Du Bois Reymond points out that Carl Ludwig was not a pupil of Johannes Müller. He studied at Marburg and followed his own course, ultimately becoming Professor of Physiology in Leipzig. He became a physiologist of the highest eminence, and, both by his own labours and that of his numerous pupils, whom he attracted from all countries, advanced many departments of physiological science, in particular our knowledge of the circulation of the blood. 


\section{HERMANN VON HELMHOLTZ}

physiological science in a manner that in some respects resembled the great work of Haller, published a century before, Johannes Müller was the greatest biological teacher of his time. In some ways he resembles John Hunter more than any other naturalist, but, owing to the circumstances in which he worked, he left behind him what Hunter did not leave-a school of ardent disciples imbued with the spirit of the master.

Müller also gave a great impetus to the movement that had already begun in Germany in the direction of the investigation of biological problems by the methods of physical and chemical science. The principles of the Baconian philosophy took root and influenced science much later in Germany than in England; and while in Germany there were, up to the time of Müller, many workers who were influenced by that school, the teaching of science, and even its investigation, more especially of physiological science, were still cramped by the speculative method of metaphysics. The fundamental problem of the nature of vital action was held generally to be beyond the domain of experimental science; the doctrine of a vital force which modulated and held in subjection all other forces held sway; and the great conception of the unity of origin of all the tissues of the body, established by the cell theory of Schleiden and Schwann, had not yet clearly dawned on the minds of physiologists.

The influence of Müller was felt throughout the 


\section{STUDENT LIFE AND EARLY MANHOOD}

world after the publication of his great text-book of physiology. Here were found not only all the facts of the science then known, but also the discussion of principles. In particular, the physiology of nerves, of nerve centres, and of the senses, was expounded in a manner that hitherto had not been attempted. Müller also laid the foundations of the school of modern experimental psychology by placing on a clear basis the mode of action of external stimuli on the terminal organs of sense. He showed that in whatever way a terminal organ is stimulated, the result is the same in consciousness, according to the nature of the particular terminal organ. Thus if we stimulate the retina of the eye by light, or electricity, or heat, or mechanical pressure, as by a blow, the result will always be the same-namely, the sensation of a flash of light, possibly of colour. Further, the same result follows any kind of irritation of the optic nerve, which conveys the impulses from the retina to the brain; and from this he deduced the great law of the specific sensibility of nerves, by which he meant that each nerve of special sense has, as it were, its own sensibility, so that, in whatever way it may be stimulated, the result will always be the same. This doctrine was especially fruitful in the hands of Helmholtz, Fechner, Brücke, Hering, and many others. It was a great step to recognise that the 'sensation due to a particular nerve may vary in intensity, but not in quality, and therefore 


\section{HERMANN vON HELMHOLTZ}

the analysis of the infinitely various states of sensation of which we are conscious must consist in ascertaining the number and nature of those simple sensations which, by entering into consciousness each in its own degree, constitute the actual state of feeling at any instant.' ${ }^{\prime}$ There can be no doubt that in this and many other departments of physiological science, Müller awakened new ideas and stimulated teachers of youth. Bowman, Sharpey, and Carpenter, in England; Allen Thomson and John Goodsir, in Scotland; Claude Bernard and Vulpian, in France; Donders, in Holland, all felt his influence. Thus he prepared the way, not only for the labours of Helmholtz, and the other young men who were his immediate students, but for the remarkable development of physiological science that has taken place since I 840 . Helmholtz long afterwards wrote words that apply with striking force both to his great master and to himself. 'When one comes into contact with a man of the first rank, his spiritual scale is changed for life. Such a contact is the most interesting event that life can offer.'

In 1842 , Helmholtz, at the age of twenty-one, presented his inaugural thesis, entitled De Fabrica systematis nervosi Evertebratorum, in which he made an important contribution to minute anatomy. In 1833 Ehrenberg discovered in ganglia, which are usually small, more or less rounded swellings on nerves, often situated at the apparent junction of

I Clerk Maxwell on Helmholtz, Nature, vol. v., p. 389. 


\section{STUDENT LIFE AND EARLY MANHOOD}

several trunks, peculiar cells or corpuscles, now called nerve cells or nerve corpuscles. These cells are found also in all nerve centres, such as the spinal cord and brain, and they lie in a fine variety of tissue, while numerous nerve fibres pass through the ganglia, apparently in close proximity to the cells. No connection between the nerve cells and the nerve fibres had been discovered, although Müller taught that in all probability such a connection existed. It was reserved to Helmholtz to make the discovery. With a very simple and primitive form of a compound microscope, almost as different from the splendid instruments of the present day as a cheap spyglass is from an astronomical telescope, he discovered in the ganglia of leeches and crabs that the nerve fibre originates from one of these corpuscles. This was an observation of fundamental importance as showing the connection between nerve fibre and nerve cell, and it has been extended throughout all nerve centres. The so-called axis cylinder of a nerve fibre, the central part of a nerve fibre, always originates from a process or pole or prolongation of a nerve cell.

$\mathrm{Du}$ Bois Reymond mentions that, during his last year of medical study, Helmholtz had an attack of typhus fever, for which he was treated gratuitously in the hospital, while his small weekly allowance for board was continued. At the end of his illness Helmholtz found himself in possession of a little fund. This was expended in the purchase of the 


\section{HERMANN vON HELMHOLTZ}

microscope which aided him in the research for his thesis. The incident throws light on the economy and simplicity of his life at this period.

We have now traced Helmholtz to the beginning of his career as a contributor to science. From 1842 , when his first paper was published, and when he was twenty-one years of age, on to 1894, the year of his death, when he had reached the age of seventy-three, papers flowed from his pen in almost uninterrupted succession. With the exception of one year, 1849 , he always published at least one important paper, and usually three or four, and occasionally more, each year, so that, when his life's work was over, no fewer than $2 \mathrm{I} 7$ distinct papers and books represented his labours. Such a life of incessant labour could not be expected to be full of incident. It is, therefore, difficult to portray his life step by step. There is not much to lay hold of in following his career; we must be content with trying humbly to tread in his footsteps in the pathways of science, and to endeavour to grasp the scope and meaning of the many discoveries he made. The great variety of his work in so many sciences suggests the method of classifying his discoveries and then attempting to show the nature of his investigations in physiology, in physiological optics, in acoustics, in mathematics, in mechanics, in electrical science. This method, while it would give coherence to this work, would make a biographical sketch 


\section{STUDENT LIFE AND EARLY MANHOOD}

almost impossible, and it is open to the objection, that it would render each chapter a somewhat unsatisfactory résumé of the science, without making us acquainted with the man. We prefer, therefore, in the following chapters to trace his career, as far as possible, by his works, as these were given to the world from his various spheres of activity. He spent his life in Berlin from 1842 to 1847 , when he became, at the age of twenty-nine, Professor of Physiology in Königsberg; he was in Königsberg from 1849 to 1856, when, in his thirty-fifth year, he was removed to the Chair of Physiology in Bonn; this he held till 1859, when, in his thirty-eighth year, he became Professor of Physiology in Heidelberg; here he remained till 1871, when he was called to occupy the Chair of Physics in Berlin in his fiftieth year; and this position he held until his death in 1894. It will give, we think, the best idea of the man to endeavour to cluster his discoveries round the centres where they were made. Thus we will see how his mind swung from one subject to another, and how his powers matured until he became a giant among his fellows. The method will also enable us to appreciate the value of his contributions to science with reference to the time and circumstances in which they were made. We will also see that while he was a master in medicine he was something more, and that at least seven sciences will hereafter claim Helmholtz as one of their most distinguished investigators. 


\section{CHAPTER III}

SCIENCF. IN GERMANY IN THE EIGHTEENTH AND EARLY PART OF THE NINETEENTH CENTURIES

THE adequate recognition of the work of a great 1 man, in any sphere of intellectual activity, depends much on a correct appreciation of the streams of tendency apparent in the time before he appeared. We must endeavour to discover the lines along which thought was progressing, and to see, not from our standpoint, but from theirs, the questions which were then agitating the minds of men. This will enable us to estimate, on the one hand, the influence of the time upon the man, and the share that other men's thoughts had in moulding his character and directing his mental energies; and, on the other hand, the extent to which he reacted on the conditions surrounding him, and the contributions he made to human knowledge. Men of science, in particular, must be dealt with in this way. The state of education, especially in the universities, the facilities for scientific work, the current of scientific opinion, must all be studied before we can fairly judge as to what the man was, and as to what work he accomplished. One result from such 


\section{SCIENCE IN GERMANY}

an investigation is, that we see that the great thinker came at an opportune time. There are times in the history of science when there is a kind of quietism. Many busy workers are engaged in the accumulation of facts, but there are no startling discoveries nor broad generalisations that seem to put things in a new light. Such periods are unfavourable to the production of great men. Yet, even during such times, there may be undercurrents of thought making for great questions. Here and there a solitary thinker may be brooding over great problems, and, although his thoughts may be dark, he is almost unconsciously preparing the way for the full revelation of the truth to the man of genius. Thus it is that to only a very few is vouchsafed the honour of making an entirely new discovery. This is an occurrence of the rarest kind. The rule is that limited observations of the truth are made here and there by men who are soon forgotten (except by the historian of science), vague and nebulous speculations, as it were, float in the air, and at last an epoch arrives, and with it the man. The epoch ushers in new ideas, new modes of looking at things, new generalisations of far-reaching character affect the views of scientific thinkers, and with this new period we usually associate the name of one man, such as Copernicus, Galileo, Newton, Linnæus, Darwin. Great, individually, as such men were, in estimating their work we must remember that they were not only highly endowed, but that they were 


\section{HERMANN vON HELMHOLTZ}

also the children of good fortune. They came on the world's stage at the right time, they caught up all the impressions of the science of their day, they added to this the product of their own labours, and thus they gave a new impetus to scientific progress.

The career of Helmholtz illustrates what has been written. To understand in some measure how he contributed so much to the science of his day, we must not only recognise his transcendent genius, but also that the times were favourable to its full development.

During the eighteenth and the beginning of the nineteenth century, science made little progress in Germany. I In chemistry the phlogiston theory led men in the wrong direction for nearly a century. The problems of physical science were still approached by the a priori method, and the speculations of Schelling and Hegel were not favourable to any method that had for its foundation the investigation of facts. Here and there important scientific results were obtained, such as Chladni's study of elastic vibrations of plates, Ritter's electrical experiments, and Seebeck's discovery of thermo-electricity, but there was no co-operation among the physicists, and there was no common goal towards which their energies were directed.

Physiology had not yet asserted her existence as a science founded on observation and experiment. She

'G. Wiedemann, Introduction to Helmholtz's Wissenschaftliche Abhandlungen. Leipzig, 1895. 


\section{SCIENCE IN GERMANY}

was still the handmaid of anatomy, and she was dominated by the metaphysical idea of a vital force. This idea hindered investigators from examining many physiological phenomena which are under the same forces as those at work in the inorganic world, and the notion that vital actions were dependent on molecular and chemical changes in living tissues, had not yet been entertained.

In France, however, science was not in this dormant state. The intellectual unrest, which culminated in the Revolution, led to almost universal scepticism, a state of mind which found expression in the writings of the Encyclopædists. For a time men lost faith in the methods and conclusions of philosophical and ethical systems, and thought was determined towards physical and chemical science. Then arose Coulomb, Lavoisier, Laplace, Cuvier, and many others, and France became the leader in scientific investigation, more especially in physics and chemistry. This state of things was not without its influence on Germany. Many young scientific men from Germany, such as Alexander von Humboldt, Mitscherlich, and Liebig received their training in Paris, and imbibed the scientific spirit of the French savants. Such men returned to their own country, and soon occupied positions of influence in the universities. In these days, as now, Paris was to a large extent France, and this produced a concentration of scientific effort which did not take place till a later period in Germany, owing 


\section{HERMANN vON HELMHOLTZ}

to the universities of the latter being scattered in the various states. By degrees, however, concentration also occurred in Germany. According to Wiedemann, an important school of mathematical physics arose in Königsberg, and at last in Berlin, as in Paris, and largely owing to the influence and fame of Mitscherlich, a scientific centre was formed.

The earlier workers in the period of scientific awakening were such men as Mitscherlich and Liebig among chemists, and Ohm, Franz Neumann, and Wilhelm Weber among physicists. These were soon joined by the contingent from Berlin, which included Poggendorff, Riess, Dove, and Magnus. The latter, Magnus, became especially a notable teacher and laboratory worker, influencing both by teaching and example a number of young and able men. These physicists were in rebellion against the metaphysical schools which had so long dominated the thought of Germany, and they swung almost to the opposite extreme, extolling nothing but experience and experiment. For a time the collection of facts seemed to be the paramount object in physical research; theory was in the background. So far did Magnus carry this view, that, as we are assured by Wiedemann, he was constantly warning his pupils not to plunge too deeply into mathematics, and he regarded experimental and mathematical physics as two separate departments. In this way, do doubt, the Berlin school built a firm foundation of fact for theoretical views, as distinguished 


\section{SCIENCE IN GERMANY}

from notions which were the outcome of metaphysics; and the work on thermodynamics of Clausius, one of Magnus's distinguished pupils, is an apt illustration of this statement. As also pointed out by Wiedemann, the writings of Helmholtz and Robert Mayer are good examples, the first of theory developed from experiment, and the second of a more metaphysical mode of investigation.

Empirical physical research has a tendency to become one-sided, and after it has been indulged in for a time, it is almost invariably followed by a more general treatment of the subject. This occurred among the disciples of Magnus. Earnest in their earlier years in the discovery of facts, in their latter they each and all were engaged in the contemplation of theoretical views then far beyond the range of experimental science.

The rise of the physico-chemical school of Berlin had an important influence on the development of physiology in Germany. Ernst Heinrich Weber was no doubt the first to ask for an explanation of the phenomena of life by examination of these phenomena by physical methods, and the application of physical laws. After him came Johannes Müller, who was at first somewhat wedded to the older quasi-metaphysical position, but in his later years he also took up the views and methods of Weber. For a considerable time, however, the notion of a vital force still held sway. Phenomena in living things were supposed to be different not only in degree, but in kind, from those in inorganic 


\section{HERMANN voN HELMHOLTZ}

matter. If this notion were to be got rid of, it could only be by prolonged investigation in a physicochemical direction. Such were the views of three young physicists and physiologists, Brücke, Du Bois Reymond and Helmholtz. As already narrated, these three joined the physicists and chemists in founding the Physical Society of Berlin. Here they found sympathy and encouragement. Here papers were read and frankly criticised. Here was developed, for the first time, an attempt to investigate physiological phenomena by the methods of chemistry and physics. Physiology, indeed, was regarded as in a sense a branch of chemico-physics, and the phenomena of nature-chemical, physical, physiological - were held to be controlled by one general principle, or rather to depend ultimately on the properties of matter. Some of these enthusiasts took even a wider sweep, and brought into their net the phenomena of psychophysics, and the physical and physiological foundations of the arts-sculpture, painting and music.

Helmholtz was without doubt the most distinguished of this group of young men. He was, to use Wiedemann's expression, and Wiedemann was a contemporary, head and shoulders above the rest. In each department of scientific labour represented by the members of this brilliant galaxy, he acquired, in after life, marked distinction; to each department he made vast additions, while he elevated the whole body of scientific knowledge. 


\section{CHAPTER IV}

HELMHOLTZ IN BERLIN-FERMENTATION-ANIMAL

HEAT

DRING the greater part of the period from his graduation in medicine in 1842 till his appointment to the Chair of Physiology in Königsberg in I849, Helmholtz resided in Berlin. He completed his term of service as assistant physician in the La Charité Hospital, and, in 1843 , he returned to Potsdam, where he discharged the duties of assistant surgeon to the regiment of Red Hussars. Private practice he never had; all his time, when off duty, being devoted to science. Coming under the notice of Alexander von Humboldt, that great man recognised his capacity, and through his influence he was relieved from military duties, and became assistant to the Anatomical Museum, Lecturer on Anatomy to the Academy of Arts, and Extraordinary Professor of Physiology to the Albert University. In the two latter appointments it is interesting to know that he succeeded his friend Ernst Brücke, who subsequently filled with great distinction the Chair of Physiology in Vienna. There is little doubt the appointment to the Academy 


\section{HERMANN vON HELMHOLTZ}

gave his mind the æsthetic bias so apparent in after years. His researches, however, were not anatomical, but physiological and physical.

In 1843 he made an important contribution to the theory of fermentation. This process has long been, and indeed still is, the cause of much controversy between chemical physicists and biologists, and from the controversy has flowed results of the highest importance to humanity. When sugar is changed into alcohol and carbonic acid in the ordinary alcoholic fermentation, the process is in some way related to the vegetable cells of the yeast plant, Saccharomycetes cerevisia, first seen by Leeuwenhoek in 1680 . For many years these minute organisms received little or no attention, but in $183^{8}$ Schwann, one of the founders of the cell theory, and Cagniard de la Tour demonstrated the vegetable nature of these yeast cells, and showed that they grew and multiplied in saccharine solutions. For the first time it was asserted that fementation in some way depended on the action of living things. Previous to 1838 Berzelius suggested that the action of the yeast is what is called catalytic, that is causing a separation or decomposition of the atoms forming the sugar in a way similar to the action of platinum black on peroxide of hydrogen, when the latter gives up an atom of hydrogen. Liebig strongly contended that there is no necessary connection between the fermentive process and the development of living organisms, and he held that the 


\section{HELMHOLTZ IN BERLIN}

organisms may simply produce a substance, the molecular vibrations of which may cause a re-arrangement of the atoms of the substance undergoing fermentation. According to this view fermentation is essentially a chemical process. A substance of unstable chemical composition is formed by the yeast cells, and by vibrations, due to chemical changes in this substance, movements are communicated to the atoms of sugar, so that these are re-arranged to form alcohol, carbonic acid, and small quantities of a few other bodies. The growth of the yeast cell is only indirectly connected with fermentation.

For a considerable time this theory held its ground, owing largely to the prestige of its illustrious author; but facts came to light that again concentrated the attention on the biological aspect of fermentation. Thus Gay-Lussac showed that clean grapes or boiled grape juice passed into the Torricellian vacuum of a barometer tube kept free from fermentation for any length of time, but that if a single bubble of air were admitted fermentation soon appeared. About I838 Schwann repeated Gay-Lussac's experiment, and showed that if the air were admitted to the vacuum through a red hot tube then fermentation did not occur. Clearly it was something in the air that caused fermentation, and that something was destroyed by heat. Further, it was shown that active fermentation was always accompanied by increased growth of the yeast, and that conditions of temperature affected the 


\section{HERMANN VON HELMHOLTZ}

process. Thus a temperature of from $20^{\circ} \mathrm{C}$. to $24^{\circ}$ C. was most favourable to it, while the process was arrested at $60^{\circ} \mathrm{C}$. Boiling destroyed fermentation. It was also arrested by freezing, but on careful thawing the process was resumed. Schwann also established the identity of the processes of fermentation and putrefaction by showing that they both were connected with the development of living organisms, and he laid the foundation for the splendid researches of Pasteur, which have created the modern science of bacteriology.

The contribution made to this discussion by Helmholtz in 1843 is of no mean importance. He showed, first, that the oxygen produced by electrolysis in a sealed-up tube containing boiled fermentable fluid, did not cause fermentation. He also performed the following ingenious experiment: he placed a bladder full of boiled grape juice in a vat of fermenting juice, and found that the fluid in the bladder did not ferment. Thus the cause of the fermentation could not pass through the wall of the bladder. If the fermentation were excited, as held by Liebig, by a substance formed by the yeast cells, and presumably soluble, one would have expected it to pass through the wall of the bladder; but if the process were caused by the small yeast cells, then one can see why fermentation was not excited, as the yeast cells could not pass through the membrane. Soon afterwards Mitscherlich showed that the yeast cells could not pass through a septum 


\section{HELMHOLTZ IN BERLIN}

of filter paper; Hoffmann proved that a layer of cotton wool had the same effect; and Schroeder and Dusch made the important demonstration, that ${ }^{\circ}$ air filtered through cotton wool is incapable of exciting putrefaction in a putrescible fluid that has been boiled. The cotton wool has sifted from the air the bodies that cause putrefaction, just as the wall of the bladder, the septum of filter paper, or the layer of cotton wool, prevents the passage of the yeast cells from a fermenting to a fermentable fluid. The conclusion, then, is irresistible that the living organisms in the air and in the yeast are the cause of putrefaction and fermentation. It will thus be seen that the comparatively simple observations of Helmholtz were of fundamental importance.

Surrounded as he was by young physicists, it is not surprising that Helmholtz approached physiology on its physical side. Physiology is essentially a composite science, inasmuch as it is closely related to anatomy, physics and chemistry. In the solution of physiological questions, the physiologist must collect facts from these three departments of knowledge. Thus, for example, in investigating the phenomena of the circulation of the blood, the physiologist, in the first place, must be acquainted with the structure of the heart and blood vessels, with the position and appearances of the valves in the heart and in many of the veins, and with the nature of the minute texture or tissue of the heart, as revealed by the microscope. Then he considers the circulation as a problem of 


\section{HERMANN VON HELMHOLTZ}

hydrodynamics, investigating and measuring the force and frequency of the heart's contractions, and determining the causes of the high pressure maintained in the arterial system, the nature of the pulse, and the uniform flow of the blood in the capillaries. These investigations are all of a physical character. Finally, if the physiologist pursues his analysis still farther, he may examine the chemical characteristics of the tissues forming the heart and vessels, the nature of chemical compounds, both organic and inorganic, existing in these tissues, and the influence of chemical substances upon the living heart. Almost every physiological problem may be attacked in a similar way, and it can only be fully solved when all the information derived from anatomy, chemistry and physics is brought to bear upon it. It will also be evident that some physiologists are attracted to one aspect of the subject, while others are drawn to another. One man endeavours to explore the mystery of living action by the microscopical examination of tissues, living and dead; another works at the chemical constitution of organs and tissues, and tries to get a glimpse into the nature of the chemical processes associated with life; while a third investigates the phenomena as special problems in physics. Helmholtz was an outstanding representative of the latter class, and he was so largely by reason of his special aptitude for physical and mathematical research, and of his surroundings. He might properly be described, even 


\section{HELMHOLTZ IN BERLIN}

at this early stage of his career, as a highly-trained physicist interested in physiological pursuits.

It is interesting to observe, that while physiology is largely indebted to physics, the latter science owes not a little to physiology, inasmuch as the consideration of physiological phenomena has, on several notable occasions, led the physicist into a new and fruitful line of research. The beginning of modern electrical science will for ever be traced back to the well-known observations of Galvani on the twitching of frogs' legs near an electrical machine, to his speculations on the existence of an animal electricity, and to the celebrated controversy that arose between Galvani and Volta, a controversy in which many of the most learned physicists and physiologists of the day took part. In like manner, the discussion of questions as to the nature of animal heat contributed not a little to the doctrine of the conservation of energy. Helmholtz took a foremost part in this movement, and there can be no doubt he was led into it, in the first instance, by physiological considerations.

The physical properties of dead matter are, as a rule, more easily observed and registered than the physiological properties of living matter, and they lend themselves more readily to mathematical investigation. Hence physical science is much farther advanced than physiological science. The physicist is surer of his ground. The physiologist has to deal with the mysterious condition we call vitality. It is therefore 


\section{HERMANN vON HELMHOLTZ}

not astonishing that physicists, as a rule, are shy of dealing with physiological problems, and that they regard many of them as practically insoluble. In the judgment of the physicist, life, vitality, the mysterious something apparently unknowable, so interferes with and obscures the play of the ordinary physical forces, as to lead him to doubt whether the physical phenomena of living matter can ever be thoroughly understood. Now it is remarkable that, although Helmholtz was already at the age of twenty-five a great physicist, he boldly entered on physiological research with the assured conviction that the play of the physical forces in living matter was under the same laws as in dead matter, and that the only way to investigate, with success, the phenomena of living matter, was to examine them by physical methods, and to submit them, as far as possible, to physical analysis.

It was in this spirit that he began to investigate the phenomena of animal heat, and this investigation led him to lay the foundations of the great doctrine of the conservation of energy. The subject occupied much of his attention from 1844 to 1848 , and he returned to it in $1850,1852,1855$ and 1859 . The old view that heat was a variety of imponderable matter had been attacked long before by Voltaire, who, in a series of elaborate experiments, endeavoured to prove that it was only a kind of internal movement; and in 1798 Count Rumford, one of the founders of the Royal Institution, after executing a series of experiments on 


\section{HELMHOLTZ IN BERLIN}

the production of heat by friction, established, in a comparatively rough way, the dynamical theory of heat, in which heat is regarded as an accident or condition of matter, a phenomenon produced by 'a motion of its ultimate particles.'

Helmholtz studied the exchanges of matter that occur in connection with muscular contractions, and he made the important observation, that such exchanges are always accompanied by the disengagement of heat. This indicated that animal heat, as produced by a muscle, arises from the chemical phenomena occurring in the muscle. Before this research, Matteucci had apparently shown the production of heat during muscular contraction by passing thermo-electric needles into the muscles of a living warm-blooded animal, and connecting the needles with a thermal galvanometer; but as in his experiments the blood was flowing through the muscle, the proof that the increase of temperature observed during the muscular contraction was due to changes in the muscle itself was not complete. Helmholtz got rid of the difficulty of having to deal with an organ through which streams of blood, possibly of different temperatures, were flowing, by making observations on the isolated muscles of 'the old martyr of science,' the frog. He devised a triple thermo-electric junction of iron and German silver, so made that it could be passed through the muscles of the thigh of a frog. A similar set of junctions were kept at a temperature as uniform as 


\section{HERMANN vON HELMHOLTZ}

possible, outside the muscles of the frog, and the two sets of junctions were connected with a thermal galvanometer, so sensitive, that deflections equivalent in thermal value to the $\frac{1}{1000}$ th of a degree Centigrade could be detected. When the muscles were caused to contract, by electrically stimulating the sciatic nerve, the junctions in the muscle became warmer than those outside the muscle, as indicated by a deflection of the needle of the galvanometer, and as the galvanometer had been empirically graduated, the actual rise of temperature was at once estimated. It was thus shown that a single muscular contraction would give an increase of from $\cdot 001^{\circ} \mathrm{C}$. to $\cdot 005^{\circ} \mathrm{C}$., and that tetanus, or cramp, lasting for two to three minutes, would cause a rise of from $014^{\circ} \mathrm{C}$. to ${ }^{\circ} \mathrm{O} 8^{\circ} \mathrm{C}$. He failed, however, to detect heat in active nerves. These quantities of heat are no doubt small, but their detection showed that the molecular processes occurring in the contracting muscle actually produce heat.

Helmholtz also extended his observations to the general phenomena of animal heat. On Lavoisier's assumption that the amount of heat liberated could be determined by the quantities of oxygen consumed and of carbonic acid produced, it had hitherto been found that there was a discrepancy between the amount of heat actually given off by the body of an animal in a given time and the amount to be expected from calculation. The calculated amount of heat was usually more than that given off the living body. 


\section{HELMHOLTZ IN BERLIN}

Helmholtz showed that less heat might be given off than could be estimated from the complete oxidation of the food supplied, indicating that the oxidation processes in the body were incomplete. $\mathrm{He}$ also computed the amount of heat given off by various channels as 2.6 per cent. in heating excrementitious matters, 2.6 per cent. in warming the air of expiration, 14.7 per cent. by evaporation of the lungs, and $80^{\circ}$ I per cent. by evaporation of sweat and radiation and conduction by the skin. These results have been corroborated and extended by many subsequent observers, and it has been conclusively established that the heat of the combustion of the food, as determined by a calorimeter, is equal to the heat given off by an animal; in short, that an animal is a living calorimeter in which the food stuffs are oxidised or burnt.

A new investigation almost invariably demands the use of new appliances. New ideas, new conceptions of method, spring up in the mind of the experimenter, and a call is at once made on his powers of invention. This is felt even in a well-furnished laboratory, and of course much more when the investigator enters on what is a virgin field of research. Helmholtz, when he began the investigation of muscular contraction, had to invent many of his tools. About this period his friend, Du Bois Reymond, was laying the foundations of his life-long work on electro-physiology, and he also invented many appliances. There is little doubt Helmholtz and he assisted each other in de- 


\section{HERMANN vON HELMHOLTZ}

vising apparatus by which the phenomena of muscular contraction could be accurately studied. Employing the method of causing a contracting muscle to write its curve on the blackened surface of a revolving cylinder, or on a moving glass plate, a method of observing the time relations of motor phenomena first suggested by Thomas Young, Helmholtz devised the well-known myograph, or muscle writer. Schwann had already worked with a rude instrument, in which the contracting muscle was caused to pull on a lever near its fulcrum, and no doubt he was the first to obtain a muscle curve, but Helmholtz improved the instrument by making the lever light, and at the same time rigid, and by other mechanical contrivances. Further, he endeavoured to keep the living muscle in conditions as favourable as possible by covering the part of the apparatus containing the muscle with a glass case, under which pieces of blotting paper, moistened with water, were placed. This 'moist chamber,' as it is technically called, became a space saturated with aqueous vapour, and thus the muscle and nerve were kept in fairly natural conditions, and the effects of cooling and drying were obviated.

Helmholtz also, in connection with this research, made arrangements by which the nerve or muscle could be stimulated by electric shocks of short duration and of a known intensity. He applied to the well-known induction coil of Du Bois Reymond, designed for physiological purposes, a modification of 


\section{HELMHOLTZ IN BERLIN}

Neef's interrupter, by which the circuit in the primary coil was opened and closed, and as the interrupter works automatically, a rapid series of shocks may be transmitted to the nerve or muscle. It was soon found that, with this arrangement, the opening shock acts more powerfully on the muscle than the closing shock, in other words, the opening shock has the greater intensity. This arises from the development, at the moment of closing the primary current, of an extra current in the primary coil, which, being in the reverse direction to that of the main primary current, so retards the development of the latter as to prolong the time during which the secondary current flows, and thus make it pass through a lower maximum intensity than is reached by the secondary current at opening when the change of the primary is more abrupt, and the secondary current lasts for a correspondingly shorter time. The total quantity of current coming from the secondary coil is the same whether the primary circuit is being opened or closed ; but the secondary current, excited at opening, attains momentarily a greater intensity. Hence the opening shock is the more stimulating. As in stimulating a nerve or muscle by an induction coil it is important to stimulate with rapid opening and closing shocks of the same intensity, Helmholtz so modified the Neef's interrupter as to equalise the currents. By his arrangement the current in the primary circuit is not wholly cut off. It is merely short-circuited. 


\section{HERMANN vON HELMHOLTZ}

Thus the primary circuit is always closed; but the decrease of current at the instant of short-circuiting has the same kind of effect in producing a secondary current as when the primary circuit is completely opened. But because the primary circuit remains a closed circuit, the extra current of self-induction retards the rate at which the current decreases, just as the extra current retards the development of the current at closing. Thus, the conditions under which the secondary currents at closing and at opening are produced are fairly similar; the intervals of time during which they last are approximately equal; and the maximum intensities reached by them are almost exactly the same. In this way the opening shock becomes nearly equal to the shock from the secondary coil at the moment of closing. ${ }^{x}$ This clever device is a good illustration of the ingenuity of Helmholtz and of his grasp of the technique of electrical experimentation.

I For details, see M'Kendrick's Text-Book of Physiology, vol. i., p. 374. Glasgow, 1888 . 
HELMHOLTZ IN BERLIN-THE CONSERVATION OF ENERGY

THE researches on muscular motion and on heat 1 led Helmholtz to the study of the great question of the relation to each other of the forces of nature, and especially, and in the first instance, to the relation of these forces to the phenomena of life. What is life? was a problem often before his mind. Was the living state to be explained by the interplay of the same chemical and physical forces as were at work in the outer world? Or, was Stahl's view to be accepted, that while the forces were the same in living as in dead matter, they were all subject to a living power or principle which held them together and caused them to work in a particular way till death came, when the physical and chemical forces, now liberated from control, assumed their supremacy and the matter forming the body again returned to the inorganic world? Was the energy of life continually replenished from some external source; or was it dependent on the energy of the 


\section{HERMANN VON HELMHOLTZ}

forces of nature supplied to it from the outer world? Was the living body, in short, only a minute portion of the mechanism of the cosmos; or was there something beyond, some spiritual fuel continually being added to its vital fires? Helmholtz thought that if the life was fed from some such source of external energy, then the living body was an example of a perpetuum mobile, a perpetual motion, an idea he had often heard ridiculed in the philosophical discussions that were not infrequent in his father's home.

If, again, the natural forces were found competent to explain the phenomena of life without the assumption of a vital force, how were these forces related to each other? About this period Helmholtz filled the humble office of assistant in the library of the Friedrich Wilhelm Institute, and in what he modestly terms his 'idle moments,' he had read the works of Euler, Daniel Bernoulli, d'Alembert, and other mathematicians of the eighteenth century, no mean indication of his mathematical powers, and he thus became equipped for the discussion of the great question. He was especially acquainted with the manifold applications made by Daniel Bernoulli, of Leibnitz's idea of vis viva.

Such considerations led Helmholtz, in his twentysixth year, to write his famous essay, Ueber die Erhaltung der Kraft-on the Conservation of Force-one of the epoch-making scientific papers of the century. Clerk Maxwell has well said:- 'To appreciate the full 


\section{HELMHOLTZ IN BERLIN}

scientific value of Helmholtz's little essay on the Conservation of Force, we should have to ask those to whom we owe the greatest discoveries in thermodynamics and other branches of modern physics, how many times they have read it over, and how often during their researches they felt the weighty statements of Helmholtz acting on their minds like an irresistible driving power ?' r

The essay was read to the Physical Society of Berlin on the $23^{\text {rd }}$ of July 1847 , and it created much excitement in the distinguished band of youthful workers. The author showed himself, at one stroke, to be a mathematician of the first order, but he also enunciated as a fundamental principle of physics the conservation of force, just as Lavoisier, seventy years before, had made that of the persistence of matter the fundamental principle of chemistry. He showed that ' if the forces acting between material bodies were equivalent to attractions or repulsions between the particles of these bodies, the intensity of which depends only on the distance, then the configuration and motion of any material system would be subject to a certain equation, which, when expressed in words, is the principle of the conservation of energy.' ${ }^{2}$ In less technical language, he established mathematically that 'force' (Kraft), or, as it is now termed, energy, is indestructible, and he shows that this principle 'contradicts no known parts of science, while it is con-

I Nature, op. cit. ${ }^{2}$ Clerk Maxwell, Nature, op. cit. 


\section{HERMANN VON HELMHOLTZ}

firmed in a striking manner in a great number of instances.' Hence it follows that the total quantity of energy or capacity for work in the universe is constant, and remains eternal and unchanged throughout all the vicissitudes of matter. Energy can change its form and locality without its quantity being changed. The universe possesses a store of energy which is not altered by any change of phenomena, and the quantity can neither be increased nor diminished. Fifteen years afterwards, in 1862, Helmholtz, in a lecture, thus states the principle:'If a certain quantity of mechanical work is lost, we obtain an equivalent quantity of heat or of chemical force, and, conversely, when heat is lost we gain an equivalent quantity of chemical or mechanical force ; and, again, when chemical force disappears, an equivalent of heat or work; so that, in all these interchanges between various inorganic natural forces, working force may indeed disappear in one form, but then it reappears in exactly equivalent quantity in some other form; it is thus neither increased nor diminished, but always remains in exactly the same quantity.... The same law holds good also for processes in organic nature, so far as the facts have been tested.' ' [For the word 'force' it would be better to use the term 'energy.']

Such a conception of the material world met with much opposition. The older physicists of

I Helmholtz's Popular Scientific Lectures, 1873, p. 360. 


\section{HELMHOLTZ IN BERLIN}

Berlin-Dove and Riess-would not admit the principle; Magnus modestly declined to express an opinion, as he thought there should be a distinction between mathematical and experimental physics; the mathematicians shook their heads, and we have it on the authority of $\mathrm{Du}$ Bois Reymond that only Jacobi, who himself had done excellent work in mechanics, saw its truth. Helmholtz, referring in after years to this opposition, said he was met by some of the older men by such a remark as this,'This has already been well known to us; what does this young medical man imagine when he thinks it necessary to explain so minutely all this to us?' Poggendorff actually refused to insert the memoir in his famous periodical Annalen, on the ground of its theoretical character. Du Bois Reymond took the manuscript to the publisher, George Ernest Reimer, then engaged in bringing out Du Bois's famous papers on animal electricity, and he not only published the paper, but gave Helmholtz a honorarium, a pecuniary recognition seldom awarded to an abstruse scientific work. The value of the work was soon recognised by the military authorities; Helmholtz became a marked man; and with the characteristic aptitude of the Germans for putting the right man in the right place, he was relieved largely from military duties, and encouraged to go on with purely scientific work. Kirchhoff, Clausius, $\mathrm{Du}$ Bois Reymond, and others of the young and 


\section{HERMANN VON HELMHOLTZ}

brilliant school, were enthusiastic in their approbation. $\mathrm{Du}$ Bois Reymond remarks, with some humour,' His supporters declared that he had set in motion the conservation of another force, much more interesting for us, the mind of Helmholtz himself.' $x$

It is now a matter of common knowledge, that while the principle of the conservation of energy slowly unfolded itself to the minds of the great scientific thinkers of the earlier part of this century, the root of the idea must be traced back to the intellectual giants Newton, Descartes and Leibnitz. Professor Tait has shown that Newton undoubtedly ${ }^{2}$ was in possession of the principal facts of the conservation and transformation of energy. In the expression of his third law of motion, ' to every action there is always an equal and contrary reaction,' the words 'action' and 'reaction' are interpreted by Newton himself in two senses. Between any two bodies connected together, such as a weight resting on a table, there is always an equal and opposite reaction. The weight presses on the table and the table presses on the weight. Two bodies may also be connected by some invisible link, such as exists between bodies that are affected by magnetic attraction, and yet the law holds good. But action and reaction may occur in another sense. 'If the activity of an agent be

I Du Bois Reymond's Gedächtnissrede. Berlin, r 896.

2 Tait's Lectures on Recent Advances in Physical Science, 1885. Lect. ii., p. 27. London, 1885. 


\section{HELMHOLT'Z IN BERLIN}

measured by the product of its force into its velocity, and if similarly the counter activity of the resistance be measured by the velocities of its several parts multiplied into their several forces, whether these arise from friction, cohesion, weight or acceleration, activity and counter activity in all combinations of machines will be equal and opposite.' In overcoming resistance, as when work is spent in altering the shape of a body, work is done against the elastic forces of the body worked against, and, according to Newton's statement, the amount of work spent, or the rate of spending work in distorting the body, is equal to the amount of work done or the rate of doing work against the elastic forces. The work is stored up in the distorted body as potential energy. Suppose, again, work is expended in a body where there is no resistance from friction, cohesion or weight, it will be spent in overcoming the inertia of a body and increasing its velocity, that is to say, the kinetic energy of the body increases. In such a case the 'rate at which work is spent is measured by the product of the momentum into the acceleration in the direction of the motion.' We know that when work is done against friction, an amount of heat is produced exactly proportional to the amount of work expended. In Newton's day, this had not been experimentally proved; otherwise Newton would probably have definitely formulated the law of the conservation of energy. As Professor Tait says- 


\section{HERMANN vON HELMHOLTZ}

'What Newton really wanted then was to know what becomes of work that is spent in friction.'

Descartes affirmed the doctrine of the constancy of the quantity of motion, that is of momentum, in the world. Leibnitz, in whose dynamical views of nature force was the ultimate reality, contended that Descartes's statement, that motion is measured by velocity, should be abandoned for the conception of a vis motrix, a moving force measured by the square of the velocity. $\mathrm{He}$ enunciated in $\mathrm{I} 686$ the principle of the conservation of vis viva, and came near a full mathematical expression of the law of the conservation of energy. Both Descartes and Leibnitz were correct in their contentions, and the principle of Descartes may be called the conservation of momentum, while that of Leibnitz is a partial statement of the conservation of energy. ${ }^{\mathrm{I}}$

The discussion is closely connected with the views held by thinkers regarding the nature of heat. Thus Bacon wrote: 'Heat is a motion, expansive, restrained, and acting in its strife upon the smaller particles of matter.' ${ }^{2}$

John Locke, by a priori reasoning, had also made a happy guess, that heat was not matter but motion, that it 'was a brisk agitation of the particles of matter,' but the statement was unsupported by experimental evidence.

I Sorley, Art. Leibnitz in Encycl. Britann., vol. xiv., p. 422.

'Bacon, Spedding's Translation, vol. iv. 


\section{HELMHOLTZ IN BERLIN}

About 1798 Count Rumford performed his famous experiments on the boring of cannon, and he observed that the heat produced was much greater than that of boiling water. The older theorists held that heat was a substance, but Rumford's work went far to prove that it was not matter. The proof was conclusively given by Humphry Davy, who obtained sufficient heat to melt ice by rubbing two pieces of ice together. In 1812 Davy wrote: 'The immediate cause of the phenomena of heat, then, is motion, and the laws of its communication are precisely the same as the laws of the communication of motion.' Professor Tait remarks in this connection: "If Davy had with this statement taken into account the second interpretation of Newton's third law, the dynamical theory of heat would have been his.'

It is said that Montgolfier entertained the idea of the equivalence of heat and mechanical work, and his nephew Seguin performed experiments with a steam engine, in which he endeavoured to ascertain whether the same quantity of heat reached the condenser as had left the boiler. Had he succeeded in showing that less heat reaches the condenser than had left the boiler, he would have found that the heat apparently lost was in proportion to the mechanical work performed by the engine.

The notion of the correlation of the physical forces was slowly shaping itself. Mrs Somerville's book on 


\section{HERMANN VON HELMHOLTZ}

the Connection of the Physical Sciences was published in 1834, but little is said about the 'connections,' except that a knowledge of one science is often essential to the successful prosecution of another. In January 1842 , Grove delivered a lecture in the London Institution on the Correlation of the Physical Forces, which was afterwards expanded into a wellknown volume. This work shows that of the various forms of energy existing in nature, any one may be transformed into any other, the one form appearing as the other disappears. No doubt this book, written in a clear and lambent style, familiarised the public mind with the new conception, and it also influenced scientific opinion. Clerk Maxwell says of this epoch in the history of science: "The fathers of dynamical science found a number of words in common use expressive of action and the results of action, such as force, power, action, impulse, impetus, stress, strain, work, energy. They also had in their minds a number of ideas to be expressed, and they appropriated these words as they best could to express the ideas. The words force, vis, kraft, came most readily to hand.'

In and about 1842 the speculations and researches of Robert Mayer of Heilbronn appeared. Only to a limited degree an experimenter, Mayer had yet wonderful clearness of vision and originality, and although his premises were sometimes inadmissible, and his reasoning faulty, he enunciated a true 


\section{HELMHOLTZ IN BERLIN}

theory and developed its applications, more especially in the organic world. He gave a popular exposition of the theory of the transformation of energy into heat, and he even calculated the dynamical equivalent of heat, ${ }^{1}$ giving it as 365 kilogramme-meters, instead of the true equivalent, ascertained experimentally by Joule to be 425 kilogramme-meters, for $\mathrm{I}^{\circ} \mathrm{C}$. (equivalent to 772 foot-pounds for $\mathrm{I}^{\circ} \mathrm{F}$.). His papers produced little effect, even in Germany, at the time of their publication, partly because they were founded so little on experimental enquiry, and partly because they were the work of an obscure physician in a country town. His writings had no influence on science until long after the truth had been proclaimed by Helmholtz. The science of energy would have progressed much as it has done had Mayer never lived; but, on the other hand, had the doctrine of the conservation of energy come first from Mayer, there would still have been the need of a mathematical thinker like Helmholtz to establish it as a law of nature. It is only fair to mention Mayer's obscure position (no fault of his) as an explanation of the fact that, when Helmholtz wrote his essay, he was totally unacquainted with Mayer's work. When, in subsequent years, it was brought under his notice, no one was more generous than Helmholtz in his estimation of the merits of his

I Mayer, Liebig's Annalen, vol. xlii., p. 233 ; Phil. Mag., 4th series, vol. xxiv., p. 371 ; Résumé in Phil. Mag., xxv., p. 378. 


\section{HERMANN vON HELMHOLTZ}

compatriot; and the question of priority, which was for a time keenly discussed by the friends of both parties, was one that gave no concern to his great mind. It is said that he bestowed even more credit on Mayer than the latter claimed for himself.

The theory of the conservation of energy was established experimentally by Colding of Copenhagen and Joule of Manchester. The works of Sadi Carnot (1824) and Clapeyron (1833) in France in relation to heat were also of first-rate importance. Carnot had shown that work was done where heat was transmitted from a body of a higher temperature to a body of lower temperature. The Danish philosopher was less of an experimenter than Joule, but he expresses his conclusions in the following unmistakable language :-

'Force is imperishable and immortal ; and, therefore, where and wherever force seems to vanish in performing certain mechanical, chemical or other work, the force then merely undergoes a transformation and reappears in a new form, but of the orginal amount, as an active force. ${ }^{I}$ In the year 1843 this idea, which completely constitutes the new principle of the perpetuity of energy, was distinctly given to me, the idea itself having been clear to my own mind nearly four years before, when it arose at once in my mind by

I Colding's Treatise, 1843, Royal Society of Copenhagen. Theses concerning Force. Nogle, Saetninger om Krafterne. 


\section{HELMHOLTZ IN BERLIN}

studying d'Alembert's celebrated and successful enunciation of the principle of active and lost forces; but, of course, the new principle was not as clear to me from the beginning as it was when I wrote my treatise in 1843 . I closed my discussion by showing that the discovery of a perpetuum mobile would be possible if my principle was wrong.' ' he anticipates Helmholtz.

The researches of Joule were final and conclusive. Extending over a period of several years, probably originating before 1840 (the first paper appeared in that year), they are models of skilful experiment and accurate induction. They were concluded in 1849 , when the dynamical equivalence of heat was finally established. This led to the enunciation of the first law of thermo-dynamics, that 'when equal quantities of mechanical effect are produced by any means whatever from purely thermal sources, or lost in purely thermal effects, then equal quantities of heat are put out of existence or are generated; and for every unit of heat measured by the raising of a pound of water, $I^{\circ}$ Fahrenheit in temperature, you have to expend 772 foot-pounds of work.' The principle was established by Joule for mechanical work, current electricity, electro-magnetism and light. Thus the grandest generalisation of physical science-the conservation of energy - is founded on the mechanical theory of heat. ${ }^{2}$

I Colding, Phil. Mag., Jan. 1864.

2 Tait, Recent Advances, op. cit., p. 64. 


\section{HERMANN vON HELMHOLTZ}

The first in Great Britain to recognise the immense importance of the principle was William Thomson, now Lord Kelvin, who applied it with such force to thermo-dynamics as to practically create this department of science. He also formulated the complementary doctrine of the dissipation of energy.

It has been necessary to give this slight sketch of the development of these great ideas so as to enable one to estimate with some degree of accuracy how much was contributed by Helmholtz. He approached the subject from the purely mathematical point of view. With the writings of Newton, Leibnitz, Descartes and d'Alembert in the field of his mental vision, he starts by making two assumptions. The first is as follows:- Suppose matter to 'consist of ultimate particles which exert on each other forces whose directions are those of the lines joining each pair of particles, and whose amounts depend simply on the distance between the particles; suppose, in fact, that something akin to gravitation force exists amongst all the particles of matter in the universe, that each particle attracts every other particle with a force which depends only on the distance between them, not in any way upon the sides which are turned to one another, so that if you know the distance between them you know the amount of the attraction, and that the attraction shall also be (in accordance with Newton's Third Law of Motion) in the direction of the line joining them. If that assumption is made, 


\section{HELMHOLTZ IN BERLIN}

then it is a consequence of the laws of motion of gross matter that if all the forms of energy depend upon motion or position of particles, the conservation of energy must hold, and also that the so-called perpetual motion would be impossible under any circumstances.'

As an alternative, Helmholtz reasoned in the following manner:-Assume the impossibility of the so-called perpetual motion, and consider also Newton's second interpretation or explanation of the Third Law of Motion, then these two thoughts would by themselves lead to the proof of the principle of the conservation of energy. But the perpetual motion has been demonstrated by experiment to be impossible. This being an experimental fact, and Newton's statement being also universally true, the principle of the conservation of energy is established. Thus Helmholtz, by a purely theoretical consideration of the matter, made the great discovery for himself. It is no detraction to the work of Helmholtz on this subject that it was theoretical. One of the main objects of theoretical research is to find the point of view in which the subject appears in its greatest simplicity. It is also its purpose to give the form in which the results of experiments may be expressed. Theory leads to the conception of functions the forms of which must be settled by experiment.

As already mentioned, the application of the prin- 


\section{HERMANN vON HELMHOLTZ}

ciple of the conservation of energy to living beings was first clearly made by Robert Mayer. Nothing will give a better notion of this line of thought than the following quotation from Mayer's well-known paper on 'Organic Motion and Nutrition':

'The second question refers to the cause of the chemical tension produced in the plant. This tension is a physical force. It is equivalent to the heat obtained from the combustion of the plant. Does this force, then, come from the vital processes, and without the expenditure of some other form of force? The creation of a physical force, of itself hardly thinkable, seems all the more paradoxical when we consider that it is only by the help of the sun's rays that plants perform their work. By the assumption of such a hypothetical action of the "vital force," all further investigation is cut off, and the application of the methods of exact science to the phenomena of vitality is rendered impossible. Those who hold a notion so opposed to the spirit of science would be thereby carried into the chaos of unbridled phantasy. I therefore hope that I may reckon on the reader's assent when I state, as an axiomatic truth, that during vital processes a conversion only of matter, as well as of force, occurs, and that creation of either the one or the other never takes place.

'The physical force collected by plants becomes the property of another class of creatures - of animals. The living animal consumes combustible substances 


\section{HELMHOLTZ IN BERLIN}

belonging to the vegetable world, and causes them to reunite with the oxygen of the atmosphere. Parallel to this process runs the work done by animals. This work is the aim and end of animal existence. Plants certainly produce mechanical effects, but it is evident that for equal masses and times the sum of the effects produced by a plant is vanishingly small compared with those produced by an animal. While, then, in the plant the production of mechanical effects plays quite a subordinate part, the conversion of chemical tensions into useful mechanical effect is the characteristic sign of animal life. In the animal body chemical forces are perpetually expended. Ternary and quaternary compounds undergo, during the life of the animal, the most important changes, and are, for the most part, given off in the form of binary compounds, as burnt substances. The magnitude of these forces, with reference to the heat developed in these processes, is by no means determined with sufficient accuracy; but here, where our object is simply the establishment of a principle, it will be sufficient to take into account the heat of combustion of the pure carbon. When additional data have been obtained, it will be easy to modify our numerical calculations so as to render them accordant with the new facts.'

(He then goes on with calculations.)

'If the animal organism applied the disposable combustible material solely to the performance of work, the quantities of carbon just calculated would suffice 


\section{HERMANN VON HELMHOLTZ}

for the times mentioned. In reality, however, besides the production of mechanical effects, there is in the animal body a continuous generation of heat. The chemical force contained in the food and inspired oxygen is therefore the source of two other forms of power, namely, mechanical motion and heat; and the sum of these physical forces produced by an animal is the equivalent of the contemporaneous chemical process. Let the quantity of mechanical work performed by an animal in a given time be collected and converted by friction or some other means into heat; add to this the heat generated immediately in the animal body at the same time, we have then the exact quantity of heat corresponding to the chemical processes that have taken place.

'In the active animal the chemical changes are much greater than in the resting one. Let the amount of the chemical processes accomplished in a certain time in the resting animal be $x$, and in the active one be $x+y$. If during activity the same quantity of heat were generated as during rest, the additional chemical force $y$ would correspond to the work performed. In general, however, more heat is produced in the active organism than in the resting one. During work, therefore, we shall have $x$ plus a portion of $y$ heat, the residue of $y$ being converted into mechanical effect.

'The maximum mechanical effect produced by a working mammal hardly amounts to one-fifth of the 56 


\section{HELMHOLTZ IN BERLIN}

force derivable from the total quantity of carbon consumed. The remaining four-fifths are devoted to the generation of heat.'

It will be seen that the doctrine of the conservation of energy was of the highest importance in physiology, as it indicated the road to a thorough investigation of the nutritional changes occurring in living matter. These nutritional changes, if in the direction of the upbuilding of tissues, are also concerned in the storing up of energy, and if, on the contrary, they are associated with the tearing down of tissue, or, in other words, with chemical decompositions, then energy is set free as mechanical motion, heat, light or electricity. The doctrine also appeared to its early teachers, at all events, fatal to any vitalistic theory. Time, however, has shown that there still are phenomena connected with living matter that are outside the range of even this great principle, such as the facts of consciousness. 


\section{CHAPTER VI}

HELMHOLTZ IN KÖNIGSBERG-MEASUREMENT OF THE RAPIDITY OF THE NERVOUS IMPULSE

T $\mathrm{N}$ 1849, in his twenty-ninth year, Helmholtz was 1 appointed to the Chair of Physiology and General Pathology in the University of Königsberg. Here he spent six busy years, fully engaged in teaching and investigation. In the year of his removal, 1849 , no contributions appeared, and we can readily believe the youthful professor was establishing himself in his new sphere of duty.

Early in this year, also, he married Miss Olga Von Velten, of Potsdam, who died soon after his settlement in Heidelberg in 1859. Two children were born of this marriage-a daughter, who became the wife of Professor Branco, a well-known geologist, and a son, who is an engineer in Munich, still survives. Helmholtz loved.a quiet home life, with the pleasures of congenial society and music, to which he was devoted. He was an accomplished pianist, and he sang a little, but his voice was not strong. As his days were devoted to scientific labour, and as he 


\section{HELMHOLTZ IN KÖNIGSBERG}

shunned publicity for the greater part of his life, there is little of incident to relate.

The stream of original papers began to flow in 1850 , and it increased in volume until he moved to Bonn in 1856 . One is astonished at the number of researches of first-rate importance. Helmholtz did not, like many, lose time in doing second-rate work that others, perhaps, could have done better. $\mathrm{His}$ scientific instinct appeared to guide him often into what are termed virgin fields. Thus he had the great satisfaction of collecting the first fruits, and he usually gathered so well as to leave little for others who came after him. Hence the researches and discoveries that were announced in rapid succession were always epoch making, and always in a special sense his own. During this period he measured the rate of the nervous impulse, he invented the ophthalmoscope, and he began those investigations on colour and sound that will for ever be associated with his name.

The measurement of the rate of the nervous impulse was accomplished in 1850 . The problem was to measure the rate at which the nervous impulse travels along a sensory nerve, say from the tip of the finger to the brain, or along a motor nerve, say from the brain to one of the muscles of the arm. When we touch the finger, no time seems to elapse between the moment of touching and the moment when we are conscious of having touched something. When 


\section{HERMANN vON HELMHOLTZ}

we will to move the forefinger, the commands of the will appear to be instantaneously carried into effect. This arises, however, from our limited appreciation of shorter intervals of time than say the one-tenth of a second, so that if less time elapsed between the moment of touching the finger and the moment of the sensation, the two events appear to be one. It was necessary, therefore, to have some means of recording the duration of short periods of time, such as the short period assumed to exist between the moment of irritating a nerve and the moment of the contraction of the muscle supplied by it.

Manifestly the subject could be investigated most easily by using the muscle of the frog and the motor nerve passing to it. Helmholtz made use of the graphic method of recording the contraction of muscle, already invented by him in the form of the well-known myograph. Just about this time electrical mechanisms had been introduced into practical physiology by Du Bois Reymond, and Helmholtz made good use of these appliances. He first employed, as a means of recording the beginning and the end of the phenomenon, a method devised by Pouillet, which consisted in noting the instant of the movement of the needle of a galvanometer when an instantaneous current was sent through the instrument, taking it for granted that the duration of the current itself was practically nothing. Suppose, then, that an arrangement was made by which a nerve could be 


\section{HELMHOLTZ IN KÖNIGSBERG}

irritated, say at a distance of two inches from the muscle, by an electric current, which also momentarily passed through the galvanometer, the movement of the needle would indicate the instant when the nerve was stimulated. Helmholtz, in the first place, improved Pouillet's method by causing the opening or closing shock from an induction coil to irritate the nerve, either near to the muscle or far from it, and he so arranged the experiment that at the moment of opening the induction current, the galvanometer circuit was closed, and was again opened by the contraction of the muscle itself. The interval, then, between the two swings of the needle was that between the moment of irritating the nerve and the moment of the muscular contraction. Arrangements were then made for irritating the nerve in two successive experiments - first, close to the muscle, and, second, at a distance of say two inches from it. It was soon found that the muscle did not respond at the instant the stimulus was applied to the nerve, and that the further away the nerve was irritated the later was the response. The first discovery was that even when the nerve was irritated close to the muscle, a period of something like the $\frac{1}{100}$ th of a second always elapsed before the muscle began to contract. In other words, the muscle did not at once respond, but some time was occupied in those molecular changes that precede contraction. This period was termed by Helmholtz the period of 


\section{HERMANN vON HELMHOLTZ}

latent stimulation. Edward Weber had endeavoured to draw a distinction between the movements of inorganic and animal matter by assuming that the latter were instantaneous, but the discovery of the latent period at once put this distinction out of the question.

Helmholtz next made use of the graphic method, introduced about that time into physiological investigation, and the muscle, by means of a myograph, was caused to write the curve of its contraction on the blackened surface of a rotating drum. About the beginning of the century, Thomas Young showed how time might be recorded by marks made on a rotating cylinder, moving with a uniform velocity. James Watt then applied the graphic method to recording the movements of the indicator of his engine on a cylinder rotated by the engine itself. Thus he obtained a curve representing variations of steam pressure at different times. This suggested to Ludwig, then at the beginning of his important investigations into the dynamics of the circulation, the conception of the kymograph, by which variations of pressure in the blood vessels of a living animal were recorded on a drum in a series of waves, the smaller ones corresponding to the individual beats of the heart, and the larger to the respiratory movements. The myograph of Helmholtz, already referred to (p. 36), recorded the shortening of the muscle with great exactitude, and thus Pouillet's galvanometrical method was discarded. He con- 


\section{HELMHOLTZ IN KÖNIGSBERG}

structed a special myographion, in which a weight, by centrifugal action, liberated a spring that set free a simple mechanism by which a current passing through the primary coil of a small induction machine was opened. The shock thus obtained from the secondary coil passed instantaneously to the nerve, the nervous impulse was generated at the point irritated, the impulse then travelled down the nerve, and the muscle contracted, writing its curve on the rotating drum. In this way two curves were traced on the cylinder, one by contraction of the muscle when the nerve was stimulated close to the muscle, and the other when it was stimulated at a distance from it. As the nerve, whether stimulated near or far from the muscle, always received the induction shock at the same moment when the cylinder had attained its maximum velocity, the two curves did not coincide at their commencement, the one corresponding to the experiment in which the nerve was stimulated at a distance being a little behind the one produced when the nerve was stimulated near the muscle. Thus during the time that the nervous impulse was travelling, say along two inches of nerve, the cylinder had travelled a short distance farther on-that is to say, had rotated round its axis. The distance between the beginnings of the two curves expressed the time occupied by the nervous impulse in passing along a given length of nerve. If the velocity of the cylinder had been 


\section{HERMANN vON HELMHOLTZ}

determined, then this distance represented a certain period of time.

By this method a single experiment gave results that could only have been obtained, with much trouble and possibilities of inaccuracy, by a whole series of observations by Pouillet's method. The experiments showed that in the motor nerves of the frog the velocity of the nervous impulse was only about ninety feet per second (that of a very quick express train), or about $\frac{1}{11}$ th part of the velocity of sound in air, a result quite unexpected. Until the question was submitted by Helmholtz to the test of experiment, the wildest conjectures had been indulged in by speculative physiologists. Thus the iatromathematicians of Montpellier said that the rapidity bore a ratio to that of the blood in the aorta, namely, in the proportion of the diameter of the aorta to that of a nerve fibre, a statement that implied a velocity of the nervous impulse 600 times more rapid than light! Haller took as the basis of his conjectures the number of vibrations made by the tongue in pronouncing the letter $R$, and, by a series of deductions, most of them wide of the mark; he strangely arrived at a conclusion not very far off what we know to be correct, namely, that the velocity was about 150 feet per second.I Johannes Müller despaired of being

'Haller's Elementa, t. iv., p. 372-'Ego vero, cum haec mere theoretica sint experimento uti malim, etsi minor summa prodit. Ita invenio summam tamen celeritatem esse muscularis liquidi ut non minus quam 9000 pedes in minuto percurrat.' 


\section{HELMHOLTZ IN KÖNIGSBERG}

able to solve the problem, chiefly because of the shortness of the nervous tracts in the living animal, and although he doubted the results given by the older physiologists, he thought that the velocity of the nervous impulse must be akin to that of light. In his great text-book he makes use of the phrase, 'Such immeasurable rapidity.' Again, he says, 'We shall probably never attain the power of measuring the velocity of nervous action, for we have no opportunity of comparing its propagation through immense space as we have in the case of light.' I Such was the state of opinion when Helmholtz took up the subject. His versatile intellect suggested the method by which the problem could be attacked through the nerves and muscles of a frog, and, as one writer remarks, 'he apparently felt as much at home with frogs' nerves and muscles, and with intervals of time of thousands of a second, as he was in after years in discussing the universe and the immense measurements of time and space involved in a consideration of the planets.'

As already mentioned, Du Bois Reymond was about the same period engaged on his researches on animal electricity. Following Matteucci, but with much finer apparatus and with clearer ideas, he had shown, by means of the galvanometer, and speciallyconstructed non-polarisable electrodes, that the transverse section of a resting muscle is negative to the

' Müller's Physiology, trans, by Baly, vol. i., p. 678 . 


\section{HERMANN vON HELMHOLTZ}

surface, as indicated by the movement of the needle of the galvanometer in a certain direction. This was termed the resting current. If, then, the muscle is caused to contract, there occurs what Du Bois Reymond called ' the negative variation,' that is to say, the needle gave ${ }_{i}$ a swing towards zero, or even crossed to the other side. This negative variation, now called 'the action current,' is an electrical phenomenon connected with the activity of the muscle, and the electric change is of sufficient intensity to irritate the nerve of a muscle preparation, as shown in Matteucci's famous experiment, usually called the 'induced contraction.' In this experiment the nerve of a muscle, $a$, is stretched over a muscle $b$, and if the nerve of $b$ is irritated by an electric shock, not only $b$ but also $a$ is thrown into contraction, because the 'negative variation' in muscle $b$ irritates the nerve of muscle $a$. Helmholtz attacked the time relations of this problem, and he thought he could demonstrate that the negative variation occurred only in the period of latent stimulation, and that it was over and gone before the muscle began to contract. All this work related to motor nerves and to the muscles and nerves of the frog.

It seemed a more difficult problem to determine the velocity in sensory nerves. When we touch a sensory nerve, the message goes to the brain, but how could it be possible to estimate the time it occupies in going that distance, seeing the brain can only respond by a 


\section{HELMHOLTZ IN KÖNIGSBERG}

muscular act? Helmholtz devised a method by which what is called the 'reaction period' may be computed, that is the time between the moment of stimulating, say the skin of the foot and the moment the individual makes a signal that he has felt the sensation. The reasoning is as follows: Suppose a sensory nerve to be excited in the hand, the theory of nervous conduction is that a change is propagated along the nerve to the brain, and that in the brain the molecular changes occur which result in a sensation. The individual having the sensation may feel it and make no sign by which anyone else might be made aware that he has felt it, or the subject of the sensation might, by a muscular movement, such as the motion of an arm, let anyone else see that he has felt the sensation. We have no means of knowing whether or not an individual has felt a sensation except by the individual making some kind of gesture or muscular movement. Now, it is clear that, if we regard the brain as the seat of the changes resulting in sensation, the nearer any stimulated portion of skin is to the brain the sooner will the brain feel and respond to the stimulus. Thus, if the skin on the big toe of the right foot be stimulated, the effect of the stimulus will pass to the brain and there call forth a sensation; but if the stimulus be applied to the skin at the top of the thigh, it is evident the effect will have to pass along a shorter length of nerve, and that the sensation in the brain will be aroused sooner. If we suppose 


\section{HERMANN vON HELMHOLTZ}

that in each case the individual who is the subject of the experiment indicates the moment he feels the sensation, and that the instant the stimulus is applied successively to the skin on the toe and on the thigh is also accurately recorded, it is clear that he will signal the sensation of stimulation of the toe a little later than when he signals stimulation of the skin on the thigh, and that the difference will indicate the time required by the change in the nerve to pass along the length of the nerve from the toe to the thigh. In the observation it is assumed that the time required for the changes in the brain, resulting in sensation and volition, for the transmission along the motor nerve, and for the muscular contraction required to signal, is the same in each experiment. Thus, supposing the total time between the moment of stimulating and the moment when the signal that the sensation has been felt and responded to be $x$, it is clear that this time is composed of $a$, the time required for the passage of the nerve current in the first experiment from the toe to the brain; of $b$, the time required for the changes in the brain involved in sensation and volition; and of $c$, the time required for the transmission along the motor nerves and for the muscular contraction to move the signal-that is, $x=a+b+c$. But if the time between the moment of stimulating the thigh to the moment of signalling be shorter, and supposing that $b$ and $c$ are constant, then $a$ will vary according to the length of the nerve. 


\section{HELMHOLTZ IN KÖNIGSBERG}

Suppose the difference of time between the registration of stimulating at the toe and at the thigh to be $y$, then in the second experiment $x=a-y+b+c$; that is, $y=$ the time occupied by the passage of the nerve current from the toe to the thigh. By this method the velocity of the nervous impulse in the sensory nerves in man is found to vary from 50 to 100 metres per second ( 160 to 300 feet).

It will be noted that for motor nerves the observations were made on the frog and for sensory nerves on man. The next question Helmholtz solved was: Is the velocity the same or different in the two kinds of nerves? By attaching the thumb to a myograph and then stimulating near the wrist and at the elbow, it was found that the muscles of the thumb contracted a little later after stimulation at the elbow; that is to say, the nervous impulse took some time in travelling from the elbow to the wrist. Two curves were obtained practically by the same method as was used in determining the rate in the motor nerve in the frog, and the velocity was found to be the same as in the sensory nerves of man. In both kinds of nerves, cold was found to retard and heat to accelerate the velocity of transmission.

These important observations not only threw light on the question of the transmission of the nervous impulse, but they prepared the way for the determination of time relations in many nervous processes. Astronomers had long known that in watching and 


\section{HERMANN vON HELMHOLTZ}

signalling the moment of the transit of a star, there were slight differences in the observations made by equally competent observers, differences apparently due to individuality. It is said that Maskelyne dismissed an assistant because, in making observations, he was always behind his master in point of time. Bessel was the first to recognise that the discrepancies were due to the fact that men feel and even think at different rates. As Hermann points out, the coincidence is striking that years afterwards, in the very university where Bessel worked, Helmholtz showed that there was a physiological basis for his conjecture. Psycho-physical investigators of later times, with improved appliances, have measured the time occupied in reflex actions, and even in those psychical operations involved in choice, discrimination and volition. Many ingenious instruments have since been devised, but the root idea of them all may be traced back to those experiments of Helmholtz, which originated the methods of the psycho-physical school of investigators. 


\section{CHA P TER VII}

HELMHOLTZ IN KÖNIGSBERG-THE OPHTHALMOSCOPE

I 1851 Helmholtz conferred an inestimable benefit on humanity, became famous far beyond the circle of his scientific friends, and handed his name on to posterity by the invention of the ophthalmoscope. Had he done little else in his long lifetime, his name would never be forgotten; and yet the invention of this instrument took its origin not in any profound investigation, but in the desire to exhibit a physiological phenomenon to his students. It was characteristic, however, of his mind that he was ever receptive of new impressions, and when an idea occurred to him, his powers were brought persistently to bear upon it, and if it involved a problem, he had no rest until it was solved. The invention of the ophthalmoscope is a striking example, also, of his singular power of combining the theoretical with the practical in his daily life; and he could turn his mind from the contemplation of the mathematical expressions of the law of the conservation of energy, tracing in his imagination its tremendous consequences, to devising the best method of illuminating the eye. 


\section{HERMANN vON HELMHOLTZ}

At the same time, although he was practical, no one more strongly denounced the pursuit of science merely for its practical results. All his physiological work, whilst of the most thorough-going kind, was pursued because it was his duty as a disciple of science to ascertain the truth, and he felt sure that any practical advantage to medicine, or to science in general, would naturally flow from what to many would seem to be abstruse and theoretical work. He did not require to invent an ophthalmoscope to show the practical side of his genius; it was the outcome of his knowledge of science, including the anatomical structure of the eye and the laws of optics. Yet the invention of this little instrument, from the time of its conception the daily companion of medical men all over the world - an instrument, too, that can scarcely be supplanted by any other-will keep his memory green when many of his more elaborate works may be forgotten, or are absorbed in the general body of scientific truth.

In a speech, delivered many years after, Helmholtz remarked, 'In Königsberg I had to teach general pathology and physiology. A teacher in a university is subject to excellent discipline, in that he is obliged each year not only to give at least an outline of the whole of his science, but also to convince and satisfy the clear heads among his hearers, some of whom will be the great men of the next generation. This necessity was most beneficial to myself. In prepar- 


\section{HELMHOLTZ IN KÖNIGSBERG}

ing my lectures, I was led to devise the method of measuring the velocity of the nervous impulse, and also to the conception of the ophthalmoscope. This instrument became the most popular of my scientific achievements; but I have already pointed to the oculists how much good fortune, rather than any personal merit, favoured me in its invention. I was endeavouring to explain to my pupils the emission of reflected light from the eye, a discovery made by Brücke, who would have invented the ophthalmoscope had he only asked himself how an optical image is formed by the light returning from the eye. In his research it was not necessary to ask it, but had he asked it, he was just the man to answer it as quickly as I did, and to invent the instrument. I turned the problem over and over to ascertain the simplest way in which I could demonstrate the phenomenon to my students. It was also a reminiscence of my days of medical study, that ophthalmologists had great trouble in dealing with certain cases of eye disease, then known as black cataract. The first model was constructed of pasteboard, eye lenses, and cover glasses used in the microscopic work. It was at first so difficult to use, that I doubt if I should have persevered, unless I had felt that it must succeed; but in eight days $I$ had the great joy of being the first who saw before him a living human retina.'

It had long been known that the eyes of certain 


\section{HERMANN vON HELMHOLTZ}

animals, more especially those of birds of prey, glisten or sparkle in the dark. If a cat is observed entering a room in shadow, her eyes may be seen like little balls of fire, and the red eyes of white rabbits and other albinos are familiar to everyone. In I $81 \mathrm{I}$, Pallas suggested that perhaps one saw in such cases the naked electricity of the retina (forte nudum electricum retina nerva). Johannes Müller proved the truth of the view first suggested by Hassenstein, that such eyes do not really emit, but only reflect light, and it was found that those eyes glistened most which were furnished with a special structure, called a tapetum, adapted for the reflection of light. Brücke was the first to show that all eyes could be made to glisten by throwing in to the eye the beam of a lantern while the rest of the room was dark; and it is said that at night he went to the Zoological Gardens and found that, by taking up a suitable position, he could illuminate the eyes of all animals. He then tried the experiment with the human eye, guided by the curious bit of information, that a servant of his father had been dismissed from his situation because it was 'uncanny' to see his eyes shining in the dark ! The first eyes that were illuminated by Brücke, so as to cause them to shine, were those of his friend Du Bois Reymond. Soon afterwards von Erlach, of Bern, who happened to wear concave spectacles, found that by placing his glasses at a particular angle, and thus reflecting light into the eyes of his patient, 


\section{HELMHOLTZ IN KÖNIGSBERG}

he could make them shine, an experiment very easily repeated. Then came Helmholtz, who went deeper into the subject, and invented the instrument. It will be seen how true it was that Brücke came near the invention, but still there is all the difference in the world between doing a thing and not doing it. The first account of the ophthalmoscope was published in $1851 .{ }^{\mathrm{I}}$

In his great work on physiological optics, the first part of which was published in 1856 , Helmholtz gives a full account of the whole subject, and as it is of extreme interest to medical men, I shall take the liberty of making full use ot it, sometimes using his own words.

Light from the eye has been observed from early times coming from the eyes of dogs, cats and other animals who had a tapetum in the fundus of the eye - that is to say, an area devoid of pigment, and covered with thin and highly-reflecting fibres. In these animals the reflection is so intense as to be easily perceived, even in unfavourable circumstances. The ancient and prevalent opinion was that those luminous eyes developed light, and that when the animals were irritated, light was evolved from their eyes under the influence of their nervous system. As the light of the eyes is best recognised when the light comes from behind the observer and skims over his head, it

I Beschreibung eines Augenspiegels zur Untersuchung der Netzhaut in lebenden Auge. Berlin, 1851 . 


\section{HERMANN vON HELMHOLTZ}

is easy to understand that a source of light so placed

- had escaped all observers. It was also held that the eyes of white rabbits and of albinos had a light of their own. Prevost, in 1810 , was the first to show that the light of the eyes of animals was never seen in complete darkness, that neither an effort of will nor irritation caused it, and that it was always due to the reflection of an incident light. Gruithuisen found the same result, and further showed that the cause of the phenomenon was in the tapetum along with the 'refraction extraordinaire' of the lens. He also saw the light in the eyes of dead animals. These facts were confirmed by Rudolphi, Johannes Müller, Esser, Wiedemann and Hassenstein. Rudolphi observed that we must look at the eye in a certain direction to perceive the light; and Esser gave a good explanation of the changes of colour by the appearance of different coloured parts of the retina which were presented successively behind the pupil. Hassenstein, finally, found that light was produced when the eye was compressed along its axis, and supposed that in the living animal luminosity might be produced voluntarily by a shortening of the axis by pressure of muscles. The earlier observers recognised, then, luminosity of the eye as a phenomenon of reflection without giving an account of the conditions that determined it.

In the human eye luminosity was observed in certain rare diseases, in particular when tumours occu- 


\section{HELMHOLTZ IN KÖNIGSBERG}

pied the fundus of the eye. Behr, in 1839 , met with a case in which the iris was absent, in which there was luminosity, and noted that the eyes of the observer must regard those of the patient in a direction nearly parallel to that of the incident rays; such was also the basis of Brücke's method of observing the ocular light. In the case of absence of the iris, the luminosity was not marked when the retina was strongly illuminated. Accommodation was imperfect in such a case.

Finally W. Cumming ${ }^{\mathrm{I}}$ and Brücke, in 1847 , found, independently of each other, the method of rendering the normal human eye luminous, when the observer looks at it in a direction nearly parallel to the incident rays. Brücke had already applied his method to the eyes of animals furnished with a tapetum. At last, Wharton Jones, in 1854, writes that Charles Babbage had shown to him, about the same time, a silvered mirror from which a small portion of the foil had been removed, by which light could be thrown into the eye, and at the same time the observer could look at it through the opening. This description applies well to the ophthalmoscope of Coccius, but as Babbage does not appear to have used lenses with his mirror, he could not, in the opinion of Helmholtz, clearly see the retina, and probably, for that reason, he did not publish the discovery. It is evident, however, that Babbage almost invented the ophthalmoscope.

"Medico-Chirurgical Trans., vol. xxix., p. 284. 


\section{HERMANN vON HELMHOLTZ}

The other aspect of the question, why the parts of the retina, even when illuminated, as in the eyes of animals having a tapetum, and, in albinos, could not be distinguished, has been made the subject of much discussion. The solution was easy. In the beginning of the eighteenth century, Mery (1704) had observed that he could see the vessels of the retina of a cat immersed in water, the eyes of which were strongly luminous. La Hire, in I 709, gave a correct explanation of this phenomenon. He said that it was due to a change in the refraction of the rays that made the eye luminous, but he did not attempt to give a more precise explanation. It was the same with Kussmaul in 1845 . He showed that the retina became clear and recognisable when the cornea and the crystallin were removed, or when a small portion of the vitreous was removed, thus shortening the axis of the eye.

Helmholtz was the first to give a complete account of the relation existing between the directions of the incident and emergent rays, and he gave the true explanation of the blackness of the pupil. $\mathrm{He}$ employed for illumination, plane unsilvered glasses, and, to see the retina better, concave lenses. H. Reute (in 1852 ), on the other hand, was the first to use a mirror having a hole in the centre, and convex glasses. As the new instrument soon acquired great importance in ophthalmology, many ophthalmoscopes of different forms have been made, but they do not involve any 


\section{HELMHOLTZ IN KÖNIGSBERG}

essentially new method for illuminating and examining the retina.

Of the light which strikes on the retina, one part is absorbed, and that principally by the black pigment of the choroid, and the other part is diffusely reflected, and returns from the eye through the pupil. In ordinary circumstances, we do not perceive the light which issues from the pupil ; this opening, on the contrary, appears jet black. We must look for the explanation in the particular conditions of refraction in the eye, and we must also remember that, owing to the pigmentation of the eye, only a small amount of light is returned from it. In all systems of refractive surfaces (lenses), which form an image of a luminous point, the rays may be traced from the image to the luminous point, traversing exactly the same path as they followed in passing from the luminous point to theimage. In other words, if we put the luminous point in the position first occupied by the image, the image will now be formed in the place previously occupied by the luminous point.

The result is as follows:-When the human eye is exactly accommodated for a luminous point, and forms an exact image of the point on the retina, if we consider the illuminated part of the retina as a second luminous object, the image formed by the media of the eye coincides exactly with the body given; so, in front of the eye, all the light which returns from the retina is directed towards the luminous body, and it 


\section{HERMANN VON HELMHOLTZ}

does not pass by the side of this body. To receive a part of this light, it is necessary that the eye of the observer be placed between the luminous body and the illuminated eye; this evidently cannot be done without intercepting the light which goes to the illuminated eye, unless we employ a special device. An observer, moreover, cannot see the light returned from one eye into the other if the last is exactly accommodated for the pupil of the observer. In these circumstances, there is formed on the retina of the eye observed an exact but dim image of the pupil of the observer. Conversely, the media of the eye under observation forms precisely on the pupil of the observer an exact image of its retinal image, and, consequently, the observer can only see in the eye of the other the reflection of his own black pupil. This explains how, in ordinary circumstances, we cannot see the fundus of the eye we look at, and how we cannot distinguish even the parts which reflect the light the most strongly, such as the point of entrance, generally white, of the optic nerve or the blood vessels. The pupil appears black even in albinos (subjects in whom the choroid has no pigment), if we take the precaution to interpose a black card, having a hole in it the diameter of the pupil, and thus prevent the light from penetrating into the eye through the sclerotic, an observation first made by Donders. It is, in reality, the light which passes through the sclerotic which gives to the pupil of albinos its well-known red colour. 


\section{HELMHOLTZ IN KÖNIGSBERG}

In the same way the objective of a camera appears black in a dark room when we throw on it the image of a single flame. If the eye observed is, on the contrary, neither exactly accommodated for the luminous body, nor for the pupil of the observer, it is possible that we may perceive a little of the light which emerges from the observed eye, and the pupil may then appear to be luminous. It is easy to see that the observer may receive light coming from all points of the retina of the eye under observation, on which falls the diffusive image of his own pupil. If we substitute a luminous disc for the pupil of the observer, the image of diffusion formed of this disc in the eye observed will coincide exactly with that of the pupil of the observer, for luminous rays will radiate from one or many points of the disc to each point of its image of diffusion ; then, conversely, the rays given off from each point of the circle of diffusion will reach one or many points of the luminous disc, that is to say, the pupil of the observer. The eye observed appears luminous when the image of diffusion of the pupil of the observer coincides with that of a luminous object in the eye observed. If then we look at an eye by a light from a flame from which we have shut off, by an opaque screen, the rays that dazzle us, whether the eye observed is accommodated for a distant or near object, its pupil will appear illuminated in red.

During the experiment accommodation must be at rest, if the observer is far away, because the 


\section{HERMANN vON HELMHOLTZ}

least inexactitude of refraction or of accommodation will allow some of the rays to reach the observer, and we are most likely to succeed if the subject of observation looks to the side. The illumination is most brilliant when the incident light falls on the place of entrance of the optic nerve, because the white substance of the papilla reflects light strongly, and because, on account of its diaphanous structure, the surface is not so uniform as to receive a perfectly sharp image.

Thus it will be seen that the invention of the ophthalmoscope was not a happy guess, but was the outcome of a careful sifting of the facts of vision. In this invention, and in its theoretical explanation, we have an excellent example of Helmholtz's thoroughness. In many of its arrangements the ophthalmoscope has been made more easy to use, and the observation of the inverted image has its advantages, but we have it on the authority of Donders and von Jaeger, that the instrument in its original form is optically complete. Helmholtz also saw how the instrument could be serviceable to ophthalmologists, not only as regards the examination of the fundus and the observation of changes in the retina, but also as to how the refractive conditions can be accurately estimated. In this way, the degrees of myopia (shortsightedness), hypermetropia (far-sightedness), and of that peculiar condition known as astigmatism (in which the meridians of curvature of the refractive 82 


\section{HELMHOLTZ IN KÖNIGSBERG}

structures, the cornea and lens, are not the same), may all be determined. The invention of the instrument was a new era, not only for ophthalmology, but also for practical medicine, as the retina may be regarded as an outlying portion of the brain; an examination of the fundus of the eye often gives the physician information as to pathological changes occurring in the nerve centres. Thus it is of service in the diagnosis of inflammatory actions in the brain, both acute and chronic; of changes in the meninges, or brain coverings; in locomotor ataxia; in the various forms of Bright's disease ; and many other maladies.

The retina presents to the observing eye the appearance of a red-coloured concave disc with a whitish oval spot to the inner side, where the optic nerve enters, from which we see branching the retinal vessels, the veins being darker in colour than the arteries, and in the visual axis lies the yellow spot, which is the most sensitive part of the retina. The vessels of the fovea centralis, a minute depression in the centre of the yellow spot, are so fine as to be invisible to the naked eye.

When von Graefe first saw the fundus of the living human eye, with its optic disc and blood vessels, his face flushed with excitement, and he cried, ' Helmholtz has unfolded to us a new world! What remains to be discovered?' Before the invention of the oph thalmoscope, diseases of the fundus, and even disturbances of refraction and accommodation of the most diverse character, 


\section{HERMANN vON HELMHOLTZ}

were not differentiated, and the same treatment was applied to all alike, often with disastrous results to the patient. In an eloquent speech by von Graefe, delivered at Heidelberg in 1858 , on the occasion of the Ophthalmological Congress, he said, 'Under our eyes we see the mists disperse, which, for hundreds of years, have clouded the view of our best observers, and an unexampled field is won for the healing art, from which, even already, after a few brief years, have been reaped most admirable fruits.' Then, turning to Helmholtz, he handed him, in the name of the Congress, a cup, on which were inscribed the words: 'To the creator of a new science, to the benefactor of mankind, in thankful remembrance of the invention of the ophthalmoscope.' Helmholtz was visibly moved, and when he went home beloved lips said to him-'Better than a decoration ?' To which he replied, 'Certainly; it is a decoration on the part of competent judges.'

Long afterwards, on 9th August 1886, at the fifth centenary of the University of Heidelberg, there was another great meeting of ophthalmologists, and Helmholtz was presented with the von Graefe medal, a memorial of the great ophthalmologist, awarded every tenth year to the man of whatever nation who has rendered the greatest service to the science of ophthalmology. Professor von Zehender was in the chair, and in the presence of many distinguished visitors to the famous university on the banks of the Neckar, 84 


\section{HELMHOLTZ IN KÖNIGSBERG}

Donders, in a brilliant speech, made the presentation. After a brief survey of Helmholtz's career, he concluded thus: 'And now, twenty-eight years after that memorable day, highly esteemed and honoured von Helmholtz, I turn to you in the name of that society for which von Graefe then spoke, and so to say, in his name, in the name of our master and patron, offer you the first honorary medal instituted in his memory. May this gift hereafter, when following the first modest tribute which our society long since ventured to offer you, Science from its highest circles, and your Emperor, whom you reverence and esteem, shall have heaped upon you all the distinctions suitable to great endowments, associated with great deserts; may this gift still remain to you a gratifying symbol of the privilege you enjoy of living in a generation that honours you as its benefactor. May this happy knowledge, which is not granted to every man of genius, illumine with its gentle light this evening of your life, in which you may see yourself always surrounded in unfading freshness of mind and body by the love of all that are dear to you.'

Helmholtz replied, and gave an interesting sketch of his contributions to science in the domain of physiological optics. $\mathrm{He}$ referred with great modesty to the invention of the ophthalmoscope, and to its important uses in the hands of ophthalmologists, in the following beautiful words: 'Let us suppose that up 


\section{HERMANN VON HELMHOLTZ}

to the time of Phidias nobody has had a chisel sufficiently hard to work on marble. Up to that time they would only mould clay or carve wood. But a clever smith discovers how a chisel can be tempered. Phidias rejoices over the improved tools, fashions with them his God-like statues and manipulates the marble as no one has ever done before. He is honoured and rewarded. But great geniuses are most modest just in that in which they most excel others. That very thing is so easy for them that they can hardly understand why others cannot do it. But there is always associated with high endowments a correspondingly great sensitiveness for the defects of one's own work. Thus, says Phidias to the smith, "Without your aid I could have done nothing of that; the honour and glory belong to you." But the smith can only answer him, "But I could not have done it even with my chisels, whereas you, without my chisels, could at least have moulded your wonderful works in clay; therefore I must decline the honour and glory, if I will remain an honourable man." But now Phidias is taken away, and there remain his friends and pupils-Praxiteles, Paionios, and others. They all use the chisel of the smith. The world is filled with their work and their fame. They determine to honour the memory of the deceased with a garland which he shall receive who has done the most for the art, and in the art, of statuary. The beloved master has often praised the smith as the 


\section{HELMHOLTZ IN KÖNIGSBERG}

author of their great success, and they finally decide to award the garland to him. "Well," answers the smith, "I consent; you are many, and among you are clever people. I am but a single man. You assert that I singly have been of service to many of you, and that many places teem with sculptors who have decked the temples with divine statues, which, without the tools that I have given you, would have been very imperfectly fashioned. I must believe you, as I have never chiselled marble, and I accept thankfully what you award to me, but I myself would have given my vote to Praxiteles or Paionios.", 


\section{CHAPTER VIII}

HELMHOLTZ IN KÖNIGSBERG - THE MECHANISM OF ACCOMMODATION-FIRST VISIT TO ENGLAND

$F^{R O M} 185$ I to 1856 , when he went to Bonn, Helmholtz was mainly engaged in researches in physiological optics. Now and again he entered on electrical problems, two papers appearing in $185 \mathrm{I}$ on the induction coil. In 1852 he gave an interesting résumé, characterised by much critical acuteness, of the progress of electro-physiology, or animal electricity, up to that date. It was in 1851 that he began the systematic examination of the eye, both as regards its anatomy and its physical constants, an examination that culminated in his great work on physiological optics; and it was also in 1852 that he invented the ophthalmometer. In this year he also wrote an important paper on the theory of heat as applied to living beings; a paper dealing with the relation of heat to work appeared in 1855 . Further, it was in 1852 that problems of a psychological nature first occupied his attention. The publication of the results of his investigations into these problems first began in 1852 with a short but fundamental paper on the nature of 88 


\section{HELMHOLTZ IN KÖNIGSBERG}

sensation, and then there followed in rapid succession a series of papers on the phenomena of colour. The first announcement of research into acoustical questions was also made in 1852 , a subject which occupied much of his attention till 1863 , when he published his great work on Sensations of Tone as the Physiological Basis of Music, a work that may fitly be called the Principia of acoustics. It was probably in Königsberg that his genius burst forth in all its splendour, although it had not yet reached its zenith, and this period was characterised by intense mental activity, as indicated both by the far-reaching nature of the problems he attacked, and by the success with which he achieved at least their partial solution.

The University of Königsberg may well be proud of her famous professor. The distinguished man who now occupies the chair of physiology there, Professor Ludwig Hermann, in an address on Helmholtz, remarks with pardonable pride: 'In a little room in the anatomical department, which was his workshop, originated the myographion, the ophthalmometer, and the ophthalmoscope. His models were first constructed with his own hands, chiefly with wire, cork, and sealing-wax, and then they were completed by Rekoss.' In these days of palatial laboratories springing up all over the world in connection with each department of science, it is well not to forget that some of the greatest results in science have been gained in humble rooms and with simple appliances. 


\section{HERMANN vON HELMHOLTZ}

Neither the most splendid buildings, fitted with the most modern appliances, nor the endowment of research, however wisely conceived, will compensate for the absence of genius. The living spirit must be the propelling force, and whilst it is reasonable that every facility for research should be afforded, a view which is now recognised in every civilised country, and mostly by those nations that form the vanguard of progress, there still remains the fact that in Science as in Art the great investigator, like the great artist, is born, not made.

Helmholtz, like all hard workers, needed periods of comparative rest, and he was wont usually to betake himself to the mountains and valleys of Switzerland. The year 1854 is memorable from the occurrence of his first visit to England, and in a letter written to his friend Ludwig, ${ }^{\text {I }}$ after his return, we get a glimpse into his first impressions :-

'Königsberg, 2, vi. 54 .

'Dear Ludwig,-England is a great land, and one feels there what a magnificent and splendid thing civilisation is, and how the minutest conditions of life bear its impress. In comparison with London, Berlin and Vienna are mere villages. To describe London is impossible; it must be seen with one's own eyes before one can attempt to form an estimate of it. A

${ }^{x}$ For this letter $\mathrm{I}$ am indebted to my friend Professor Hugo Kronecker, of Bern, whose Life of Helmholtz is eagerly expected. It is understood that many letters have been placed at his disposal. 


\section{HELMHOLTZ IN KÖNIGSBERG}

visit to London marks an epoch in one's life ; after such a visit, one learns to judge human actions on a scale hitherto unknown. I have been very unfortunate in meeting scientific men, missing Rankine, Brewster, Joule, Thomson, and Wheatstone, but with Faraday, Stokes, Sabine, Grove, Airy, Bence Jones, Andrews the chemist, Hamilton the mathematician, and many others of lesser importance, I have had better luck. These men seem to be as generous as Swiss tourists are odious!

'Bence Jones is "a man among men," as we say in Berlin. He invited me to his villa at Folkestone, on the sea coast, where I met Du Bois Reymond and his wife. Our friend has become quite an Englishman. I was received there as heartily as if I had been an old friend. I spent three weeks sight-seeing in London, and when I left it for the meeting (of the British Association) in Hull, I had not even seen the half of it. The organisation of the meeting at Hull greatly interested me. There was not much scope for physics, chemistry, and such like sciences, in which a man must work by himself, and the leaders of these sciences kept in the background. For other sciences, however, such as meteorology, ethnology and geology, where there must be co-operation among many observers, the meetings (of sections) were of great importance. There were over 800 members, and, in addition, 250 ladies who came to listen. As a foreigner, I was the guest of Dr Cooper, a physician, 


\section{HERMANN vON HELMHOLTZ}

who entertained me most hospitably. I then spent eight days in Scotland, to feast on nature. Edinburgh is a jewel among cities. The Scotch Highlands have a peculiar majesty, from their proximity to the Atlantic Ocean; but they are, on the whole, barren and monotonous, and not to be compared with the Alps. I saw Fingal's Cave in beautiful weather, then unceasing rain compelled me to return. I travelled home viâ Hull and Hamburg, and arrived with a very empty purse. My health has greatly benefited by the trip, but my teeth troubled me on the journey, and made for a time my physiognomy asymmetrical.'

In after years Helmholtz paid not a few visits to this country, and more especially to his friend of many years, Lord Kelvin. Between these distinguished men, the foremost in their time in physical science, there always existed the warmest friendship. Often differing on scientific questions, each had admiration and respect for the powers and achievements of the other.

To return to the physiological work of Helmholtz during the early fifties, there can be no doubt the researches on the mechanism of accommodation and on sensations of colour were of the first importance. His singular combination of anatomical, physiological, physical, and mathematical knowledge fitted him specially for this work. Up to his day no one had appeared like him in this respect, and it may be questioned if anyone now exists who can be placed on the same platform 


\section{HELMHOLTZ IN KÖNIGSBERG}

with Helmholtz, much as many physiologists, especially in Germany, now cultivate physics and mathematics.

The ophthalmometer, an instrument of too technical a character to be here described, ${ }^{\mathbf{I}}$ enabled Helmholtz to determine many of the optical constants of the eye, more especially as to the radii of curvature of the refractive surfaces, the cornea and lens. He was also able to solve the interesting problem as to the focussing or accommodating mechanism of the eye, by which it adapts itself for distinct vision within a certain range.

In the normal eye parallel rays coming from infinity are brought to a focus on the retina, and a distinct image is formed. When rays are not brought accurately to a focus on the retina, the image is indistinct, by the formation of circles of diffusion around its margin. It is evident that if an object be brought too close to the eye for the refractive media to focus it on the retina, circles of diffusion will be formed, with the result of causing indistinctness of vision, unless the eye has some power of altering its length or the curvature of its refractive surfaces. That the eye has some such power of accommodation is proved by the observation that if we look through the meshes of a net (the net say 3 feet from the eye) at a distant object, we cannot see both the meshes and the object with equal distinctness at the same time. At one moment the meshes will be seen distinctly

${ }^{1}$ Fully described in Appendix D, p. 718, of my Outlines of Physiology. Glasgow, 1878 . 


\section{HERMANN vON HELMHOLTZ}

and at the next the distant object. Again, if we persistently look at objects close to the eye, say within 6 inches, there is a sense of effort and the eye becomes fatigued. The range within which the accommodating mechanism works is, in the normal eye, from 65 metres (about 70 yards), the so-called punctum remotum, to $\frac{1}{5}$ th metre (20 centimetres, say Io inches), the punctum proximum. Beyond 65 metres rays emanating from an object may be practically regarded as parallel, and they will be focussed on the retina without effort; from 65 metres to $\frac{1}{5}$ th metre the accommodating mechanism comes into play so as still to bring the more divergent rays to a focus on the retina, and thus secure distinct vision; and lastly, within a distance of $\frac{1}{5}$ th metre (except in juvenile life) the accommodating mechanism ceases to act, the rays that enter the pupil are now too divergent to be focussed on the retina, and there is blurred vision. If we cut off the more divergent rays by looking at the near object (say 2 inches from the eye) through a hole in a card, then we can see the object distinctly as we now use the central pencils of rays which may be slightly divergent or nearly parallel. The pupil, the diameter of which is lessened by contraction of the iris, serves the same purpose. Consequently, when we look at a near object the pupil contracts. The question arises, how is this wonderful mechanism carried out ?

If we hold a lighted candle in front, and a little to 


\section{HELMHOLTZ IN KÖNIGSBERG}

the side of a living eye, three reflections, or little specks of light, may be seen in the eye. The brightest one, an erect image, is on the anterior surface of the cornea; the next, also erect, but much less distinct, is on the anterior surface of the crystalline lens; and the third, extremely faint and difficult to see, is inverted and comes on the posterior surface of the lens. The one on the anterior surface of the cornea has no doubt been long familiar, the 'light of the eye,' represented by artists in a portrait by the little speck of yellowish white paint. The next, on the anterior surface of the lens, was long ago observed by Sanson, who looked for it in connection with the appearance of cataract ; while the third was first discovered by one of the older physiologists-Purkinje, who detected many things, so that his name appears in every physiological text-book. A Dutch observer, Cramer, made the happy observation that if the eye suddenly transfers its gaze from a distant to a near object, the middle image moves nearer the most anterior image, and at the same time becomes smaller. As this image is a reflection from the anterior surface of the lens, and as an image on a more convex lens is always smaller than one on a less convex surface, it will be evident that when the eye focusses on the retina the more divergent rays that come from a near object, it changes its curvature and becomes more convex. Accommodation, then, consists in an increasing convexity of the lens, beginning when the eye looks 


\section{HERMANN vON HELMHOLTZ}

at an object at a distance of 65 metres and ending when the near point is reached at a distance of $\frac{1}{5}$ th metre.

Before these observations were made, the most diverse views had been advanced by physiologists as to the mechanism of accommodation. Some denied that any change took place in the refractive media, and also that any change was necessary; others, that a change took place in the form of the globe of the eye, the organ becoming compressed by the muscles that move it, so that it became slightly longer for near objects than for those at a great distance; others, that the contraction of the pupil that takes place when we look at a near object is sufficient to explain the mechanism; others, that there was a change in the curvature of the anterior surface of the cornea; others, that the lens was displaced backwards or forwards by the mucular iris; while, finally, the true explanation, verified by the facts already stated, had many supporters from the time of Descartes downwards. The first correct observation was undoubtedly made by Thomas Young. ${ }^{\mathrm{I}}$ His experiment consisted in looking through wire gauze at a luminous point. An image of diffusion is then seen, traversed by straight lines, which are the shadows of the wires of the gauze. These lines are quite straight when we look at a distant object, but they appear to be curved

I Phil. Trans. 1801, vol. i., p. 23, also vol. i. of Toung's Works, edited by Peacock. London, 1855 . 


\section{HELMHOLTZ IN KÖNIGSBERG}

at their extremities if the eye is directed to an object close at hand, a result that can only be explained by supposing that the lens becomes, in the latter case, more convex. This experiment, difficult of execution, excited the admiration of Helmholtz, who always regarded Young as a man before his time, and one of the greatest of English philosophers. Max Langenbeck, ' about 1849 , came near the true explanation, but it was reserved for Cramer to complete the discovery. He observed the image of a flame, reflected from the anterior surface of the lens, by means of a short focus telescope, and noticed the essential fact that the image became smaller when the eye was directed to a near object.

Helmholtz, unacquainted at the time with the work of Langenbeck and Cramer, now took up the question, and, with his usual thoroughness, went to the bottom of it. He arrived at the same conclusions as Cramer, but he went much farther. Here, again, there was no question of priority. When Cramer's work was brought under his notice by the writings of his friend Donders, who rescued Cramer from oblivion, ${ }^{2}$ Helmholtz at once recognised his merits. Donders, in the speech already referred to, said: ' If it be a satisfaction to me to venture to claim the first for my countryman, D. A. Cramer, I must

${ }^{x}$ Klinische Beiträge. Göttingen, 1849 .

${ }_{3}$ Tijdschrift der Maatschappy voor Geneeskunde, 1851, vol. xi., p. 15 ; also Nederlandsch Lancet, 2 i. p. 529, I851-2. 


\section{HERMANN vON HELMHOLTZ}

not omit to state that Helmholtz shortly afterwards arrived independently at the same result. With a noble modesty, for which I thank him, he declared himself convinced, after an examination of the papers sent to him, that the enigma of accommodation, upon which so many enquirers had exhausted their ingenuity, was in reality solved as to the main point, and very little now remained for him to do in the researches he contemplated.' Helmholtz, in the first instance, contrived a little instrument, the phakoscope, by which the images in the eye may be seen even better than in a darkened room. Then he invented an instrument for the purpose of measuring the size of any image reflected from a curved surface. This, one of the most ingenious devices, is known as the ophthalmometer. It depends essentially on the displacement to one side caused by holding a plate of thick glass obliquely in front of any object. The object may thus be displaced through a distance equal to its breadth, and the angular movement may be read off on a graduated disc attached to the axis rotating the glass plate. Helmholtz used two plates, rotating in opposite directions, so that the object was displaced both to the right and left, and the image was viewed by a short focus telescope placed behind the plates. The instrument may be graduated empirically, or it may be used with the aid of a formula by which the size of the object may be readily calculated. An image is first obtained by throwing into the eye reflec98 


\section{HELMHOLTZ IN KÖNIGSBERG}

tions from three little mirrors placed on a rod in the same plane as that of the eye under examination. These little specks of light are thus seen in a straight line, reflected on the anterior surface, say, of the cornea, and the distance between the two most distant specks is the breadth of the image; the third little speck is exactly midway between the other two. The ophthalmometer is then, from a suitable distance, directed towards the eye, and the plates are rotated until the object divides into two, and the displacement is continued until there has been an apparent movement through the breadth of the object. The angular displacement is then noted, and, as already stated, by the use of a formula, the size of the reflected image may be calculated in, say, millimetres, or fractions of a millimetre. Finally, if the size of the real object (the distance between the two mirrors farthest apart on the rod), the distance of the plate from the eye (the vertex of the cornea), and the size of the reflected image (as measured by the ophthalmometer), are given, it is easy to calculate the radius of curvature of the reflecting surface. Helmholtz, by means of this beautiful arrangement, was able to show (I) that the radius of curvature of the cornea for near and distant objects does not change ; $(2)$ that the length of the radius of curvature of the anterior surface of the lens, when the eye looks at an object far away, is Io millimetres, and is only 6 millimetres when the eye looks at a near object, that is to say, 


\section{HERMANN vON HELMHOLTZ}

in the latter case, the anterior surface of the lens becomes more convex; (3) that the posterior surface of the lens also becomes slightly more convex, as for near objects the radius of curvature becomes shorter $(5.5 \mathrm{~mm}$.) than for distant objects $(6 \mathrm{~mm}$.) ; (4) that when we look at a near object, the distance of the vertex of the cornea from the anterior surface of the lens becomes shorter $(3.3 \mathrm{~mm}$.) than for a distant object $(3.7 \mathrm{~mm}$.) ; and that during accommodation the lens becomes thicker, being $3.8 \mathrm{~mm}$. in thickness for a distant object and $4.3 \mathrm{~mm}$. for a near object, or from, approximately, a $\frac{1}{6}$ th to a $\frac{1}{5}$ th of an inch. This amount of change is quite sufficient to bring to a focus on the retina rays of light emanating from an object looked at within the limits of accommodation.

It only remained to explain how the curvature of the lens can thus be changed, and here Helmholtz brought his anatomical knowledge to bear upon the question. Thomas Young, and many of the older observers, thought, erroneously, that the lens was a muscular structure. ${ }^{1} \quad$ C. Weber, about 1850 , electrically excited the eye, and observed the anterior surface of the lens moving towards the cornea. Cramer also electrically irritated the eye, and concluded that a change of form was produced by contractions of muscular structures in the eye itself, and he attributed

'Disquisitiones quae ad facultatem oculum accommodandi spectant. Marburg, 1850, p. 31 . 


\section{HELMHOLTZ IN KÖNIGSBERG}

the movements chiefly to the iris. This muscular structure contains both circular and radiating fibres. As a matter of fact, distinct radiating fibres cannot be seen in microscopical preparations. Suppose both circular and radiating fibres contracted simultaneously, then, according to Cramer, the circular fibres offered resistance to the contraction of the radiating fibres, and thus the parts of the lens behind them, that is near the margins, were compressed, while the central part of the lens, meeting with no resistance behind the pupil, was pressed forward. Donders next attached importance to the fringe of elastic tissue on the inner wall of the canal of Schlemm, from which both the fibres of the iris and of the ciliary muscle appear to originate. The latter muscle is a fringe of muscular tissue, the fibres of which radiate backwards, and are attached to the ciliary processes of the choroid or vasculo-pigmentary coat of the eye. It lies near the zonule of Zinn, and was at one time termed corpus ciliare, the ciliary body. Brücke described it in the following words: "The muscle is very easy to find, as it is nothing else than the light grey ring which one finds on the outer surface of the anterior part of the choroid after separation of the sclerotic, and which has up till now played so unhappy a part in anatomy under the names of ligamentum ciliare, orbicularis ciliaris, circulus ciliaris, ganglion ciliare, etc.' It may now be well named the tensor choroidei, or, as Donders suggests, the musculus 


\section{HERMANN vON HELMHOLTZ}

Brückianus, in honour of its discoverer. Helmholtz took up the matter at this point, and made the happy suggestion, which is now universally accepted as the true explanation, that in accommodation the fibres of the ciliary muscle contract and tend to draw the ciliary processes of the choroid forward. Passing in close proximity to these processes, and connected with them, is a thin transparent membrane, the hyaloid membrane, which lines the posterior chamber of the eye. Anteriorly this membrane divides into two layers, one passing before and the other behind the lens, forming what is termed its capsule. The lens is thus bound down, as it were, by its capsule, more especially by the portion of it passing over its anterior surface. When, then, the ciliary processes are pulled forward by the ciliary muscle, the tension of the layer of the capsule in front of the lens is diminished, and the anterior surface of the lens bulges forward by its elasticity. There are certain circular fibres of the ciliary muscle that also assist in this beautiful mechanism. When the eye is again directed to a distant object, the fibres of the ciliary muscle relax, and the lens is flattened by the pressure of the capsule.

Finally, and to complete the demonstration, Helmholtz showed, that to accomplish accommodation, no other change in the eye is necessary, and he described an imaginary or schematic eye, slightly differing from the eye of Listing, and for this eye he calculated the 


\section{HELMHOLTZ IN KÖNIGSBERG}

optical constants as they exist for near and distant vision in accommodation. $\mathrm{He}$ then found that the positions of these constants, such as the position of the anterior focus, the positions of the nodal and principal points, and the posterior focus, varied for near and far vision as they would do if the only changes occurring during the mechanism were in the curvatures of the anterior and posterior surfaces of the lens, as ascertained by experiment and measurement by the ophthalmometer. So the question was finally settled. The discovery of the part played by the lens in accommodation is one of the greatest triumphs in modern physiology. Lucid mathematical and experimental proofs have been given of its correctness, and all other theories have been entirely abandoned. 


\section{CHAPTER IX}

HELMHOLTZ IN KÖNIGSBERG-ANIMAL ELECTRICITY

T $\mathrm{N}$ after life Helmholtz made important mathe1 matical and physical contributions to the theory of electrical actions, and it is interesting to observe, while the fact is in keeping with the plan of his whole career, that he was led into this path from the side of physiology. Before he left Berlin, and while he was in Königsberg, his friend Du Bois Reymond was carrying on those researches into animal electricity that have made him famous. Helmholtz witnessed and took part in many of his experiments, favoured him with criticisms, and solved theoretical problems that arose in the course of the enquiry, more especially as to the distribution of electricity on conductors of various forms. By using a delicate, high-resistance galvanometer, and by the use of non-polarizable electrodes, a new impulse was given to the experimental investigation of animal electricity. If from living muscle, for example, currents could be led off into the galvanometer, as had been done by Nobili about 1827 and by Matteucci ten years later, it was manifestly 


\section{HELMHOLTZ IN KÖNIGSBERG}

of great importance that no contact or galvanic electricity should be generated by bringing the electrodes against the living tissue. The desideratum was what is now called a system of non-polarizable electrodes. Helmholtz tried unsuccessfully to make such electrodes of pure silver immersed in a solution of a salt of silver. Later it was found that pure zinc amalgamated on the surface, and immersed in a saturated solution of sulphate of zinc practically fulfilled the conditions, a result that could not have been theoretically anticipated, and was discovered by a lucky hit. With pads of blotting paper immersed in zinc troughs containing the solution of sulphate of zinc, and with pads of sculptor's clay moistened with saliva laid on the paper pads to protect the muscle from the irritant action of the sulphate of zinc, perfect non-polarizable electrodes were obtained.

It was then demonstrated that if a living muscle, say the gastrocnemius of a frog, is cut in transverse section, and if one clay point is applied to the middle of the longitudinal surface and the other to the middle of the transverse section, a current will flow through the galvanometer in such a direction as to indicate that the surface is positive to the transverse section. To explain these phenomena, Du Bois Reymond advanced a physical theory which may thus be shortly described. If we take a cylinder of zinc, having a bit of copper soldered on each side, and plunge it into dilute sulphuric acid, or even water, 


\section{HERMANN VON HELMHOLTZ}

there are formed an infinite number of currents, which travel through the water from the zinc to the copper, and a portion of these may be conveyed by conductors applied to the zinc and to the copper. If, then, a galvanometer be interposed in the circuit, it will be found that the zinc, forming the centre of the cylinder, is positive, and that the copper, forming the sides, is negative, a result comparable to that obtained from a muscle. Du Bois Reymond therefore suggested that each muscular fibre is composed of an infinite number of small electro-motive elements, analogous to the cylinder composed of zinc and copper above described. Each little element would have a positive equatorial zone and two negative polar zones, and we may conceive it to be plunged into an intermediate conducting material. He did not mean that these electromotive molecules, or 'carriers of electromotive force,' existed in any histological sense ; they were to be regarded as nothing more than 'the foci of chemical change,' and they were analogous to the molecules entering into the conception of the physicist when he discusses electrolysis.

$\mathrm{Du}$ Bois Reymond, in his earlier experiments, thought he obtained a current from an uninjured muscle, that is, from one whose longitudinal and transverse sections were natural and not artificially produced. Later, however, he discovered that if special precautions had been taken not in the slightest degree to injure the muscle, no current was obtained 


\section{HELMHOLTZ IN KÖNIGSBERG}

in the resting state, though on the production of tetanus, caused by irritating the nerve supplying the muscle, a negative variation, or current in the opposite direction, was observed. If a current were obtained when the muscle was at rest, it was in greatly diminished amount, and might even be in a contrary direction. This was explained by supposing that in the uninjured muscle, the tendonous end, which is the natural transverse section, contains a layer of electromotive molecules, with their poles reversed, so that their positive surface is towards the transverse section. This layer $\mathrm{Du}$ Bois Reymond termed the parelectrotonic layer, and when one removes it by making an artificial cross section, the full muscle current is obtained.

The laws of the dispersion of currents in irregularly shaped conductors had been only partially determined for conductors of two dimensions by Kirchhoff, and for three by Smaasen, but the results were not sufficient for the complicated conditions of a muscle. It was also difficult to show, on the electromotive molecule theory, why weak currents could be obtained from a point say in the centre of the transverse section and any other point in the transverse section near the periphery, and also between a point in the equatorial region of the muscle, on its surface, and any point nearer each end. These results could not be explained by the copper-zinc model. Helmholtz stepped in here, and, by his analytical power, developed the theory of 


\section{HERMANN vON HELMHOLTZ}

current distribution in non-prismatic conductors. He showed that, on the assumption of peripolar molecules in the muscle substance, no weak currents could occur on the surface or in transverse sections, and that the difference of potential between the surface and the transverse section would not increase with the size of the muscle. He also showed that the differences between the results of the actual experiment and what was to be expected from $\mathrm{Du}$ Bois Reymond's assumption might simply be due to the weakening of the electromotive forces by contact with air, with fluids such as are used in the experiment, and by dying of the muscle substance. Further, he argued that the electromotive forces in the muscle, and certainly in the model, are modified by polarization. Subsequent experiments by $\mathrm{Du}$ Bois Reymond himself, and especially by Hermann, support this view.

In the address given by Donders, when he presented Helmholtz with the von Graefe medal, he said that the latter had denied the pre-existence of electromotive forces in muscle. This observation evidently caused some annoyance to Du Bois Reymond, as, in his éloge on Helmholtz, he repudiates the statement. No doubt, in one of his writings, Helmholtz indicated that in the uninjured muscle no current could be demonstrated between the surface and the natural cross section (tendon), but he explained to $\mathrm{Du}$ Bois Reymond that this was a mistake, and that the uninjured natural cross section was either weakly negative 108 


\section{HELMHOLTZ IN KÖNIGSBERG}

or neutral, and sometimes even weakly positive to the longitudinal surface. Du Bois Reymond further states:- 'But so little did Helmholtz intend to deny the pre-existence of electrical forces in muscle, that, on the contrary, in the paper we are here considering, he allows my hypothesis of the peripolar electromotive molecules full play as the cause of the muscle current, and declares, in so many words, "it stands to reason that the electric forces of the current-surrounded molecules must be taken into account in any theory of their movement." ' Further, Helmholtz suggested a theory to Du Bois Reymond in which the electromotive effects were harmonised with the phenomena of muscular contracility, but this does not appear to have been published.

These views of Du Bois Reymond, which had at all events the qualified support of Helmholtz, found an opponent in Ludwig Hermann, then professor in Zurich, and now in the chair in Königsberg, once occupied by Helmholtz. He demonstrated that in the absolutely uninjured frog's muscle there is no current, and showed conclusively, that the current of the resting muscle, when it is cut in transverse section, as directed by Du Bois Reymond, causes the death of a thin layer of the muscle, and so produces difference of potential. This difference theory refers all electromotive effects of muscle to two kinds of physiological change. The first part of the theory is, that the dying portion of the substance behaves itself negatively to 


\section{HERMANN VON HELMHOLTZ}

the living, and the electromotive force has its seat in the demarcation zone between the living and the dying. To this he adds a rider, that not only death, but irritation as well, causes the affected substance to become negative to the unaffected portion. He further shows that the really important electrical phenomenon is the negative variation, that is the current flowing in the reverse direction when the muscle is caused to contract, now called the action current. Still it must be observed that Hermann's statement is no final explanation. It does not explain why the dying muscle becomes negative to the living, and it is possible that again we may be obliged to have recourse to some such hypothesis as that of Du Bois Reymond.

Helmholtz, when he was showing electrical experiments of this nature to his audience of students at Königsberg, hit upon the device (not original, however) of attaching a bit of silvered glass to the astatic needle of his galvanometer, and by this means he reflected a beam of light on a screen, thus making it possible to see at a distance the smallest movement of the needle. This method was independently employed for the galvanometer and electrometer by Thomson (now Lord Kelvin), and it has adaptations well known in every laboratory. It was about this time also that he perfected the arrangements for equalising the opening and closing shocks of the induction coil described in chapter iv., p. 36. 


\section{HELMHOLTZ IN KÖNIGSBERG}

His physiological work also led Helmholtz to investigate the phenomena of induction currents, more especially as to their duration. He also studied the physiological effects, observed by Brücke, of electric shocks of extremely short duration in large conductors applied to the human body. These researches led to the invention of the well-known pendulum myograph.

$\mathrm{Du}$ Bois Reymond mentions as an amusing example of Helmholtz's untiring energy that, as a recreation between periods of intense mental activity, he was in the habit of watching through a telescope the good people of Königsberg as they walked along the streets near his laboratory. Weber had studied human locomotion, describing and drawing the movements of the limbs. Helmholtz found that Weber had made several mistakes, more especially as to the way of putting down the foot, and his observations were verified long afterwards by instantaneous photography and by other methods devised by Marey, ${ }^{\mathbf{I}}$ Professor of Physiology at the College of France.

${ }^{x}$ E. J. Marey, Animal Mechanism, Book II., chap. iii. London, 1874 . 


\section{CHAPTER X}

HELMHOLTZ IN KÖNIGSBERG-STUDIES IN COLOUR

FOM 1852 to 1856 , when he removed to
Bonn, Helmholtz was much occupied with the phenomena of colour. Thus, in 1852 , there appeared the paper on Sensation already alluded to; two papers, the first mainly critical, and the second more constructive, on Sir David Brewster's Analysis of Sunlight, and a fundamental paper on the Theory of Colour; and in 1855 we have three papers, all dealing with colour sensation. As often happens, the minds of men of science in different parts of the world may be occupied with the same question about the same period of time. The rifts in the clouds through which shafts of sunlight pass down to the earth may be observed only by the few, but here and there, in the crowd, the eyes of keen observers are attracted by their beauty. Just about this time the phenomena of colour were almost simultaneously before the minds of Sir David Brewster, James Clerk Maxwell, and Helmholtz. Brewster was first in the field, his paper appearing in The Transactions of the Royal Society of Edinburgh in 1822. The first pub- 


\section{HELMHOLTZ IN KÖNIGSBERG}

lished paper of Maxwell was a letter to Dr George Wilson, to be found in the Transactions of the Royal Society of Arts for 1855 , but he had before this date been experimenting with his well-known colour top, and the results of his experiments are recorded in the Transactions of the Royal Society of Edinburgh, vol. xxi., p. 185. As already mentioned, in 1852, Helmholtz published his first paper.

To appreciate the work of these distinguished men, and more especially the part taken by Helmholtz in placing the theory of colour on a sound basis, let us go back for a little to fundamental ideas regarding light, gradually accumulated before they appeared on the scene. It was once held that a luminous body shoots out from itself minute particles, which, passing to the observer's eye, give rise upon impact to the sensation of light. This corpuscular theory, while it satisfactorily explained many of the facts, failed in an explanation of others, and it has now been entirely disproved. Its place is taken by the undulatory theory, first suggested by Huygens in 1690 , reconciled to some extent with the discoveries of Newton by Euler, advocated by Hartley, and finally established by a study of the phenomena of interference by Thomas Young and by Fresnel. This theory gives a complete explanation of all the phenomena of light. According to this view, light, objectively considered, is simply a mode of motion of a substance called the luminiferous ether which pervades 


\section{HERMANN vON HELMHOLTZ}

not only what is commonly regarded as space, but also all translucent substances. By the molecular movements of luminous bodies, this ether is set vibrating in a series of waves. The ether vibrations that constitute these waves may be conceived to be at right angles to the direction of the ray of light, just as the surface of calm water, which has been agitated by a stone, rises and falls as the waves spread outwards. Thus a cork floating on the water, traversed by a wave, oscillates up and down nearly at right angles to the direction of the wave. These wave-like movements of the ether impinging on the retina set up in it changes which result, after their effect has been transmitted to the brain, in the sensation of light, but the sensation in no way resembles its physical cause, although it varies with variation of the stimulus. ${ }^{\mathrm{I}}$ The intensity of the sensation varies with the amplitude of the wave. Large waves give rise to a sensation of bright light, small waves to a sensation of dim light. Again, the sensation of colour depends on the rapidity with which the waves follow one another, or, in other words, on the length of the wave. This rapidity, though inconceivably great, may still be accurately determined. Ordinary sunlight, as Newton showed, is composed of a series of colours (using the word in an objective sense) blended together, but yet separable from one another, because each colour is due

I Physiology of the Senses. By M'Kendrick and Snodgrass. London, 1893 , p. 115 . 


\section{HELMHOLTZ IN KÖNIGSBERG}

to a series of waves differing in rate of succession from the others. Thus the waves that give rise to a sensation of red light follow each other at the rate of about 435 millions of millions per second, while those of violet light succeed each other at about 764 millions of millions per second. Between these we have an infinite number of series of waves, each giving rise to a special colour sensation, and so between the red and the violet of the spectrum we have a gradation of colour roughly described as orange, green, blue and indigo, but each of these is itself made up of countless shades, which melt as gradually and imperceptibly into one another as the colours of a sunset sky. The retina is not sensitive to vibrations of the ether succeeding each other more slowly than those of red light, although it may be demonstrated that these exist and originate electrical and thermal phenomena; nor to those which come more quickly, although the latter have marked chemical activity, and give rise to fluorescence.

Solar or white light is, then, a compound of all the colours in definite proportion. A body which reflects solar light to the eye without changing this proportion appears to be white; but if it absorbs all the light, so as to reflect no light to the eye, it appears to be black. If a body held between the eye and the sun transmits light unchanged and is transparent, it is colourless; but if translucent, it is white. If it transmits or reflects some rays and absorbs others, it 


\section{HERMANN vON HELMHOLTZ}

is coloured. If, for example, it absorbs all the rays of the solar spectrum but those which give rise to the sensation of greenness, we say that the body is green in colour. But this greenness can only be perceived if the rays of light falling on the body contain rays which have the special vibratory rate that is required for this special colour. For, if we use as our light any other pure-coloured ray of the spectrum, say the red, its rays being absorbed, the body appears to us to be black. A white surface seen in a red light seems to be red, in a green light green, as it reflects all colours alike, absorbing none. To the normal eye the colour physically depends, then, on the nature of the surface of the body, as was first shown by Robert Boyle, and of the light falling upon it, and the sensation of colour only arises when the body reflects or transmits the special rays to the eye. If two rays of different wave-lengths affect one part of the retina at the same time, they are fused together, and we have the sensation of a third colour different from its cause. Thus, if red be removed from the solar spectrum, all the others combined will give a sensation of a greenish yellow, although we cannot, with the unaided eye, analyse this into its components. Certain colour sensations, such as red or green, are simple in the sense that they cannot be originated by any combinations of other colours; while other colours, such as purple, can be produced by certain definite mixtures, and they are therefore called compound. 


\section{HELMHOLTZ IN KÖNIGSBERG}

Newton laid the foundation of the theory of compound colours. He showed that two beams that differ optically, that is as regards the periods and amplitudes of their ether vibrations, may be alike chromatically, that is to say, they may give rise to the same kind of colour sensation. Thus, by mixing red and yellow, an orange colour may be produced like that of the spectrum, but differing from it in that the former may still be analysed by a prism into red and yellow, whereas the orange of the spectrum cannot be so resolved. By his well-known diagram of colour, Newton also showed that in any mixture of colours, the quantity and quality of each being given, it was possible to determine the colour of the compound. While the result of mixture of colours in the production of compounds can thus, by a geometrical method, be represented with approximate correctness, their true relations, as was shown by Clerk Maxwell, ${ }^{\mathbf{x}}$ can only be determined by direct experiment.

With his usual experimental dexterity and philosophical acumen, Thomas Young was led to a great generalisation on the subject of colours, in which it is asserted that the three simple colour sensations are red, green and violet, and while these cannot be produced except by the impact of light of a certain wave-length on the retina, and are therefore simple, any other colour may be matched by a mixture of

I An interesting account of Clerk Maxwell's work on the subject is given by Glazebrook in his Life of Maxwell. London, 1896, p. 93. 


\section{HERMANN vON HELMHOLTZ}

these three primaries. The quality of the compound colour so produced depends on the proportion of the intensities of the components, and its brightness depends on the sum of these intensities. There is no proof that these effects depend entirely on changes occurring in the retina; the probability is, as was indeed suggested by Young himself, that they are connected with phenomena occurring in the brain.

Sir David Brewster ${ }^{\text {I }}$ developed a new theory of colour sensation, in which the three primitive colours were red, yellow and blue, ${ }^{2}$ and it was assumed that they corresponded to three kinds of objective light. Each of these varieties gave throughout the spectrum rays of all degrees of refrangibility, but the red predominated at the lower end, blue at the upper end, while yellow ruled the middle. Coloured media absorbed in different proportions rays of the same refrangibility, but of different colours. This theory was combated by Airy, Draper and Melloni, and it has now been entirely abandoned. It was founded mainly on the colours apparently assumed by light in passing through various transparent and colourless media; phenomena, however, that can be explained by dispersion or diffusion even in clear prisms and in the media of the eye. Brewster's investigations undoubtedly led to renewed research, and it was at this point

I Trans. of Royal Soc. of Edinburgh, ix., p. 433 ; xii., p. 123. Pogg. Annalen, xxiii., p. 435 .

${ }^{2}$ Leonardo da Vinci, Trattato della pittura, Paris, 1651, named four simple colours, yellow, green, blue and red. 


\section{HELMHOLTZ IN KÖNIGSBERG}

Helmholtz took up the subject. We have it on his own authority, that his attention was directed to it by a consideration of Müller's doctrine of the specific energy of nerves, mentioned at p. 13. In his speech on receiving the Graefe medal, he said, 'Not being inclined to describe in my lectures things I had not myself seen, I made experiments in which I blended the colours of the spectrum in pairs. To my astonishment, I found that yellow and blue gave not green, as was then supposed, but white. Yellow and blue pigments, when mixed, no doubt gave green, and until then the mixing of pigments was supposed to produce the same effect as the mixing of the colours of the spectrum. This observation not only at once produced an important change in all the ordinarily accepted notions of colour mixture, but it also had an even more important effect on my views. Two master minds of the first rank, Goethe and David Brewster, were of opinion that yellow and blue could be directly seen in green. Their observations were made with pigments, and they thought they could divide their perception of the resulting colour into two parts, yellow and blue, while in reality, as I was able to show, neither were present. I was thus drawn over to the empirical theory of perception, and it indicates even now the contrast between my position in the theory of colour perception and that of Hering and his followers, who hold firmly to the opinion, that one can decompose the perception into its component parts.' 


\section{HERMANN vON HELMHOLTZ}

The true explanation of why yellow and blue pigments yield green may thus be shortly stated, and almost in the words of Helmholtz: ${ }^{\mathrm{r}}$-When light falls on a powder composed of transparent particles, only a small portion is reflected from the surface; the rest penetrates the particles, and is only returned by the surfaces of separation of particles situated more deeply. Thus a single plate of clear glass reflects $\frac{1}{25}$ th of the light which strikes its surface, two plates will reflect $\frac{1}{13}$ th, and many plates will reflect nearly the whole of it. If the glass reflects only $\frac{1}{2} \frac{1}{5}$ th of the incident light, the rest must be reflected by the deeper layer. In the same way the surface of coloured powders furnishes only a small part of the light which emerges from them; the deeper parts give back a greater proportion. Light reflected from the surface is always white; that alone which is returned by the deeper layers is coloured by absorption, and the tint will be deeper as the light penetrates more deeply. Consequently coloured powders are more deeply coloured if the grains are of considerable size than if they are very minute. Reflection depends on the number of surfaces, and not on the thickness of the particles. Consequently, if the particles are large, the light must go through a greater thickness to reach the same number of reflecting surfaces than if the particles are small, and thus, if the particles in a thick powder are large, the rays absorbable by the substance will be

Optique Physiologique. Paris, 1867, p. $3_{36}$. 


\section{HELMHOLTZ IN KÖNIGSBERG}

taken up to a greater extent, and the coloured light coming back from the powder will be deeper and more saturated than if the particles were small. Suppose, now, that yellow chrome is mixed with indigo blue. The light reflected from the particles of chrome will be orange, yellow and green, the blue and violet being absorbed, and that from the indigo blue will be green, blue and violet, the orange and yellow being absorbed. If, now, the light that has passed through a particle of chrome traverses a particle of indigo blue, all the colours will be absorbed except the green. Consequently the green alone will reach the eye.

On the other hand, if the pure spectral colours, yellow and blue, pass into the eye so as to affect the same spot on the retina, the result is a sensation of white, because, in this case, both the yellow and the blue wave-lengths fall on the terminal organ. This ingenious explanation has many important applications, not only as regards the colours reflected from mixtures of powders, but also the mode of action of all coloured surfaces both in the inorganic world and on the surfaces of plants and animals. It shows how the texture of the surface modifies the result.

Helmholtz then devised an ingenious method by which two spectra could be simultaneously examined, through a slit shaped like the letter $\mathbf{V}$, in such a way that a portion of one spectrum was superposed on the other. In this way all possible mixtures of two simple colours could be made with the intensities of 


\section{HERMANN vON HELMHOLTZ}

the colours in the two spectra, and the mixed rays, passing through a lens, were directed on the same spot of the observer's retina. This method differs from that of using a rotating disc, sectors of which could be coloured at pleasure, a method used by Thomas Young, but worked out with great exactitude by Clerk Maxwell, in the form of his well-known colour top. The arrangement of the rotating disc is such that a little area of retina is struck in rapid succession with reflected rays of different wavelengths, say now the long waves of red, then the short of violet, with the result that the sensation is that of purple.

By mixing the pure colours of the spectrum, Helmholtz showed that red and violet gave purple; red and blue, rose; red and green, dull yellow; red and yellow, orange; yellow and violet, rose; yellow and and blue, white; yellow and green, yellow-green; green and violet, pale blue; green and blue, bluegreen; and blue and violet, indigo; but he was unable by any combination to produce red, green and violet. Further, he formulated several important principles with regard to sensations of colour. Thus the quality of every luminous sensation depends on three variables-luminous intensity, tone, and degree of saturation. A sensation of colour produced by a certain quantity, $x$, of coloured rays mixed in any way whatever may be always reproduced by a certain amount, $a$, of white light with a certain quantity, $b$, 


\section{HELMHOLTZ IN KÖNIGSBERG}

of a saturated spectral colour (or purple) of a determinate tone. From the physical point of view, mixed light is compounded of various waves of different wavelengths ; but the sensation caused by the mixture falling on the retina may be always considered as a function of three variable quantities-(I) the quantity of saturated coloured light ; (2) the quantity of white light which may be added to produce the same sensation of colour ; and (3) the length of the wave of coloured light. He also investigated mathematically the construction of a geometrical table of colours. Finally, he revived and extended the hypothesis of Thomas Young, ${ }^{\mathrm{I}}$ which attempted to explain and account for the phenomena of colour.

How comes it that we perceive differences in colour? We may look for the cause in various directions. We might suppose a molecular vibration to be set up in the nerve-endings synchronous with the undulations of the luminiferous ether, without any change in the chemical constitution of the sensory surface; and we might suppose that where various series of waves corresponding to different colours act together, these are fused together, or interfere with each other in such a way as to give a vibration of modified form or rate corresponding somehow to the sensation arising in consciousness. Or, again, we might suppose that the effect of different-coloured rays is to promote or retard chemical changes in the

1 Lectures on Natural Philosophy, 1807. 


\section{HERMANN vON HELMHOLTZ}

sensory surface, which again so affect the sensory nerves as to give rise to differing states in the nerves and nerve centres with differing concomitant sensations. The first line of thought is at the basis of the hypothesis of Thomas Young. He supposed that there are three fundamental colour sensations-red, green and violet-by the combination of which all other colours may be formed, and that there are in the retina three kinds of nerve elements, each of which is specially responsive to the stimulus of colour of one wave-length, and much less so to the others. If a pure red colour alone act on the retina, only the corresponding nerve element for red sensation would be excited, and so with green and violet. But suppose the colour to be mixed, then the nerve elements will be set in action in proportion to the amount of constituent excitant rays in the colour. Thus, if all the nerve elements be set in action, we shall have white light; if that corresponding to the red and green, the resultant sensation will be orange or yellow ; if mainly the green and violet, the sensation will be blue or indigo, and the like. Helmholtz succinctly puts it as follows :-

(I.) Red excites strongly the fibres sensitive to red, and feebly the other two-sensation, red.

(2.) Yellow excites moderately the fibres sensitive to red and green, feebly the violet-sensation, yellow. 


\section{HELMHOLTZ IN KÖNIGSBERG}

(3.) Green excites strongly the green, feebly the other two-sensation, green.

(4.) Blue excites moderately the fibres sensitive to green and violet, and feebly the red-sensation, blue.

(5.) Violet excites strongly the fibres sensitive to violet, and feebly the other two-sensation, violet.

(6.) When the excitation is nearly equal for the three kinds of fibres, then the sensation is white.

Another mode of expressing the theory is to say that each primary sensation of red, green and violet is excited in some degree by almost every ray of the spectrum, but the maxima of excitation occur at different places, while the strength of stimulation in each case diminishes in both directions from the maximum point. Thus when the three sensations are equally excited, white light is the result; green is caused by a very weak violet stimulation, a stronger red, and a still stronger green stimulation. At each end of the spectrum we have only the simple sensations of red and violet, and all the intermediate colour sensations are compounds of varying proportions of the three primaries.

According to this theory, red blindness is attributable to the absence of the red sensation, and green blindness to the absence of the green sensation. When the green and violet sensations are equal in 


\section{HERMANN voN HELMHOLTZ}

amount, a red-blind person sees what is to him white, and when the red and violet are equal, a green-blind person will have a sensation of what in turn is to him white, although, to the normal eye, these parts are bluish-green in the one case and green in the other, as the green sensation is in each added to the sensations of red and blue.

The subject is fully discussed in Helmholtz's great work, Handbuch der physiologischen Optik, the first part of which appeared in 1856 and the last in 1867 . The first part of a new edition appeared in 1885 , and the last in the year of the death of Helmholtz, 1894. In the new edition he returns to the subject of colour vision, and materially modifies the views in his earlier writings as to what is now universally known as the Young-Helmholtz theory of colour sensation. It is fitting that the two great names should be linked together. Helmholtz finally held that luminosity or brightness plays a more important part in our perceptions of colour than has been supposed. He also, by analysing the colours of the spectrum with great care, aided by his pupils, and more especially by Arthur König, was able from these data to determine three fundamental colour sensations, the first red $(a)$, which is a highly-saturated carmine-red; the second green $(b)$, like the green of vegetation; and the third blue (c), like ultra-marine. Each spectral colour he supposed to be made up of certain proportions of these fundamental colours, or of a combination of two of 


\section{HELMHOLTZ IN KÖNIGSBERG}

them added to a certain amount of white. Thus 100 parts of green are composed of I 5 of $a, 51$ of $b$, and 34 of $c$; or, to take other examples, spectral red contains, in 100 parts, 42 of $a, 1$ of $b$, and 57 of white; yellow-I I of $a, \mathrm{I} 4$ of $b$, and 75 of white; and blue -2 of $a$, I I of $c$, and 87 of white. The white gives the element of brightness. According to this view, it is not necessary to suppose that in the redblind the red-perceiving elements are awanting, or that in the green-blind the green-perceiving elements are absent, but that these elements may be stimulated with intensities different from those affecting the normal eye. ${ }^{\mathrm{I}}$

It is foreign to the purpose of this book to criticise the theory, or to contrast it with the rival theory of Hering, which assumes molecular processes in the retina of a katabolic (pulling down or disintegrative) and an anabolic (building up or reconstructive) kind. Suffice it to say, that while there are a few special cases not yet completely explained by the YoungHelmholtz theory, on the whole it accounts for the general facts in a satisfactory and convincing manner.

The investigation is eminently characteristic of Helmholtz. He examined the facts with the minutest care, and with the aid of arrangements and apparatus of the most ingenious and perfect kind, and then he endeavoured to refer all the facts to a general

${ }^{1} \mathrm{M}$ 'Kendrick and Snodgrass, op. cit., p. 169. 


\section{HERMANN voN HELMHOLTZ}

principle. As remarked by Sir John Herschel, 'x 'we must never forget that it is principles, not phenomena - laws, not insulated independent facts-which are the objects of inquiry to the natural philosopher. As truth is simple, and consistent with itself, a principle may be as completely and as plainly elucidated by the most familiar and simple fact, as by the most imposing and uncommon phenomenon. The colours which glitter on a soap-bubble are the immediate consequences of a principle the most important from the variety of phenomena it explains, and the most beautiful, from its simplicity and compenduous neatness, in the whole science of optics.'

I Discourse on the Study of Natural Philosophy. London, 1830, p. $x_{3}$. 


\section{CHA P TER XI}

\section{HELMHOLTZ IN BONN AND HEIDELBERG- SENSATIONS OF TONE}

ELMHOLT'Z was appointed to be Professor 1 of Physiology at Bonn in 1856, when he was thirty-five years of age, and near the zenith of his powers. Here he remained till 1859 , when he was invited to the chair in Heidelberg, a position he filled till $187 \mathrm{I}$. The three years at Bonn were characterised by the same intellectual activity. Having in Königsberg laid the foundation of his great work on physiological optics, he next proceeded to the examination of the sense of hearing, and here he conquered a new world, and made it peculiarly his own. Again, the guiding principle was Johannes Müller's doctrine of specific energy, and again he proceeded step by step to survey the whole region of inquiry-on this occasion it was acoustics-from the point of view of the physiologist, but fully equipped, not only with anatomical knowledge, but with all the methods and modes of reasoning of the mathematician and physicist. 


\section{HERMANN vON HELMHOLTZ}

There can be no doubt that one of the secrets of the marvellous activity in research of Helmholtz was, that there was the most intimate connection between his function of a professor, whose duty it was to teach, and that of an original investigator. Teaching and investigation went hand in hand. $\mathrm{He}$ investigated because he wished to speak of matters at first hand, and thus he did not merely recapitulate the views of others. Again and again he took up a problem, so that he might master it himself, and be enabled to make it clear to his pupils. Thus there was not only freshness in his teaching, as he was continually breaking new ground, but he was year by year adding to scientific knowledge. It is, of course, in the highest degree unlikely that the impetuous and masterful intellect of Helmholtz would have acted otherwise under almost any circumstances; but, at the same time, the circumstances in which he was placed favoured its development. He was obliged, year after year, to take a general survey of his science; he was always associated with the young, and there is nothing more inspiring for a teacher than to have to satisfy young and ardent minds. Even if these are only the minority of a class, their presence is a subtle inspiration, stimulating to new effort. The example of Helmholtz, therefore, is a strong argument in favour of combining teaching with working; and the results, not only in his case, but in many others, show that, in the advancement 


\section{HELMHOLTZ IN BONN}

of science, it may not be the wisest course to endow research alone and to relegate the researcher to a kind of monastic solitude. It will, on the whole, be better for him and better for science to prosecute research, because he must communicate to others the fruits of his own labours.

The first paper on Physiological Acoustics appeared in 1854 , and consisted mainly of a review of the work done by others up to 1849 . The ground having in this way been cleared, three papers appeared on Combination Tones in 1856 , one upon Vowel Tones in 1857 , a lecture on the Physical Basis of Harmony and Dissonance in 1858, another on Vowel Tones, and two on the Theory of Open Organ Pipes in 1859, a paper on Musical Temperature, another on the Motions of the Strings of a Violin, and a lecture on Timbre (Klangfarbe) in 1860, a paper on Reed or Tongued Organ Pipes in 186I, a short paper in 1862 on the Arabic and Persian Scales, and at last, in 1863, there appeared the great work, Die Lehre von den Tonempfindungen als physiologische Grundlage für die Theorie der Musik, or Sensations of Tone as the Physiological Basis of Music. A well-known monograph on the mechanics of the bones of the middle ear and of the drumhead (membrana tympani), involving an elaborate anatomical investigation of these organs, did not appear till 1869.

It is difficult to give the reader an adequate notion either of the work on physiological optics or of that on 


\section{HERMANN VON HELMHOLTZ}

physiological acoustics. They must be read, referred to, consulted over and over again, before one can appreciate the wealth of material to be found in these volumes. They are not merely historical accounts of all that has been done up to the date of their appearance in that particular department of science, but, at the same time, the bibliography is of the most complete description, showing the unwearied literary activity of the author. A notice is given, often critical, of the works of writers from the earliest down to the most recent times. In these notices there is a generous estimate of the labours of those who have gone before. There is an absence of polemical writing; if the author does not agree with the results obtained in a particular research, this is frankly stated, and the experimental error, or the illogical result, is pointed out and calmly brushed aside. But great as are the merits of these books, even from this point of view, their charm is their freshness. The reader feels that the author has gone over every bit of the ground himself, and there is scarcely a page that is not enlivened by the results of personal research. Everywhere one feels the grasp of a master, whether in the exposition of the subject in hand or in its mathematical treatment; and it is characteristic of Helmholtz that, with a kind of literary modesty, a profound mathematical discussion of a difficult question is often relegated to an appendix at the end of the chapter, whilst it really may con- 


\section{HELMHOLTZ IN BONN}

tain not only the gist of the matter, but be full of suggestions for coming observers.

We shall now endeavour to give a short account of the contributions of Helmholtz to the theory of hearing, and in doing so it will be more convenient and intelligible if we make the attempt, not in the chronological order of Helmholtz's papers, but in connection with the physiological mechanism of the ear itself. Sound waves are collected by the external ear and transmitted by the external canal or meatus to the drumhead. The drumhead is subjected to periodic pressures corresponding to the individual waves of sound, and thus it moves inwards with each pressure and outwards by its elasticity. These movements of the drumhead are transmitted across the middle ear or tympanum to the internal ear by a chain of bones, the malleus, incus and stapes. Lastly, the internal ear consists of a very complicated arrangement of sacs, in which lie the nerve endings immersed in fluid, and the nerve endings receive, in their turn, the pressures communicated by the chain of bones, ending in the base of the stapes, which fits into the oval window. How these nerve endings are so affected by these pressures as to stimulate the fibres of the auditory nerve is the ultimate problem of hearing. How do we become conscious of pitch, of loudness or intensity, and especially of the timbre, quality or klangfarbe of a tone, so that we at once recognise the instrument producing it, whether it be 


\section{HERMANN vON HELMHOLTZ}

a trumpet, a violin or a human voice? It will be evident, also, that an answer to these questions constitutes what Helmholtz calls the physiological basis of sensations of tone. The answer, however, cannot explain the esthetic relations of music; it cannot explain why, of all the arts, this is the one which, while it is the most intangible, yet stirs the very depths of our being, and gives expression to feelings, longings, aspirations, contemplations, that can never find full recognition in the most splendid efforts of the painter or the sculptor. The work of Helmholtz, in the first place, laid the physiological foundation, and afterwards he did little more than indicate the path along which we must travel from the foundation into the region of æsthetics. Himself a musician, not only in the sense of enjoying music, but also because he had studied theory as a musician is obliged to do, and because he was thoroughly acquainted with musical literature-and especially with that of his great countrymen Beethoven, Mendelssohn, Wagner, and the brilliant galaxy of lesser German composershe was eminently qualified for the task. Indeed, it seemed as if Nature had raised in Helmholtz a man of such a rare combination of endowments, that she could safely whisper to him some of her secrets in this borderland of physics, physiological action and æsthetics, feeling assured that he would be a just and faithful interpreter.

Helmholtz was the first to examine the mechanism 


\section{HELMHOLTZ IN BONN}

of the drumhead in a satisfactory manner. Had the drumhead been a uniformly flat-stretched membrane, the amplitude of its movements, in response to the varying pressures of sound waves, would be greatest in the centre, while it would diminish as the periphery of the membrane was approached. Helmholtz showed that it is not flat, but composed of numerous fibres so arranged as to present the convexity of a curve outwards, that is, meeting the sound waves falling upon them, while the membrane, as a whole, bulges inwards. In this way a very small change in the pressure of the air causes a considerable increase in the tension of the fibres, and as the force exerted upon the handle of the malleus (the bone attached to the membrane) increases, the amplitude of the movement of that bone diminishes. Thus the special form of the drumhead secures a maximum of efficiency for tones of the feeblest intensity.

$\mathrm{He}$ then proceeds to examine the mechanism of the chain of bones, showing that they constitute a lever in which the force is applied at the handle of the malleus where it is attached to the membrane, the fulcrum where the short process of the incus abuts against the wall of the tympanum, and the work is done at the base of the stapes, where it pushes into the oval window, on the other side of which we have the labyrinth. The lever is such as to diminish the amplitude of the movements at the base of the stapes, while the work is done over a smaller area 


\section{HERMANN vON HELMHOLTZ}

than that of the drumhead, and thus effective, but very minute, pushes to and fro are communicated to the delicate structures in the inner ear. Helmholtz also investigated the little saddle-shaped joint between the incus and the head of the malleus, showing that when the drumhead was pushed in very strongly there was a curious rotation of the surfaces of the bones so that they interlocked, and thus further pressure could not be communicated to the stapes; while, on the other hand, if the drumbead was distended outwards, as by inflating the tympanum through the Eustachian tube, there was no danger of pulling the base of the stapes out of its place, because the little joint opened up, the head of the malleus swinging free from the depression in the incus. Thus the danger of injuring the inner ear by violent movements of the drumhead, either outward or inward, is reduced to a minimum by these exquisite arrangements. In this investigation Helmholtz proves to the hilt his claim to be a competent anatomist.

It was, however, in the region of the internal ear that Helmholtz won for physiological science the greatest triumphs. Up to the date of his investigations this was known almost solely to the anatomists, who laboriously described its various parts and covered it over with a barbarous terminology, which is still the terror of students. The physiologists had little to say as to its probable functions, and the mathematicians and physicists and writers on acoustics 


\section{HELMHOLTZ IN BONN}

generally, regarded it as a wilderness of sacs and tubes involving problems almost incapable of solution. ${ }^{\mathrm{r}}$ Musicians, on the other hand, did not expect much help from physical and physiological science. Imbued with a love of their art, they were mainly occupied with the consideration of its æsthetic relations, they were unacquainted with the methods of scientific analysis, and they rather dreaded investigations into the minute structure of the parts and also the torturing expedient of physical experiment. Why an octave or a fifth should be more satisfying to the ear than a minor third; why certain chords had a character of their own; what was the physiological basis of discords; what was the true nature of beats; what was the physiological significance of the progression of the notes in a melody; what were the physiological laws, if any, that regulated the development of musical capacity in the human race; all these were questions the musicians cared little about, and if they did allow them to occupy their attention they were dismissed as insoluble. Men took refuge in the notion that music was music because it was adapted to our spiritual nature, and they thought there was little use in endeavouring to examine the physical and physiological materials of which musical tones were composed. Helmholtz changed all this by attempting to give an intelligible account of the mechanism of the internal ear.

I Sir G. B. Airy on Sound. London, 1871 . 


\section{HERMANN VON HELMHOLTZ}

This organ, as already said, consists of a complicated series of sacs and tubes filled with fluid. In certain situations the walls of the sac contain highly-differentiated epithelial structures, which are intimately related to the terminal filaments of the auditory nerve. ${ }^{\mathrm{I}}$ The problem is to explain how the pressures transmitted by the foot of the stapes affect these terminal structures in such a way as to excite sensations corresponding to the pitch, intensity and quality of tones.

Two small sacs, the utricle and saccule, are the first structures that receive the impulses of the base of the stapes. The utricle communicates with the semicircular canals, and the saccule with the long spiral duct of the cochlea. The oval window, into which the base of the stapes fits, is covered by a membrane. Suppose the base of the stapes to be pushed in by the pressure of a wave of sound, then, since the delicate sacs and canals are all inclosed in cavities in the bone, having rigid walls, it is clear that, as the fluid is practically incompressible by the force applied, no movements could be communicated to any of the delicate nerveendings. But one part of the osseous wall, next the tympanum or middle ear, has a round opening, also covered by a membrane. Thus, when the base of the stapes is pushed inwards, the membrane cover-

I In some parts of this chapter I make free use of an article on Hearing in Schäfer's advanced Text-Book of Physiology, vol, ii, written by my pupil, Dr Albert A. Gray, and myself. 


\section{HELMHOLTZ IN BONN}

ing the round window passes outwards, and thus a to-and-fro pressure is communicated to the fluid in the sacs and tubes with each pressure of a wave of sound.

Helmholtz emphasizes strongly a remark first made by Riemann, that the dimensions of the internal ear are so small as to form only a small part of the wavelengths, even of tones of high pitch. The whole of the membraneous labyrinth may be regarded as part of any wave acting on the ear, and the wave is not arrested by the labyrinth as waves of light are arrested by the retina, but they sweep onwards through the bones of the head. The fact of the labyrinth being so small, relatively to the size of the wave, makes no difference in the result; so that the labyrinth is acted on in the same way, whether the ear receives a wave of thirty feet in length, such as is produced by the longest pipe in a modern organ, or a wave of twothirds of an inch, produced by the highest note of a piccolo flute. The nerve-endings are very much smaller, but they also act as minute portions of any wave, and any reasoning as to the effect of such waves is quite irrespective of the small dimensions of the receiving organs in the internal ear. This point is of great importance in the consideration of the theory of hearing advanced by Helmholtz.

It is clear, then, that the number of movements communicated to the structures in the internal ear in, say a second of time, depends on the pitch of the 


\section{HERMANN vON HELMHOLTZ}

note, as it can be shown experimentally that as a note rises in pitch the number of pressures also increases. Helmholtz, for this and other purposes, improved the syren of Cagniard-de-la-Tour, and invented the well-known polyphonic syren now found in every physical and physiological laboratory. Another way of looking at this question of pitch is to say that it depends on the duration of the individual pressures. For example, the variation of pressure involved in a tone of 256 vibrations per second will last the $\frac{1}{2} \frac{1}{6} \mathrm{t}^{\text {th }}$ of a second, while that of its octave will last only the $\frac{1}{512}$ th of a second. It is not necessary, therefore, to have a large number of pressures per second to arouse a sensation of a tone of a certain pitch; a small number, possibly only a few, if they come at a given rate, will be quite sufficient. If now we suppose that there are nerve-endings, say in the cochlea, so constructed as to have each its own period of vibration, when pressures come in at a certain rate, the structures adapted to that rate will be thrown into action, and we can conceive movements to be excited. These movements will in some way stimulate the nerve-ending, and a nervous impulse will be transmitted to the brain, in which will arise, by some molecular process, utterly unknown, the sensation of a tone of that pitch. Again, on such a supposition, it is easy to explain intensity or loudness. This will evidently depend on the amplitude of movement of 


\section{HELMHOLTZ IN BONN}

the base of the stapes, on the amplitude of the excursions of the vibratile bodies in the cochlea, and on the degree of stimulus given to the nerve.

The base of the stapes is chiefly opposite the utricle, although it partly abuts against the saccule. On the wall of the utricle, immediately in front, there are no nerve-endings or modified epithelium, but on the back wall we find a ridge called the crista acoustica, on which are long cells having bristle-like points which are directed towards the base of the stapes. In front of these bristle cells lies a mass of otoliths, or ear stones, consisting of carbonate of lime. The pressures must be communicated, in the first instance, to the otoliths, and by them to the bristle cells. As the bristle cells are fixed, while the otoliths are capable of moving backwards and forwards in a fluid, it is clear that one impulse from the base of the stapes may cause the otoliths to oscillate, and, by thus making a series of impacts on the points of the bristle cells produce in them a more or less prolonged excitation. This was the opinion of Johannes Müller. Helmholtz, on the contrary, considered the matter from the physical point of view, and his opinion was that the thin membrane, bearing the bristle cells, will readily move to the impacts of the stapes, and the heavy otolithic mass, by virtue of its inertia, will move more slowly at first, but it will continue to oscillate, and thus keep up stimulation. The long and extremely light bristles also appeared to him to 


\section{HERMANN vON HELMHOLTZ}

be well adapted for sympathetic resonance, but, as they were of small mass, they could not long continue their motion. Again, according to him, the ampullæ at the ends of the semi-circular canals, in which there are also nerve-endings similar to those in the crista, being wide cavities with narrow exits, are suitable for producing a central current, which partly passes into eddies, and these would deflect the bristles, causing an oscillation. A movement of the whole mass of the bristle, floating in the fluid, would not serve the same purpose, but discontinuous streams of different strengths and in different directions would do so effectively. Thus Helmholtz contributed to our knowledge of what may take place in the saccule and utricle and ampullæ. Researches made since his time have suggested that these parts may not have to do, strictly speaking, with hearing, but with the reception of those greater variations of pressure on which the sense of equilibrium depends. They may have to do with the appreciation of mass movement, and only indirectly with those more delicate variations of pressure on which true hearing depends.

Hitherto we have considered only the reception of simple harmonic (sometimes termed simple pendular) vibrations which are known to be physically related to pure tones. The sensation of a pure tone, such as can be excited by carefully bowing a tuning fork, mounted on a resonance box, or by an open organ pipe caused to sound gently by a 


\section{HELMHOLTZ IN BONN}

steady stream of air at low pressure, is analogous to that of a pure colour, such as the red, green, or violet of the spectrum. Such tones, however, are seldom heard, the majority of tones being compound and analogous to mixtures of simple colours, such as red and violet producing purple, and so on. This fact was long known to writers on acoustics, but it was Helmholtz who first made an exhaustive examination of such compound tones, and pointed out their importance in connection with the question of quality, timbre, or klangfarbe (clang tint), as he termed the nature of the sensation by which we distinguish one tone from another, although of the same pitch and of the same intensity.

If we help the mind by representing to ourselves the varying forms of waves on the surface of water, some with long smooth backs, others with narrow crests and longer troughs, some with the slope in the ascent sudden and with others more gradual, we see that there may be an almost infinite variety of wave-forms. (By the term 'wave-forms' we mean only the manner in which the changes of pressure are represented diagrammatically.) So it is with sound. Instead of a simple pendular vibration we may have vibrations or pressures of complicated form, which may cause the drumhead to move outwards and inwards through a complicated path of excursion. These movements correspond to the action of a compound wave. Thus pressures of a similar character pass into 


\section{HERMANN vON HELMHOLTZ}

the cochlea and sweep over the nerve-endings. The question is, how does the cochlea behave in such circumstances, and will its action explain quality of tone ?

Helmholtz attacked the problem both by analysis and by synthesis. In the first place, he was familiar with Ohm's ${ }^{1}$ application in 1843 of Fourier's principles to the decomposition of a sound wave of any type into a number of simple harmonic vibrations, each simple harmonic vibration corresponding to a simple tone such as a tuning fork approximately gives. Fourier's ${ }^{2}$ theorem states that any given regular periodic form of vibration can always be produced by the addition of simple vibrations having vibrational numbers which are once, twice, three times, etc., as great as the vibrational number of the given motion; and further, if we know the amplitudes of the simple vibrations and the differences of phase, then any regular periodic motion can be shown to be the sum of a certain number of harmonic vibrations; in other words, the compound wave may be analysed into a set of constituents of definite periods. Applying this to the motion of the air close to the ear, we find that any such motion, corresponding to a musical tone, may be always, but for each case only in a single way, shown to be the sum of simple harmonic motions, corresponding to the partial tones of this compound musical tone.

I Poggendorff's Annalen der Physik, t. lix., p. 513 ; t. lxii., p. 1.

2Théorie Analytique de la Chaleur. Paris, 1821 . 


\section{CHAPTER XII}

HELMHOLTZ IN BONN AND HEIDELBERG-SENSATIONS OF TONE CONTINUED

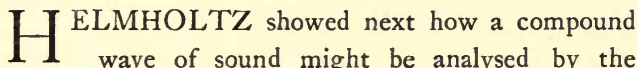
application of the principle of resonance. The air in any cavity or vessel, such as a bottle with a narrow neck, or the familiar shell held to the ear, which, in the days of childhood, we thought gave us the sound of the sea, is thrown into sympathetic vibration by the vibrations of any sounding body in its vicinity, if the vibration periods of the body and of the cavity are approximately the same. In the first instance Helmholtz used, as had previously been done by $\mathrm{Ohm}$, two bottles, with fairly wide mouths; and then the size of the cavity could be altered by filling the bottle more or less full of water. Streams of air were directed across the mouths through flattened gutta-percha tubes. The bottles were tuned to $b$ and $b^{\prime}$, an interval of an octave. The sound of the first bottle was like the vowel $U$, but when the sound of the 


\section{HERMANN VON HELMHOLTZ}

second was added to it the resultant sound was more like $\mathrm{O}$. Helmholtz was able to distinguish the sounds in the mixture. This experiment suggested the use of resonators. These were, in the first instance, cones and cylinders made of pasteboard, and finally the resonators, in the hands of Rudolf König, a native of Königsberg, now established in Paris, took the form of hollow brass globes, each with a narrow, nipplelike end, which was introduced into the ear, while the other was directed to the source of sound. By the use of a number of such resonators, each tuned to a particular tone, it is possible to analyse a compound wave of sound into its constituents. However complicated the wave may be, the ear will pick up the tone of the resonator, and this tone will sound loudly in the ear. This invention was of the greatest importance in practical acoustics, as it enabled the observer to sift a mass of sound, and it did for the ear what the prism of Newton did for the eye. Helmholtz also worked out the mathematical theory of resonance in great detail. Many years ago the writer, with a feeling of veneration, had the satisfaction of seeing the original resonators of Helmholtz in the physiological laboratory of Heidelberg.

Helmholtz then laid stress on the fact, that the ear is capable of analysing a compound tone, even without the aid of resonators. Musicians and

${ }^{x}$ For an exposition, see Lord Rayleigh on Sound, vol. ii, p. I7I. London, I894. 


\section{HELMHOLTZ IN BONN}

physicists have long known that if a violin string is plucked, and attention is fixed on the sensation of tone, we not only hear that of the musical tone whose pitch is determined by the period of the large vibrations of the string, but in addition to this, the ear becomes aware of a whole series of higher musical tones, called the harmonic upper partial tones. The first one, termed the fundamental or prime partial tone, or the prime, is the lowest, and generally the loudest, of all, and it is the tone by whose pitch we judge of the pitch of the whole compound musical tone. The partials are so arranged that the first partial, or second harmonic constituent, is the octave of the prime, with twice the number of vibrations; the second, the fifth of this octave, with three times the number of vibrations; the third, the second higher octave, with four times the number of vibrations; the fourth, the major third of the second higher octave, with five times the number of vibrations of the prime; the fifth is the fifth of the second higher octave, or a minor third above the fourth partial, with six times the number of vibrations of the prime in the same time. Thus the partials go on, becoming generally fainter, to tones making seven, eight, nine, etc., times as many vibrations in the same time as the prime. We may also avoid using the word 'partials' altogether, and call the harmonic constituents the first, second, third, etc., harmonics. 


\section{HERMANN vON HELMHOLTZ}

Helmholtz had forks constructed, the frequencies of which were in the order of a harmonic series, beginning with one having a pitch of 256 vibrations per second. These were then $\mathrm{Ut}_{2}(c), \mathrm{Ut}_{3}\left(c^{\prime}\right), \mathrm{Sol}_{3}\left(g^{\prime}\right), \mathrm{Ut}_{4}\left(c^{\prime \prime}\right)$, $\mathrm{Mi}_{4}\left(e^{\prime \prime}\right), \mathrm{Sol}_{4}\left(g^{\prime \prime}\right), 7\left(b^{\prime \prime} b\right.$ nearly $), \mathrm{Ut}_{5}\left(c^{\prime \prime \prime}\right)$, etc. They were mounted on resonance boxes, by which the volume of sound was much augmented. Thus any combination of the partials with the prime could be readily obtained by suitable bowing, and at the same time while the compound tone fell on the ear, the observer could effect an analysis by means of resonators. Since the invention of this method, Rudolf König has adapted his beautiful device of manometric flames, aided by the rotating mirror of Wheatstone, for the demonstration of the analysis of a compound tone. ${ }^{\mathrm{I}}$

It will be evident that various combinations of the waves of the prime with those of the partials will produce varieties of wave form, and that the form of the resultant wave will be modified by the phase and the amplitude of the constituent waves. But we have seen that the ear can resolve musical tones into a series of partials, and that it behaves in accordance with the proposition advanced by $\mathrm{Ohm}$, namely, that the human ear perceives pendular vibrations alone as simple tones, and resolves all other periodic motions of the air into a series of pendular vibrations, hearing

${ }^{1}$ For a figure of the apparatus, see .M'Kendrick's Physiology, vol ii., p. 686 . 


\section{HELMHOLTZ IN BONN}

the series of simple tones which correspond with these simple vibrations.

The interesting question now arises, whether the ear, having to deal with waves varying almost infinitely in form, is differently affected by such waves, according as their form represents various modes of pressure (pushes and pulls) on the drumhead and conducting mechanism ? When we sound the harmonic series of forks from $U_{t}$ to $U_{t_{5}}$, we hear a rich harmonious sound, and we can analyse the sensation, and pick out the tone of any particular partial, more especially if it is slightly strengthened by a touch of the bow. By varying the order and intensity of the partials, we can produce a very large number of wave-forms, but the general character of the harmonious sound remains the same. In other words, waves may differ much in form, but if they contain the same harmonic constituents, the sensational effect will be the same. This would appear to indicate that the ear takes no cognisance of phase. Helmholtz invented a special apparatus to investigate this question. This costly apparatus was presented to him by King Maximilian of Bavaria. It consists of a harmonic series of forks, electrically driven, and so arranged that they can be sounded in any order and with various intensities, according to changes produced in the size of the orifices of their appropriate resonators. ${ }^{\mathrm{I}}$ The resona-

'A figure of the apparatus is given in M'Kendrick's Physiology, vol. ii., p. 691 . 


\section{HERMANN VON HELMHOLTZ}

tors may thus be put slightly out of tune, their resonance is weakened, and thus the phase is altered. Helmholtz stated the result as follows :- 'Differences in musical quality depend solely on the presence and strength of partial tones, and in no respect on the difference in phase under which these partial tones enter into composition.' This statement has been disputed by Lord Kelvin, on theoretical grounds, and by Rudolf König, who has submitted it to the test of experiment; but Lord Rayleigh remarks, regarding König's experiment, 'the results are in harmony with the view that would ascribe the departure from Ohm's law, involved in any recognition of phase relations, to secondary causes.' I Physically, timbre must be due to the form of the vibration curve, otherwise telephoning would be impossible; but the ear always analyses the curve into its constituents.

With the view of establishing his theory of hearing on a firm basis, Helmholtz made a careful examination of the question of the existence of damping arrangements in the ear. Suppose tones are pouring into the ear in rapid succession, and that the effect of one tone has not died away before the influence of the next one is felt, musical effect would be disturbed. This would certainly occur if we executed a shake on a piano of eight or ten notes in a second, so that each note would be sounded four or five times. But it is well known that the sensation excited by such shakes is rough and

${ }^{1}$ Rayleigh, op. cit., vol. ii., p. 469 . 


\section{HELMHOLTZ IN BONN}

unpleasant, indicating, in the opinion of Helmholtz, ' that the vibrating parts of the ear are not damped with sufficient force and rapidity to allow of successfully effecting such rapid alternation of tone. It is therefore highly probable that a damping mechanism exists.'

The next step was to attempt to explain how the cochlea, in which the nerve-endings exist in the form of the remarkable organ of Corti, can analyse tone, and with the development of this theory, however much it may have to be modified as time goes on, the name of Helmholtz will be imperishably connected. There are only three ways in which the nerveendings may be affected. Either (I) small vibratile bodies may exist so as to transmit the pressures sent to the filaments of the auditory nerve, each vibratile body having a frequency period of its own; or (2) individual nerve fibres may be directly excited by waves of a definite period, that is to say, there may be differences in the nerve fibres, so that they have a selective action; or (3) the organ may be affected as a whole, all the nerve fibres being affected by any variations of pressures, and thus the power of analysis, which is admitted, would be relegated from the peripheral to the cerebral organs.

The first hypothesis seems à priori to be probable, for the following reasons:-(I) The existence of such bodies would give a natural explanation of many, if not all, of the phenomena; (2) the evidence of comparative physiology points to gradually-increasing 


\section{HERMANN vON HELMHOLTZ}

complexity in the structure of all the terminal organs of special sense, as if there arose a necessity for differentiation and discrimination in the effects of various kinds of stimuli; and (3) investigations into the action of all the sense organs, such as those of touch and temperature in the skin, of light and colour in the retina, of taste in the tongue, and of smell in the olfactory region, all indicate specialization of function in the peripheral apparatus.

Although the conception that vibrators exist in the cochlea flitted before the minds of Thomas Young, John and Charles Bell, and Johannes Müller, it was first clearly put forward by Helmholtz. It may be shortly stated as follows:-(I) In the cochlea there are vibrators, tuned to frequencies within the limits of hearing, say from 30 to 40,000 or 50,000 vibrations per second ; (2) each vibrator is capable of exciting its appropriate nerve filament or filaments, so that a nervous impulse, corresponding to the frequency of the vibrator, is transmitted to the brain,- not corresponding necessarily as regards the number of nervous impulses, but in such a way that when the impulses along a particular nerve fibre reach the brain, a state of consciousness is aroused which does correspond with the number of the physical stimuli, and with the period of the auditory vibrator; (3) the mass of each vibrator is such that it will be easily set in motion, and after the stimulus has ceased it will readily come to rest; (4) damping arrangements exist in the ear, 


\section{HELMHOLTZ IN BONN}

so as to quickly extinguish movements of the vibrators; (5) if a simple tone falls on the ear, there is a pendular movement of the base of the stapes, which will affect all the parts, causing them to move; but any part whose natural period is nearly the same as that of the sound will respond on the principle of sympathetic resonance, a particular nerve filament or nerve filaments will be strongly affected, and a sensation of a tone of a definite pitch will be experienced, thus accounting for the discrimination of pitch ; (6) intensity or loudness will depend on the amplitude of movement of the vibrating body, and consequently on the intensity of nerve stimulation; (7) if a compound wave of pressure be communicated by the base of the stapes, it will be resolved into its constituents by the vibrators corresponding to the tones existing in it, each vibrator picking out its appropriate constituent and thus irritating its corresponding nerve filament, so that nervous impulses are transmitted to the brain, where they are fused in such a way as to give rise to a sensation of a particular quality or character, but still so imperfectly fused that each constituent, by a strong effort of attention, may be specially recognised. This last statement affords an explanation of the analytic powers of the ear.

Now the structure of the ductus cochlearis, in which the nerve-endings exist, meets the demands of this theory. It is highly differentiated, and its parts appear suitable for executing independent vibra- 


\section{HERMANN vON HELMHOLTZ}

tions. The minute size of the structures does not present any difficulty; because, however minute the vibrators might be, if they had different periods, they must act in obedience to the same principles of resonance as larger bodies do outside the ear. In 1863, Helmholtz was of opinion that the different degrees of tension in the arches of Corti indicated capacity for vibrating at different periods. Soon after, it was shown by Hasse that these rods do not exist in birds, animals presumably capable of appreciating tones; and Hensen pointed out that the membrana basilaris, on which the rods rest, consisted of transverse fibres, which varied in length approximately from $\frac{1}{50}$ th of an inch, at the base of the cochlea, to ${ }_{3}^{2} \frac{1}{0}$ th of an inch at its apex. This led Helmholtz to suggest that it is probably the breadth of the membrana basilaris in the cochlea which determines the tuning. He pointed out that the membrane was in a state of tension transversely, while it has only little tension in the longitudinal direction, and that such a membrane had very different properties from that of a membrane which had the same tension in all directions. The membrane, in fact, behaves like a system of stretched strings, bound together by a semifluid substance. Each string or fibre would act independently of the others, and would be set into vibration by an impulse to the fluid in the scala vestibuli, corresponding to its period. Consequently, if a part of the membrane were called into action, one 


\section{HELMHOLTZ IN BONN}

of its radial fibres, which corresponded to the exciting tone, would vibrate, and the vibrations would extend with diminishing strength on the adjacent portions of the membrane. Possibly some of the structures on the surface of the membrane might act as dampers. In this way the parts of the membrane near the base of the cochlea would be adapted for the higher, while those near the vertex of the cochlea would be suitable for the deeper tones. Corti's arches are, therefore, of secondary importance, serving either as supporting structures, or for transmitting vibrations of parts of the basilar membrane to the rows of hair cells placed on their backs.

Helmholtz also discussed the question as to whether histological evidence as to the number of possible vibratile structures is such as will satisfy the demands of theory. He attempted to answer this question on the basis of E. H. Weber's statement, that practised musicians can 'perceive even a difference of pitch for which the vibrational numbers are as 1000 to I00I,' or the $\frac{1}{6 t^{2}}$ th of a semitone, a smaller interval than that between two of Corti's arches, on the assumption that there are about $33 \frac{1}{3}$ for each semitone in each cochlea ; and he accounted for the apparent deficiency by the explanation, that if a tone came in between the pitch of two of the arches, 'it would set them both in sympathetic vibration, and the arch would vibrate the more strongly which was nearest in pitch to the proper tone.' This would also ex- 


\section{HERMANN vON HELMHOLTZ}

plain how it is that when we listen to the syren, as its disc revolves faster and faster, our sensations go on, not by leaps and bounds, but continuously. Since the time when Helmholtz wrote, histological evidence has accumulated, the rods and arches of Corti, the fibres of the membrana basilaris, the hairs cells, and even the nerve fibres in each auditory nerve, have been counted, and it has been conclusively established that there is in the cochlea a sufficient number of possible vibratile masses to satisfy this theory.

He then proceeded to examine the cause of consonance and dissonance, and to apply his theory in explanation. If we sound simultaneously two forks that are in unison, the waves coincide and one sound is heard; but if the pitch of one of the forks is slightly flattened, the waves do not coincide, and there are maxima and minima. A rapid, rattling, beating sound will then be heard, as if there were individual thuds on the ear. If the forks are nearly the same in pitch, the beat, as it is termed, will be heard as a rising and falling in the intensity of the sound, and as the difference in pitch between the forks is increased, there is also an increase in the number of the beats. If such beats are few in number, so as to be readily counted, the sensation of waxing and waning is not disagreeable; but if they are sufficiently numerous, it may be impossible to count them, and the sensation is disagreeable. Such a sensation is that of dissonance. Helmholtz found the sensation to be most 


\section{HELMHOLTZ IN BONN}

disagreeable when the ear is affected by about 33 beats per second; if they are more numerous, the sensation is rough and unpleasant. Further, even when the frequency of beats is much greater than the number of vibrations required to produce the sensation of a tone, the sensation is never uniform, but is of a rough, intermittent character.

If now we sound an interval on an instrument giving forth compound tones, such, for example, as an octave, each note will have its corresponding partials; and as these come closer and closer together the higher they are in the series, it is clear that they may come within beating distance, and thus give a certain harshness to the sound. The beating distance may, for tones of medium pitch, be roughly fixed at a minor third; this interval, of course, will expand for intervals in low, and contract for intervals in high ranges of the scale. Thus, the same interval in the lower part of the scale may give slow beats that are not disagreeable, while in the higher part it may cause harsh and unpleasant dissonance. Two given notes will produce this 'beating' harshness when the difference of their vibration number is about 70 or 80 . Thus a minor third will sound pleasant in the higher ranges of the scale. There will be a slight roughness at medium pitches; while in the lower ranges there will be harshness and possibly perceptible beating. On the other hand, if 


\section{HERMANN voN HELMHOLTZ}

the interval be small, say a semitone, the beating, in the lower part of the scale, may be so slow as not to be disagreeable, whereas in the higher part it may cause harsh and unpleasant dissonance. The sensational effect of beats then depends rather on the difference of the vibration numbers than on the interval. As a rule, the partials up to the seventh are beyond beating distance, but above this they soon come close together. In the neighbourhood of the tenth, the interval may be about a tone, of the sixteenth, a semitone, and still higher they come together so as to cause dissonance. This fact explains why intervals sound so harsh when produced by reeds, the sounds of which are rich in upper partials, and also the harsh but brilliant quality of intervals sounded on two trumpets. Intervals even when produced on instruments giving compound tones with few harmonic constituents, such as flutes, have still their own character. Helmholtz applied his theory with consummate skill, not only as an explanation of the quality of musical tones in many instruments, the human larynx included, but also of the satisfying character of certain musical intervals, as contrasted with the discordant character of others. Thus unison $\frac{1}{1}$, minor third $\frac{6}{5}$, major third $\frac{5}{4}$, fourth $\frac{4}{3}$, fifth $\frac{3}{2}$, minor sixth $\frac{8}{5}$, major sixth $\frac{5}{3}$, and octave $\frac{2}{1}$, are all concords; while a second $\frac{9}{8}$, minor seventh $\frac{16}{9}$, and major seventh $\frac{15}{8}$, are discords. The smoothest interval is the octave, next the fifth, then the fourth, 


\section{HELMHOLTZ IN BONN}

major third, and so on. What he did not explain is-Why the sensation should be disagreeable when two portions of the membrana basilaris, sufficiently near, are thrown into vibration? For some unexplained reason, if two nerve filaments sufficiently near are simultaneously stimulated, or if they are stimulated in the intermittent manner peculiar to beats, the sensation is disagreeable. Helmholtz contrasts it with that caused by a flickering, light on the eye. There is, in listening to beats, always an effort at analysis, and it may be that this effort gives rise to a disagreeable sensation when the number of beats reaches a certain amount.

While the theory explains the dissonance of intervals produced by instruments that are rich in partials, how does it apply to cases in which there are no partials, but only prime tones, as when the tones are produced by well-bowed tuning-forks and open organ pipes? This question also was attacked by Helmholtz, and led to the examination of what he termed combination tones. If, for example, two forks representing a fifth are properly bowed, sounding the fork of lower pitch first and that of higher pitch afterwards, we may hear a weak lower tone, the pitch of which is an octave below that of the first fork. This is known as a combination tone. Such tones he divided into two classes-differential notes, in which the frequency is the difference of the frequencies of the generating tones; and summational 


\section{HERMANN vON HELMHOLTZ}

tones, having a frequency which is the sum of those of the tones producing them. Then, when a fifth is sounded, the differential tone is an octave below the low note; with a fourth it is a twelfth ; with a major third, two octaves; with a minor third, two octaves and a major third; with a major sixth, a fifth; and with a minor sixth, a major sixth. Such differential tones, first heard by Sorge about I 740, are usually associated with the name of Tartini. Summational tones were discovered by Helmholtz. It is clear that there must be differential tones of several orders, according as they are produced between the generating tones themselves, then between the differential tone and each of the generators, and so on. It is not difficult to detect differential tones, but this is not the case with summational tones. Helmholtz, who had a remarkably acute and well-trained ear, heard them first with the polyphonic syren and the harmonium, and afterwards with organ pipes and tuning-forks. On the other hand, Hermann and others assert that they cannot hear these tones. There can be little doubt, however, that both kinds of combination tones may have an existence outside of, and quite independent of, the ear. Helmholtz states that "whenever the vibrations of the air or of other elastic bodies, which are set in motion at the same time by two generating simple tones, which are so powerful that they can no longer be considered infinitely small, mathematical theory shows that vibrations of the air must arise which have 160 


\section{HELMHOLTZ IN BONN}

the same vibrational numbers as the combination tones.' I Recently Rücker and Edser have demonstrated the objective existence of such tones. ${ }^{2}$ Combinational tones may, however, as Helmholtz clearly showed, be produced in the ear itself, because of the elastic asymmetry of the drum.

The importance of these combinational tones in the theory of hearing is obvious. If the ear can only analyse compound waves into simple pendular vibrations, in a certain order, how can it detect combinational tones, which no doubt can be heard, and yet do not belong to that order? For example, when the interval is harmonic $(400,500)$ the combined wave-forms make a wave of 100 of frequency, so that the ear, like Fourier's theorem, may easily pick out this tone; but how will it deal with intervals of incommensurate numbers, such as 407,483 ? Yet this combination tone of a frequency of 76 will be heard as distinctly as one arising from two tones having frequencies of 400 and 500. This is still a great difficulty, as it cannot be said that experiments made by many others since the time of Helmholtz have removed it. Experiment shows that combinational tones are produced when the notes of intervals are sounded strongly on instruments like tuning-forks, whose notes are nearly simple tones, free from upper partials; and that these combinational tones may produce beats with any of the generators, or among themselves; and these beats, feeble as they

I Sensations of Tone, trans. by Ellis, p. 235. 2 Phil. Mag., April 1895 . 


\section{HERMANN vON HELMHOLTZ}

may be, produce that feeling of less and less consonance until we come to intervals that are truly dissonant. One might suppose that in the case of tones that abound in partials, combinational tones might be produced by the partials, and thus a new source of beats might lead to confusion and discord; but theory shows that dissonance due to combinational tones, produced between partials, never occurs except when it has already taken place by the action of the partials among themselves. ${ }^{\text {I }}$

Closely connected with this subject is the investigation of the cause of the quality of the human voice, more especially as to vowel tones. This also engaged the attention of Helmholtz, and it was treated by him in his usual masterly fashion. ${ }^{2}$ Why should a vowel, spoken or sung, always have, even with the voices of different persons, the same quality, so that we have no difficulty in distinguishing $A$ from $E$ and $E$ from $O$ ? Donders ${ }^{3}$ was the first to show that the cavity of the mouth, as arranged for the giving forth of a vowel, was tuned as a resonator for a tone of a certain pitch, and that different pitches corresponded to the forms of the cavity for the different vowels. This he discovered, not by the use of tuning-forks, but by the peculiar noise produced in the mouth when the different vowels are whispered. The cavity of

1 Sedley Taylor, Sound and Music. London, 1873 .

${ }^{2} \mathrm{Gel}$. Anz. d. k. bayer Acad. d. Wissensch, 1859.

3 De Physiologie der Spraak klanken, 1870, 8. 9. 


\section{HELMHOLTZ IN BONN}

the mouth is then blown like an organ pipe, and by its resonance reinforces the corresponding partials in the rushing wind-like noise. Helmholtz adopted another method. To determine the pitch of the cavity of the mouth, considered as a resonance cavity, he struck tuning-forks of different pitches, and held them before the opening of his mouth. Then, the louder the proper tone of the fork was heard the nearer 'it corresponded with one of the proper tones of the included mass of air.' As the shape of the mouth could be altered at pleasure, according to the vowel to be emitted, it was easy to discover the pitch of the included mass of air for each vowel. He came to the conclusion that 'the pitch of the strongest resonance of the oral cavity depends solely upon the vowel for pronouncing which the mouth has been arranged.' He also found the same resonances for men as for women and children. He then carefully examined the form of the oral cavity for each vowel, and showed how very slight changes could account for the quality being slightly altered for different dialects. $\mathrm{He}$ also demonstrated that the tones of the human voice are adapted to the powers of the human ear. The ear, by its resonating powers, favours the development of these partials, especially the higher ones, which give a peculiar character to human tones. His theory as to vowel-tone is summed up in the following sentence:- 'Vowel qualities of tone consequently are essentially distinguished from 


\section{HERMANN VON HELMHOLTZ}

the tones of most other musical instruments, by the fact that the loudness of their partial tones does not depend upon the numerical order, but upon the absolute pitch of those partials; thus, if I sing the vowel $\mathrm{A}$ to the note $\mathrm{E} b$, the reinforced tone $b^{\prime \prime} b$ is the twelfth partial tone of the compound; and when I sing the same vowel $\mathrm{A}$ to the note $b^{\prime} b$, the reinforced tone is still $b^{\prime \prime} b$, but is now the second partial of the compound tone sung.' ${ }^{\prime}$ He also endeavoured to reproduce, but with imperfect success, the tones of vowels by means of the same apparatus as he employed in the investigation of the influence of phase (p. 149). The theory of the absolute pitch of vowels, as advocated by Helmholtz, has met with great opposition, and to it is opposed the theory of relative pitch, but space forbids a critical examination of the subject. ${ }^{2}$

These important investigations, the results of which appeared from time to time, mostly after he had settled in Heidelberg, were collected by Helmholtz into his great book on Sensations of Tone, and formed Parts I. and II. Part III. is occupied with a discussion of the relationship of musical tones, the different principles of musical style in the development of music, the tonality of homophonic music, the music of the Greeks, consonant triads, keys, discords, the laws of progression, and the rsthetical relations of the whole

Sensations of Tone, p. 172.

2 Discussed in article on Vocal Sounds in Schäffer's Text Book, vol. ii., p. 59, by M'Kendrick and Gray. 


\section{HELMHOLTZ IN BONN}

subject. The mere enumeration of the subjects discussed will give one a faint idea of the breadth and fulness of this magnificent work. And yet even all this was only a part of the labours of Helmholtz in acoustics. As already mentioned, there is scattered throughout the volume, and in appendices, numerous examples of a mathematical treatment of the subject under discussion. In addition, we have papers on the motion of the strings of a violin, communicated, during one of Helmholtz's visits to his friend Lord Kelvin, then Professor William Thomson, to the Philosophical Society of Glasgow, on Igth December I860. In this paper he fully discussed and represented graphically the course of the vibration. ${ }^{I}$ As already mentioned, he investigated mathematically the theory of damping, and calculated, for various intervals, the number of vibrations, after which the intensity of a free vibration is reduced to one-tenth. He estimated also the pitch of the partials produced immediately after a tuning-fork has been struck. He invented an electric interrupter, so as to produce an intermittent current in the best way and without making a noise by the production of sparks. He discussed the reciprocal relations of sounds, showing that a sound originating at one point is perceived at another point, even if there are obstacles between the two points, with the same intensity as if it originated at the last point and was perceived at the first ; just as

1 See also Rayleigh's Theory of Sound, op. cit, vol. i., p. 231. 


\section{HERMANN vON HELMHOLTZ}

in optics, if one point can be seen from a second, the second can also be seen from the first. Sound shadows may thus be produced, but they are only partial, in consequence of the wave-lengths of sound being great in comparison with the sizes of ordinary obstacles. In connection with this subject, in 1860 , he published an important paper, in which he examined the movements of the air in open organ pipes, and extended Green's well-known theorem, the chief application of which belongs to Statical Electricity. ${ }^{\mathrm{I}} \mathrm{He}$ gave the correct theory for the open organ pipe. Lagrange, Daniel Bernoulli, and Euler assumed that at the opening the pressure could not vary with that of the surrounding atmosphere; but Helmholtz showed that in ordinary cases the inertia of the air outside the pipe has the effect of practically diminishing its length. $\mathrm{He}$ also took into account the friction of the air against the walls of the tube, a point omitted by his predecessors. $\mathrm{He}$ also investigated some of the conditions under which the hammer of the pianoforte strikes the strings. He invented a vibration microscope for the examination of vibrating points on any body, say a violin string, so as to see the well-known figures of Lissajous. He established the mathematical relation of velocity and density in the propagation of small disturbances in gas or air.

As already mentioned, he examined mathematically the laws that regulate the actions of resonators of various

- Rayleigh, op. cit., vol. ii., p. 145 . 


\section{HELMHOLTZ IN BONN}

forms and with variously-shaped apertures. He investigated the special mode of action of many musical instruments, and in particular, divided those having tongues into inbeating and outbeating. In the first case the passage is opened when the tongue moves inwards, that is against the wind, as happens in the clarinette. Lip instruments, such as the trombone, belong to the second class, the passage being open when the lips are moved outwards or with wind. I It may be said that the whole theory of the mode of action of tongue pipes is due to Helmholtz. He also gave a formula for the velocity of sound in narrow tubes.

When Helmholtz first heard of the telephone, he remarked to $\mathrm{Du}$ Bois Reymond:- 'The invention seems so self evident, that I do not consider it necessary to advance a theory. Of course, I have for years gone to bed with Fourier's theorem in my head, and I have got up with it still there, so I must not judge others by myself.' His friend observes, that possibly it was on one of these nights that he was obliged to get up and lull his intellect by playing Bach's fugues on a magnificent grand piano presented to him by Messrs Steinway of New York in recognition of his services to music. On another occasion, he was interested and amused by the delightful experiment of causing a highly-trained vocalist to sing the vowels with the dampers off the strings, when of course they were returned little changed in quality. From the time

1 Rayleigh, op. cit., vol. ii., p. 234. 


\section{HERMANN vON HELMHOLTZ}

when Pythagoras is said to have discovered the arrangement of tones in an octave, by observing that the sounds of the blacksmith's hammer in the forge produce a fourth, a fifth and an octave, and was then led to obtain harmonic proportion between the strings of the heptachord, all who investigate musical tones know that, although these are fleeting sensations, they depend physically on numerical relations between various kinds of movements; but it was Helmholtz, more than any other philosopher, who examined the whole range of the phenomena, physical as well as physiological, and whose work will for generations remain an enduring monument to his genius. 


\section{CHAPTER XIII}

HELMHOLTZ IN HEIDELBERG-MINOR PHYSIOLOGICAL RESEARCHES

T must be remembered that, both at Königs1 berg and Bonn, Helmholtz lectured on anatomy as well as physiology, and in Königsberg he had general pathology in addition. This makes it more wonderful, that he should have been able to find time for so much physiological research, while it explains his familiarity with human anatomy. Even in the latter science-a region one would suppose so harvested as not to leave a straw for the most industrious gleaner-he found something to contribute to human knowledge.

In 1856 , his first year in Bonn, Helmholtz communicated two short papers to the Medical Society of the Lower Rhine, both of an anatomico-physiological character. The first related to the anatomical structure of the thorax. He first showed that the ribs are attached behind to the vertebræ and in front to the sternum, and, during a state of rest, the anterior ends are on a lower plane than the posterior. When the ribs rise during inspiration, the sternal 


\section{HERMANN vON HELMHOLTZ}

attachment moves forwards, and thus the ribs and their cartilages are submitted to torsion. Thus each rib-ring has a kind of elasticity like that of a hoop lying on a plane surface, and is stretched antero-posteriorly until it is slightly oval, and the thorax may be regarded as built up of such a series of rings. Each ring is in a position of stable equilibrium, until it is submitted to the muscular effort of inspiration, and to which it springs back by its elasticity. $\mathrm{He}$ also demonstrated the greater mobility of the upper part of the chest in the female than in the male. Finally, he took the view, that the external intercostals were inspiratory, while the internal had more to do with abdominal breathing.

Somewhat later in the same year, he lectured on the muscles of the arm, and gave the result of observations made both on the cadaver and on the living subject. Most of the actions described are now found in all anatomical books. He described specially the movements of the clavicle and scapula. $\mathrm{He}$ then gave an account of the possible movements of the arm at the shoulder joint, supposing the arm to be extended at an angle of $45^{\circ}$, with the flexor surface directed forwards. $\mathrm{He}$ accurately defined three axes of rotation, one horizontal from before backwards, a second parallel to the length of the upper arm, and a third perpendicular to the two former. As regards the process of supination of the 


\section{HELMHOLTZ IN HEIDELBERG}

forearm-that is, moving it so as to direct the palm upwards, he is of opinion that the real supinator is the biceps, and that the so-called supinator longus is a real flexor. The strongest supination, when the arm is stretched, is brought about by the simultaneous action of both biceps and triceps, and when the arm is flexed, then supination is brought about by the biceps alone. The action of the palmaris longus comes into play when the hand is made hollow, and it appears to protect the flexor tendons from the pressure of the folded skin. Finally, he showed that in the flexed position, the first phalanges can be rotated round their own axis by the interossei muscles, a movement which had not previously been observed.

The movements of the eyeballs were of great interest to Helmholtz, and he solved some of the difficult problems of single vision with two eyes. $\mathrm{He}$ had, as he himself remarked, a gift of seeing things in their geometrical relations, so that he was able to deal with questions of this nature with the greatest ease. In the year 1862 , there appeared the first paper on the form of the horopter, that imaginary field in space, rays from any objects on which must fall on corresponding points of the two retinæ, and consequently give rise to the sensation of a single image. The year 1863 saw two papers on the movements of the human eyes, giving an account of 


\section{HERMANN vON HELMHOLTZ}

numerous ingenious experiments, and containing a mathematical treatment of the subject. In 1864 , he delivered the Croonian Lecture to the Royal Society - a famous lecture-' On the Normal Motions of the Human Eye in relation to Binocular Vision,' and this was followed in the same year by two papers on the horopter. In the following year, 1865, he published a paper on the Influence of the Orientation of the Eyeballs on the Projection of the Retinal Pictures, another on Stereoscopic Vision, and a third on the Movements of the Eyeballs. At the Congrès périodique internationale d'Ophtalmologie à Paris, in I867, he read a paper on Stereoscopic Vision and the Sense of Relief. He returned to the question in I 878, after he became Professor of Natural Philosophy in Berlin, and even so late as $\mathbf{I} 88 \mathrm{I}$, in his sixtieth year, he published a note in the Philosophical Magazine on the same subject.

It is somewhat difficult to give an account of the results of those researches in untechnical language, but it is only fair to Helmholtz to make the attempt. A picture of an external object is formed on the retina of each eye by the lens-like structures placed in front of it, in accordance with the laws of dioptrics. The two pictures, however, give the sensation of one object. Further, we can move the eyeballs so as to direct them to the object we wish to examine. Thus we can move them simultaneously up to the heavens or down to the earth, or to the right side 


\section{HELMHOLTZ IN HEIDELBERG}

or to the left. We can also look straight onwards, as when we gaze at the horizon, in which case the visual axes are parallel; or we can look at a nearer object, converging the visual axes so as to cause them to meet at the object under examination. The effect of these movements is always to bring the images upon corresponding parts of the two retinæ, and if they fall upon these, and not upon others, then there is single vision; but if, from various causes, the images fall on other, or non-corresponding points, there will be double vision-that is to say, we shall see two objects instead of one. The pairs of points that give rise to single vision were termed by Johannes Müller corresponding points, and the assumption was that from any such pair of points similar nerve-fibres passed to the brain, and were possibly there so united as to give rise to the consciousness of a single object.

Further, it has long been known that the retina of each eye is related to both sides of the brain, or, to put it conversely, each side of the brain is related to both eyes. If the optic nerves are traced backwards, they are found to unite in the well-known optic commissure, and from the latter two great bands of fibres, termed the optic tracts, carry the nervous impulses to the brain. The whole of the nerve-fibres from the retina of each eye do not, however, cross or decussate in the commissure in the human mechanism, as was at one time supposed, but they do so in 


\section{HERMANN vON HELMHOLTZ}

many animals, as, for example, in the pigeon. Thus a pigeon, in a sense, sees an object on its right side with its left brain, and vice versâ, and as the eyeballs in the bird are directed to the sides, it probably sees now with one eye, now with the other, and if objects are immediately in front or immediately behind its head, they probably form indistinct images, the bird does not see distinctly, and it therefore rotates its head with a well-known pert-like or quizzical action, so as to bring one eye to bear on the object. In man, however, and in all the higher mammals, the decussation is not complete, and the arrangement is probably most complicated in man himself, so to meet the circumstances of his erect position with eyes in front, looking straight out upon the world. The fibres from the nasal side of each retina cross in the commissure, while those from the temporal sides keep to their corresponding sides. Thus, in the eyes of a reader of this page, the nerves from the temporal side of the right eye keep on the same side in their course to the brain, but those from the nasal side cross over; on the other hand, the nerves from the temporal side of the left eye also keep on the same side, and those from the nasal side cross in the commissure. The right brain is thus related to the temporal side of the right eye and to the nasal side of the left, and the left brain is related to the temporal side of the left brain and to the nasal side of the right. In 


\section{HELMHOLTZ IN HEIDELBERG}

this way the effect is as if the retinæ were brought together, and the one were placed behind the other.

In understanding vision with one eye there is no special difficulty. The globe might rotate round three possible axes, a vertical, a horizontal, and an anteroposterior. Movements are affected by four straight muscles (recti) and two oblique. The four straight muscles (rectus superior, rectus inferior, rectus externus, rectus internus) arise from the back of the orbit, and pass forwards to their insertion in the front part of the eyeball, or its equator, if we regard the anterior and posterior ends of the globe as the poles. The two obliques (while one of them also originates at the back of the orbit) come as it were from the nasal side, the one goes above the eyeball and the other below, and both are inserted into the eyeball on the temporal side, the superior oblique above, and the inferior oblique below. The six muscles work in pairs. Thus the internal and external recti turn the eye round the vertical axis, so that the line of vision is directed to the right or left. The superior and inferior recti turn the eye round the horizontal axis, and thus the line of vision is raised or lowered. The oblique muscles turn the eye round an axis passing through the centre of the eye to the back of the head, so that the superior oblique lowers while the inferior oblique raises the visual line. Helmholtz was the first to discover that the oblique muscles, in certain circumstances, cause a slight rotation of the eyeball round the visual line 


\section{HERMANN vON HELMHOLTZ}

itself. Normally, the superior rectus co-operates with the inferior oblique, and the inferior rectus with the superior oblique.

The two eyeballs are also associated in their movements in the most exquisite manner, an association accomplished by a nervous mechanism which need not here be discussed. Suffice it to say, that when we look, say to the right side, the right external and the left internal recti work together, and when we look towards the left side, then there is harmonious co-operation between the left external and the right internal recti. Again, the two superior recti act together if we look upwards, and the two inferior if we look downwards; if we look downwards pensively to the right side, the inferior recti of each eye, along with the superior oblique on the same side, and the internal rectus on the left side all come into play; while, if we look to the left side, the corresponding muscles for that movement are brought into action; and, finally, if we look upwards and to the right, then the superior recti contract, and are aided by the inferior oblique on the right side, and the internal rectus on the left; while, if we assume the same attitude to the left, the superior recti again act, and are assisted by the inferior oblique on the same side, and the internal rectus on the right. As these muscles are innervated, in many cases, from opposite sides of the brain, it is clear that the cerebral actions must be of a very complicated character. All these movements are under the control of 


\section{HELMHOLTZ IN HEIDELBERG}

the will, at least up to a certain point, but it was reserved to Helmholtz to show that there are other and slighter movements that are altogether involuntary. Thus no one can voluntarily diverge the visual lines; in other words, it is impossible voluntarily to cause simultaneous contraction of both external recti. Nor can we voluntarily rotate the eyeball round the antero-posterior axis, but here, again, slight involuntary movements may be made. We can thus turn the line of vision into every possible direction, but when its direction has been fixed, the position of the eye is also fixed, and is beyond our control.

Helmholtz studied the subject by taking advantage of the method of Donders, which, by an ingenious device, he greatly improved. In this method, the apparent position of after-images produced by exhausting the retina, say, with a red or green object, was compared with that of a line or fixed point gazed at with a new position of the eyeball. The ocular spectra soon vanish in this experiment, but a good observer can determine with great accuracy the coincidence of lines with the ocular spectra. Thus, after producing an after-image with the head in the erect position, the head may be placed into any inclined position, and if the attention is then fixed on vertical lines, it can easily be seen whether the after-image coincides with the lines. As the after-image must remain in the same position on the retina, if it coincides with the vertical lines, it is evident there must 


\section{HERMANN vON HELMHOLTZ}

have been a slight rotation of the eyeball. The coincidence always takes place, and thus it is proved that there is an involuntary rotation. Helmholtz also showed that this minute rotation had the advantage of enabling us to judge more correctly than we would otherwise do of the position of external objects. If the eyeball is thus rotated, the optic image will be slightly displaced, but if its new position is parallel to its former position, there is no apparent motion; but if the rotation is only through infinitely small angles, the eye may move round axes perpendicular to the visual line, and thus the optic images will remain parallel to their first positions. Now Listing had already discovered the law that, in the so-called third positions of the eyeball, it rotates, not round an antero-posterior axis, but round axes perpendicular to the visual line. Helmholtz demonstrated the truth of this law, and, finally, by the calculus of variations, solved the mathematical problem.

He next proceeded to investigate single vision with both eyes. The two fields of view that seem to be superposed are the corresponding or identical points of Johannes Müller. But we see things in relief; this may also be done with Wheatstone's stereoscope, and in neither case can we perceive the duplicity of the images. Helmholtz showed, however, that if we suppose two objects, say two stereoscopic pictures, to have vertical lines or meridians that are not in reality truly vertical, but each set slightly inclined to the right or 


\section{HELMHOLTZ IN HEIDELBERG}

left, and if we look at these through a stereoscope, the 'squinting' lines accurately coincide, thus showing that in double vision it is not the real vertical meridians of the fields of view that coincide, but the apparently vertical meridians. The horizontal meridians always coincide. Thus while the retinal horizon is horizontal for both eyes, the apparently vertical meridians are not perpendicular to it, as had been hitherto supposed, but they diverge at their upper extremity, at an angle of from $2^{\circ} 22^{\prime}$ to $2^{\circ} 33^{\prime}$. Corresponding points are therefore equally distant from each retinal horizon, and from each apparently vertical meridian. This led to the examination of the true geometrical form of the horopter, by which is meant the locus of those points of space which are projected on corresponding retinal points, and he found that it is generally a line of double curvature produced by the intersection of two hyperboloids, that is to say, it is a twisted cubic curve formed by the intersection of two hyperboloids which have a common generator, and in some special cases it is a combination of two plane curves. ${ }^{\mathrm{I}}$ The curves pass through the nodal points of both eyes. An infinite number of lines may be drawn from any point of the horopter so as to be seen single, and these lines lie on a cone of the second order whose vertex is the point. Helmholtz also showed that when we look at the horizon, the

I The mathematical demonstration is given in Heath's Geometrical Optics, p. 233. Cambridge, 1887 . 


\section{HERMANN vON HELMHOLTZ}

horopter is really a horizontal plane passing through our feet, thus warranting the name first given to it by Aguilonius in 1613. The horopter in this case is the ground on which we stand. Experiments show 'that the forms and the distances of these objects which are situated in, or very nearly in, the horopter, are perceived with a greater degree of accuracy than the same forms and distances would be when not situated in the horopter.'

The investigation of this subject led Helmholtz to the invention of the telestereoscope, an instrument containing a combination of prisms, by which two images of distant objects can be seen as if the eyes were widely separated in the head. Consequently, combination takes place, and the objects are seen in relief. Further, Helmholtz, in his later researches, came to the conclusion, that the apparent fusion of two retinal images cannot be explained by any anatomical arrangement, but that it is due to a mental act. Brücke's notion, that the perception of solidity might be due to sensations excited by muscular contractions causing convergence of the visual axes, is negatived by Dove's observation, that the illusion of stereoscopic pictures is also produced when they are illuminated by the electric spark, lasting less than the $\frac{1}{4000}$ th of a second, and in this short time there cannot be the slightest movement of the eyeballs. The study of stereoscopic lustre, also first noticed by Dove, pro180 


\section{HELMHOLTZ IN HEIDELBERG}

duced when one stereoscopic picture is white and the other grey, shows also that the impressions on the two retinæ are not combined, in this case, into one sensation. There is a rivalry of the fields of visions, best seen in the rivalry of colours, when one stereoscopic picture is red and the other blue. A true combination purple is not produced, but there is a peculiar 'sheen,' and the red at one moment has the predominance, and the instant after it is the blue.

The whole of this beautiful research is a good illustration of the method of Helmholtz. Complicated as the movements of the eyeball apparently are, they become simple when we consider that they are just the movements that are necessary to see single objects with two eyes. It was this simple principle that guided Helmholtz. Only those, however, who have read the chapters on the subject in his Physiological Optics can form a conception of the amount of work expended upon it. The bibliography alone is a model of literary research.

In 1869 , he investigated the cause of hay-fever, a troublesome affection to which he was susceptible, and which interfered much with his pleasure during holiday time. He announced the discovery in a letter to Binz, who secured its insertion in Virchow's Archiv für pathologische Anatomie. Helmholtz found in the mucus of the nasal secretions of persons affected by this disease micro-organisms of a vegetable nature, I8 I 


\section{HERMANN VON HELMHOLTZ}

and having observed the researches of Binz on the poisonous action of sulphate of quinine on such organisms, he applied to the mucous membrane of the nostrils a solution of one of the salt in eight hundred of water, with almost instant relief. This therapeutical measure was first carried out in 1867; it was often repeated, and, in 1872 , Helmholtz told Binz that he was quite cured. 'To medical men Helmholtz's descriptions of the disease will be interesting, and possibly it shows that he might have made an excellent clinical observer. ${ }^{\mathrm{I}}$

'An extraordinary violent sneezing then sets in, and a strongly corrosive thin discharge, with which much epithelium is thrown off. This increases, after a few hours, to a painful inflammation of the mucous membrane and of the outside of the nose, and excites fever, with severe headache and great depression, if the patient cannot withdraw himself from the heat and the sunshine. In a cool room, however, these symptoms vanish as quickly as they come on, and there then only remains for a few days a lessened discharge and soreness, as if caused by the loss of epithelium. I remark, by the way, that in all my other years I had very little tendency to catarrh or catching cold, while the hay-fever has never failed, during the twenty-one years of which I have spoken, and has never attacked me earlier or later in the year than the time named.'

I Nature, vol. x., p. 26, May 4, 1874. Letter to Prof. Tyndall from Prof. Binz of Bonn. 


\section{CHAPTER XIV}

HELMHOLTZ IN BERLIN-PHYSICAL RESEARCHES

\section{- ELMHOLTZ occupied the Chair of Physiology 1 in Heidelberg from 1859 to $187 \mathrm{I}$, when he} was placed in the chair of Magnus in Berlin. In Heidelberg he lectured upon physiology only, and he had thus greater leisure to devote to physical and physiological research. During this period of eleven years, he contributed nearly sixty papers, and, of these, twenty-four were on physical questions. Even this statement, however, does not give full expression to his intellectual activity, for the great work on Physiological Optics made its appearance in parts in 1856 , 1860 , and 1867 , and the equally valuable book on Sensations of Tone was published in 1863 , both books full of the results of special research. He also lectured at the Royal Institution of Great Britain on the Conservation of Energy in 1864, and, from time to time, he delivered, and in 1865 and I87 I published, some of those admirable popular lectures that represent the highest class of that form of literature in any language. 


\section{HERMANN vON HELMHOLTZ}

Indeed, it may be said that this was a transitional period in the life of Helmholtz. A born physicist, as he himself often said, he more and more occupied his mind with some of the deepest problems in this department of science. From 1866, when he published a well-known paper on the sounds emitted by a contracting muscle, and 1867 , when the elaborate investigation of the bones of the ear appeared, he published little that was purely physiological, and he devoted himself almost entirely to physics. As he felt that this was his vocation, he left physiological research to a great extent in the hands of pupils, assisting and counselling them in their work, sometimes co-operating in publication, as when, in 1867 and 1870 , he issued the results of a research by himself and his pupil Baxt on the velocity of the nervous impulse in the motor nerves of man.

On the death of Magnus in $187 \mathrm{r}$, it was felt that only one of two men in Germany could take his place as Professor of Physics in the University of Berlin. $\mathrm{Du}$ Bois Reymond, who was then Rector of the University, was empowered by von Müller, the Minister of Education, to go to Heidelberg and persuade Kirchhoff, one of the founders of spectrum analysis, or Helmholtz, to accept the vacant chair. The Government of Baden would not allow Kirchhoff to leave, and so the chair was offered to Helmholtz. This he accepted with some reluctance, for he loved the wooded hills around Heidelberg and the old 184 


\section{HELMHOLTZ IN BERLIN}

romantic town, but no doubt also he yielded to the entreaty of his friend with pride and satisfaction. He had now raised himself to the position of being the first physicist in Germany, and his fame extended throughout the scientific world. The young army surgeon, who astonished his friends twenty-four years before by writing the 'tract' I (as it is modestly called by himself and by Clerk Maxwell), was now, at the age of fifty, in a position where he could give his undivided attention to his first love-physical science -a position, also, specially suited to his inclination and talent.

The years rolled on till 1887 , when another great change took place in the career of Helmholtz. His life-long friend, Werner von Siemens, the electrician and man of affairs, founded a great Physico-Technical Institute at Charlottenburg, near Berlin, and Helmholtz was chosen as its first director. The object of this institute was (I) to deal with costly and difficult scientific investigations not likely to be undertaken in any ordinary physical laboratory, such as those relating to standards of measurement; and (2) to undertake special technical procedures, including the testing of all kinds of thermometers, constructed on the most approved principles, the testing of aneroids, mercurial barometers, the examination of all kinds of instruments for electrical measurements, the examination of photometric instruments, and the

'Die Erhaltung der Kraft; or, The Conservation of Energy. 


\section{HERMANN vON HELMHOLTZ}

establishment of a unit of light; the testing of tuning forks, the construction of universal screws, and, indeed, all methods and instruments having to do with higher technical research and instruction. The Institution had at least one point of contact with the medical profession, as we find that 25,000 clinical thermometers were tested and stamped during the first three years.

Werner von Siemens, whose admiration for the talents of his friend was boundless, wished Helmholtz to be entirely relieved from teaching, so as to leave his energies freedom to work in the higher regions of research, but circumstances made it important that Helmholtz should retain his chair. This he did till the year of his death in 1894 , lecturing during the session twice a week on such special subjects as the mathematical theory of vibrations, electrodynamics, and the mathematical developments of light and sound. In the Institute, with a staff of fifty officials, Helmholtz had now to undertake much administrative work, and he performed this part of his duties with the same zeal and thoroughness that had characterised his whole life. It was certainly work different from that to which he had been accustomed, far removed, for example, from the fascinating study of sense-perceptions, but it was public work to which Helmholtz attached great importance. His mind still soared into the loftiest regions of scientific thought, and some of his most advanced papers on mathematical physics 


\section{HELMHOLTZ IN BERLIN}

appeared during the last ten years of his busy life. Further, he was cheered by the social brightness of a happy home life. In $186 \mathrm{I}$, Helmholtz entered upon a second marriage with Miss Anna von Mohl, of a Würtemberg family of high social position. This lady became the worthy helpmate of so great a man; by her side many of his immortal works were created, and their home was the centre of a brilliant social, artistic, and intellectual circle. Two children were born of this marriage. The elder son, Robert, died in 1889 at a comparatively early age, after he had given promise of having inherited some of the aptitude for mathematical and physical research which so distinguished his father; while the daughter knit together the houses of Siemens and Helmholtz by marrying the son of Werner von Siemens. The loss of his son was deeply felt, and it is said that Helmholtz never recovered from the blow. Thus the brilliancy of his career was dimmed by his experience of sad events that come to all alike.

During the last twenty-three years of his life, Helmholtz devoted his energies entirely to the investigation of physical problems. The only exception to this statement is, that questions of a philosophical nature, which will be dealt with in a future chapter, also engaged his attention. To these questions he was led by the consideration of his theory of knowledge, founded on the thorough examination he had made into the nature of sensation and perception. In 


\section{HERMANN vON HELMHOLTZ}

physical science he occupied himself almost wholly with profound discussions, of a highly mathematical character, into hydrodynamics, or the motions of fluids, whether liquid or aeriform; into the nature of the ether and its relations to electrodynamics and thermodynamics; into some of the phenomena of light; and into principles concerned in the movements of atoms and lying at the root of mechanics. $\mathrm{He}$ also applied his profound knowledge of the more hidden physical movements to an explanation of chemical phenomena, more especially as to the relation of these phenomena to the law of the conservation of energy; and, finally, he passed into the region of the physics of certain meteorological phenomena, such as the nature of clouds. It is remarkable, as showing the vigour of his intellect, that he was creative up to the year of his death. Year after year he ventured higher and higher in the choice of problems on which to exercise his powers, and although he gave the results in his ordinary lectures, the number of pupils, and indeed of physicists, throughout the world, who could follow him, became fewer and fewer.

Helmholtz had transcendent gifts as a mathematician. We have it on the authority of Du Bois Reymond, that not long before he wrote the tract on the conservation of energy, his younger friends were astonished at his mathematical attainments and at the width of his reading of the more famous I 88 


\section{HELMHOLTZ IN BERLIN}

mathematical treatises. Had he chosen pure mathematics as his future field of labour, there is no doubt he would have won distinction here as elsewhere, but he always subordinated mathematics to the investigation of physical questions. He did not revel in the deduction of the purely abstract truth of geometry and algebra, but the abstract propositions and methods of mathematics were to him a means to an end, and he knew that mathematical analysis is only a rigid system of logic in which wrong premises may conduct more surely to a wrong conclusion. He therefore always endeavoured, if possible, to obtain data on which to base his calculations. Yet no one knew better that mathematics will win victories where experiment may be beaten, and that, to use the words of Lovering, 'mathematical analysis, with its multitudinous adaptations, is the only key which will fit the most intricate wards of the lock guarding the treasury of science.' 'Thus, in a review of Vol. I. of Lord Rayleigh's Theory of Sound, ${ }^{\text {I Helmholtz }}$ remarks : 'Without the resources of mathematics, a really complete insight into the casual connection of the phenomena of acoustics is altogether impossible.' Again, he says: 'We see in mathematics the logical activity of our mind in its purest and most perfect form, and while we are conscious of the toil and of the difficulty in forming abstract ideas, we have at the same time confidence in the security, influence,

${ }^{5}$ Nature, vol. xvii., p. 238. 


\section{HERMANN vON HELMHOLTZ}

and fruitfulness of such mental labour.' The same is true of all departments of physics, and especially of those departments that deal with the hidden properties of matter. It need scarcely be said that the pure mathematicians, men always of the first mental calibre, are forging the tools with which the physicists of the future will attempt to solve still more recondite problems than those that at present engage their attention. When the monumental labours of such men as William Rowan Hamilton, Joseph Sylvester, and Arthur Cayley are looked at from this point of view, it will be seen that advanced mathematics does not consist merely of a series of mental gymnastics, but that the subject is of the highest practical importance, because it leads the way to an adequate conception of the phenomena in the physical universe.

' O wretched race of men, to space confined! What honour shall you pay to him whose mind

To that which lies beyond hath penetrated ? The symbols he hath formed shall sound his praise, And lead him on to unimagined ways,

To conquests new in worlds not yet created.' ${ }^{1}$

It may be said, in the words of Helmholtz's greatest pupil, Heinrich Hertz, that the ultimate function of science is to formulate the problems of nature mathematically, and thus bring the logical consequences of thought into harmony with the phenomena happening,

'Lines written by Clerk Maxwell with reference to Cayley. 


\section{HELMHOLTZ IN BERLIN}

or appearing to happen, in the outer world. When this has been accomplished, then all physical problems will be solved. Even now the mind can imagine such a being as arose to the mental vision of Laplace, thus described by Helmholtz himself: 'An intelligence which at any given instant should know all the forces by which nature is urged, and the respective situation of the beings of which nature is composed; if, moreover, such a mind were sufficiently comprehensive to subject these data to calculation, such an intelligence would include in the same formula the movements of the largest bodies of the universe and those of the smallest atoms. Nothing would be uncertain to such an intelligence, and the future no less than the past would be present to his eyes.'

G. H. Wiedemann, ${ }^{\mathrm{t}}$ a contemporary of Helmholtz, aptly points out that he had two methods of looking at things, which he used according to the nature of the problems treated and their state of development. (I) In his earlier works, and in a few of the later ones, Helmholtz starts from general principles of dynamics, or from general differential equations, and attains results without special assumptions as to the structure of matter, or the nature of electricity. Examples of this method are afforded by the tract on the conservation of energy, by his examination

Introduction to Helmholtz's Wissenschaftliche Abhandlungen, vol. iii. Leipzig, 1895 . 


\section{HERMANN VON HELMHOLTZ}

of Weber's statement of electrical action at a distance, and by his papers on hydrodynamics ; (2) later works, such as those on electrolysis and on the more hidden movements implied in his theory of cyclic systems, show Helmholtz taking advantage of molecular hypotheses. In his appreciation of Helmholtz's labours, Wiedemann gives this little personal touch to the picture that seems to bring the man before us: 'Helmholtz did with nature just what he did in looking at a picture or listening to a piece of music. He looked for a scientific foundation and analysed his feelings. The waves of the sea breaking on Cape d'Antibes roused his scientific spirit. From the relative velocity of the wind and the number of waves on the surface of the sea, he drew conclusions as to the arrangement of the clouds, and these were submitted to mathematical investigation. ${ }^{\mathrm{I}}$

An exhaustive account of the physical researches of Helmholtz would far exceed the limits of this work; and indeed it is almost impossible to give the results in untechnical phraseology without running the risk of being much misunderstood, and yet no true notion can be formed of this great Master in Medicine without recognising that it was in physical research, both in the animate and inanimate world, that he truly excelled. In this department the labours of his life may be summed up under six heads: (I) On the Conservation of Energy ; (2) On Hydrodynamics ; (3) On

'Wiedemann, op. cit. xxxi. 


\section{HELMHOLTZ IN BERLIN}

Electrodynamics and Theories of Electricity; (4) On Meteorological Physics ; (5) On Optics ; and (6) On the Principles of Dynamics.

\section{On the Conservation of Energy.}

This has already been dealt with in Chapter V., and it has been shown that Helmholtz played an important part in formulating, from a mathematical standpoint, this great principle. ${ }^{\mathrm{I}}$ In the labours of his after life it was his guiding star. It pointed out the path of research, while it was the final test to which all theories were submitted. The tract not only established the theory from general principles, but it contained illustrations of an electrical character to which reference is still made in all discussions of the subject. ${ }^{2}$ In later researches he verified Lord Kelvin's doctrine of the dissipation of energy that only certain forms of energy can be completely changed into others-a result in accordance with the second law of thermodynamics, which asserts that it is impossible, by the unaided action of natural processes, to transform any part of the heat of a body into mechanical work, except by allowing heat to pass from that body into another at a lower temperature. 3 This is the modern

${ }^{I}$ See Tait's Sketch of Thermo-dynamics, p. 68. Edinburgh, 1877 .

${ }^{2}$ Clerk Maxwell. Electricity and Magnetism, vol. ii., p. 176. Oxford, 1873 .

3 Clerk Maxwell. Theory of Heat, p. 153. London, 1872 . 


\section{HERMANN VON HELMHOLTZ}

basis of Carnot's principle, and was first given in a somewhat less definite form by Clausius, who published his work soon after he had reported to the Physical Society of Berlin on Helmholtz's paper on the Conservation of Energy. Helmholtz, in 1883, also applied the principle to chemical phenomena. ${ }^{\mathrm{I}}$ Starting from the fact that heat never passes from a colder to a warmer body without making the former colder and the latter warmer, and that all the energy which already exists as heat cannot be converted into visible external energy, he drew a great distinction between free and restricted energy. Thus the energy of the chemical changes in a galvanic element cannot, without further chemical changes, become a measure of the electro-motive force; only a small part of the energy appearing as electrical energy. In all chemical changes in which heat appears, all the energy does not appear as heat, but a portion is still locked up in the chemical compounds. Thus the internal energy of a system may be said to be composed of free and restricted energy, of which the former can be changed into work while the second appears as heat. He thus gives us a glimpse into the dynamics of chemical processes, and especially those of dissociation.

\section{On Hydrodynamics.}

Helmholtz published eight important papers on the

I Wissenschaftl. Abhandlungen, Bd. iii., s. 92. 


\section{HELMHOLTZ IN BERLIN}

movements of fluids. It was in $185^{8}$, while he was Professor of Physiology in Bonn, that he published his famous paper on Vortex Motion.'. The paper was adversely criticised by the French mathematician

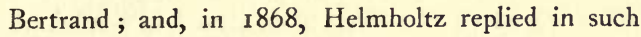
a manner as to silence controversy, in three papers published in the Comptes Rendus de l'Académie des Sciences de Paris. In the same year appeared a valuable paper on the discontinuous motion of fluids; in the following year, one on stationary streams; and, in 1873, an important theoretical paper, in which is developed a theorem with respect to geometrically similar movements of fluid bodies; and their application to the mechanical problem of steering balloons. There are also remarks on the mechanism of flight. Undoubtedly the most important of these contributions to science is that on vortex motion, an investigation that had baffled such great mathematicians as Euler and Lagrange, on account of inherent difficulties. Stokes first pointed out the real distinction between vortex and non-vortex motion; but it was reserved for Helmholtz to discover the fundamental laws which govern vortex motion.

A fluid differs from a solid body in that its particles, within certain limits, can move relatively to one another. Practically, even in the most mobile or least viscous of fluids, relative motion of contiguous

I Wissenschaftl. Abhandlungen, Bd. i., s. 101. 
parts is more or less gradually destroyed by virtue of viscosity or fluid friction. In a viscid fluid there is a great internal friction; and from this extreme case we can pass by gradations to fluids of less viscosity until we arrive at a very mobile fluid like sulphuric ether. This suggests the abstraction of a perfectly frictionless fluid, in which there is no tangential stress between elements sliding past one another. The greater part of the theory of hydrodynamics deals with such an ideal fluid, for the simple reason that our mathematical methods are insufficient to attack the general problem of the motion of a viscous fluid. Although no known fluid is even approximately frictionless, nevertheless the study of the ideal frictionless fluid leads to important results and must ultimately enable us to understand better the effects of fluid friction. In 1858 Helmholtz investigated, mathematically, the laws of vortex motion in a frictionless fluid. In addition to the very remarkable theorems in hydrodynamics, to which Helmholtz was led and on which Lord Kelvin and others have based whole theories of the ultimate constitution of matter, the investigation has another important side. The mathematical formulæ are identical with certain formulæ in electromagnetism, so that, as Helmholtz himself pointed out, there is a striking analogy between the two apparently distinct classes of phenomena, hydrokinetics and electrokinetics. Indeed all mechanical models that aim at explaining the reciprocal relations of electricity and 196 


\section{HELMHOLTZ IN BERLIN}

magnetism require rotating elements; and vorticity of some kind seems to be an essential feature of electromagnetic action.

Wherever in a fluid vortex motion exists, there is rotation of the smallest imaginable particle about some axis. Starting from this conception, which Stokes was the first to describe clearly, Helmholtz proceeds to investigate the forms and behaviour of vortices. A vortex line he defines as a line drawn through the fluid in such a way that its direction at any point is the axis of rotation of the element at that point. A vortex filament is part of the fluid marked off from the surrounding fluid by drawing the corresponding vortex lines through all points of the circumference of an infinitely small plain area. Thus each vortex filament may be imagined to be shut off from the surrounding fluid by a thin layer or mantle of vortex lines. Vortex lines form closed curves in a finite fluid; and vortex filaments form closed filaments or rings, simple or knotted. The simplest type of a vortex ring is a circular anchor ring, every element rotating round the circular axis. Such a vortex ring advances through the fluid in the direction of motion of the elements on the inside of the ring. An ordinary smoke-ring shows the essential nature of the motion very well. If two vortex rings have the same axis and the same sense of rotation, and if they both advance through the fluid in the same direction, the first ring, $a$, will widen, and suffer retardation, 


\section{HERMANN VON HELMHOLTZ}

and the second, $b$, will become narrower, and suffer acceleration, $b$ ultimately overtaking $a$, and, under favourable conditions, passing through it. Then they will separate and again follow each other, but $b$ will widen, and $a$ contract, until $a$ will pass through $b$. Thus the vortex rings will pass alternately through each other. On the other hand, if the coaxial rings have equal radii and equal rotational movements, but in opposite senses, they will approach each other and suffer distension, and this mutual approach and simultaneous spreading out will go on indefinitely until the rings are infinitely close and infinitely wide.

In an incompressible frictionless fluid rotatory movements can neither originate nor disappear; the vorticity, or product of any section of the ring and the speed of rotation, then is an unchangeable quantity. As they move in the surrounding fluid they are always composed of the same particles. Thus the vortex rings have perpetuity. They may jostle against each other and undergo endless changes of form, but they cannot be broken or dissolved. They have the indestructibility which is believed to belong to the ultimate constituents of matter. Lord Kelvin made Helmholtz's investigation the basis of the splendid hypothesis; that the atoms of matter are composed of minute vortex rings in the ether, and he worked out in detail the analogy between such rotational movements and 


\section{HELMHOLTZ IN BERLIN}

electro-magnetic phenomena. Even this idea as to ether being the basis of matter seems to have lurked in the all-embracing mind of Newton, for he says : 'Thus, perhaps, may all things be originated from aether.' ' In later years, Helmholtz accepted Lord Kelvin's idea and contributed remarkable mathematical papers in its support. The element, according to this conception, is neither a solid atom, nor a mass of atoms, but a whirl in a fluid ether. The molecules of a particular element have one invariable and unchangeable mass; when the substance is incandescent, its molecules are vibrating, and emit the same kind of light, being tuned, as it were, to definite pitches. As Lovering said: 'The music of the spheres has left the heavens and condescended to rhythmic molecules. There is no birth or death or variation of species. If other masses than the precise ones which represent the elements have been eliminated, where, asks Clerk Maxwell, have they gone? The spectroscope does not show them in the stars or nebulæ. The hydrogen and sodium of the remotest space is in unison with the hydrogen and sodium or the earth.' 2 Finally, the theory of vortex motions has made it possible to understand in some measure the transmission of magneto-electric effects through an intervening medium, and it has also helped to dispel

I Letter to the Secretary of the Royal Society, Henry Oldenburg, Jan. 1676. (Hist. of Royal Society, by T. Birch, vol. iii., p. 250).

${ }^{2}$ Joseph Lovering. Address to American Association for Advancement of Science. Hartford, Aug. 14, 1874. 


\section{HERMANN vON HELMHOLTZ}

the fiction of action at a distance. Some idea may be formed of the possible variety of forms of vortex atoms by simply looking at the illustrations of Professor 'Tait's remarkable paper upon Knots. ${ }^{\mathrm{x}}$

${ }^{x}$ Scientific Papers, vol. i., p. 273. 


\section{CHAPTER XV}

HELMHOLTZ IN BERLIN-PHYSICAL RESEARCHES CONTINUED

T r868, Helmholtz pressed farther the analogy 1 between the equations of fluid motion and those of electricity and heat in a paper on movements in discontinuous fluids. He also endeavoured to account for certain discrepancies that exist between theory and experiment. He found that such discrepancies are greatest in cases where the current enters a wide space through an opening having sharp edges. In such circumstances, discontinuity of the fluid occurs ; it is, as it were, torn asunder, and a surface of separation is formed with rounded edges; rupture will only occur with increased velocity of the fluid. These investigations have also a practical bearing on the theory of the flow of water through cylindrical pipes, and on the origin of rotational movements. In this memoir, also, he showed the applications of several formulæ to electricity, in which the co-ordinates are expressed as functions of the potential and its conjugate functions. For example, he discussed the case 


\section{HERMANN vON HELMHOLTZ}

of an electrified plate of finite size parallel to an infinite plane surface connected with the earth.

It was important for hydrodynamical theories to determine with exactitude the internal friction of fluids. Two important researches were undertaken. In one, along with G. von Piotrowski, Helmholtz observed the friction that occurs at the borders of the fluid where it touches the surrounding medium. A globe of metal, having a polished and gilded interior, was filled with various fluids and swung round a perpendicular axis, while the delay in the vibrations or movements at the border was observed and measured by means of a mirror reflecting a beam of light into a telescope. This method was similar to that previously employed by Bessel, whose observations and mathematical deductions are fully discussed. In long thin tubes, as was shown by Poiseuille, the upper layer of fluid adheres firmly to the walls of the tube, but this was shown not to be the case with the polished globe when filled with water, though it was true as regarded alcohol and ether. The other research dealing with questions regarding friction was mathematical, and completed the theory of stationary or static streams in fluids.

The theorem as to the geometrically similar movements of fluid bodies, issued in 1873 , made it possible to draw some practical conclusions regarding the steering of balloons, with which the behaviour of a 


\section{HELMHOLTZ IN BERLIN}

ship was compared and contrasted. Helmholtz suggested cigar-shaped balloons. The conditions of flight also arrested his attention. $\mathrm{He}$ was of opinion, on theoretical grounds, that the great condor of the Andes has probably reached that limit of size at which a bird can still soar in the air by the action of the muscles of its wings; and he despaired of man ever being able to lift himself from the ground by muscular action alone, however ingeniously applied.

\section{On Electrodynamics and Theories of Electricity.}

Electrical phenomena of all kinds irresistibly attracted Helmholtz throughout his whole life, and his works show, from the tract on the conservation of energy of 1847 down to a paper on Clerk Maxwell's Theory of the Movements of the Ether, published in 1893, the year before his death, a succession of about thirty communications, mostly all of the first importance. So early as 1851 he measured the duration of induced electrical currents.

For many years the conception of the action of Newton's law of gravitation dominated the minds of physicists, and suggested the notion of 'action at a distance.' That is to say, it was supposed to be possible that one body might act upon another without the existence of any tangible or intangible intervening medium. And yet this was not the opinion of Newton himself, for, in his third letter to Bentley, he wrote :- 'That 


\section{HERMANN VON HELMHOLTZ}

gravity should be innate, inherent, and essential to matter, so that one body may act upon another at a distance, through a vacuum, without the mediation of anything else, by and through which their action and force may be conveyed from one to another, is to me so great an absurdity, that I believe no man, who has in philosophical matters a competent faculty of thinking, can ever fall into it.'

The notion of action at a distance was the first conception of electrical action, and it found expression especially in the well-known law of Wilhelm Weber. $\mathrm{He}$ endeavoured to explain electrical attractions by the assumption of a force acting in straight lines, and following the same laws as the laws of gravitation. This was supported by Coulomb. Suppose two electrified bodies near each other, then the intensity of the force is inversely proportional to the square of the distance between the two quantities of electricity on their respective surfaces and directly proportional to the product of the two quantities. There is also repulsion between like, and attraction between unlike, electrical states. Further, it was supposed that this force was instantaneously propagated through space. Weber differed from Coulomb, in holding that both the velocity at which the electric quantities approached or separated, and also the acceleration of the velocity, had an influence on the amount of force exercised between the two bodies. Other similar hypotheses were in vogue, such as those of F. E. Neumann, 204 


\section{HELMHOLTZ IN BERLIN}

his son, C. Neumann, Riemann, Grassmann, and Clausius. According to Helmholtz, the field of electrodynamics was at this time a pathless desert. ('So war das Gebiet der Elektrodynamik um jene Zeit zu einer unwegsamen Wüste geworden.') ${ }^{\mathrm{x}}$ The theory of electrical action at a distance gave little satisfaction.

Then arose the conception that actions between electrified bodies occupied time and required an intervening medium. The turning-point between the old and the new conceptions was reached in 1837 , when Faraday published his experiments on the specific inductive capacity of substances. Faraday proved that the force of repulsion between two similar quantities of electricity depends not only on the quantities and on their distance apart, but also on the intervening medium. ${ }^{2}$ The English philosopher had a genius for experiment, and he was guided by a marvellous insight into hidden processes. As has been well said by Clerk Maxwell,-' Faraday, in his mind's eye, saw lines of force traversing all space, where the mathematicians saw centres of force attracting at a distance; Faraday saw a medium where they saw nothing but distance; Faraday sought the seat of the phenomena in real actions going on in the medium, they were satisfied that they had

I Introduction by Helmholtz to Die Prinzipien der Mechanik, von Heinrich Hertz, s. xi.

2 An excellent account of electrical units is given by Magnus Maclean in his work on Physical Units. London, 1896. 


\section{HERMANN vON HELMHOLTZ}

found it in a power of action at a distance impressed on the electric fluid.' Lord Kelvin writes, - ' Faraday, without mathematics, divined the result of mathematical investigation; and what has proved of infinite value to the mathematicians themselves, he has given them an articulate language in which to express their results. Indeed, the whole language of the magnetic field and lines of force are Faraday's. It must be said for the mathematicians that they greedily accepted it, and have ever since been most zealous in using it to the best advantage.'

It was one of Helmholtz's mental qualities, that he was never satisfied with an inadequate explanation. $\mathrm{He}$ examined all the theories of electrical action and found them insufficient. His studies were at first of a critical nature, without experimental investigation. He showed that certain consequences of Weber's law were inconsistent with, or even contradicted, the law of the conservation of energy, although, on the other hand, they gave a satisfactory explanation of many of the facts. Helmholtz demonstrated that the law led to the idea of infinite speed, and also implied that the centre of gravity of static electricity was changeable. With Coulomb's statement, that electric forces act through space similar to gravitation, and follow substantially the same law, he was more in accord. He accepted Neumann's notion or law of potential with reservations.

The special work of Helmholtz on electrodynamics 206 


\section{HELMHOLTZ IN BERLIN}

has been thus shortly stated by Professor Rücker : ${ }^{I}$ 'From 1870 onwards, Helmholtz published an important series of papers on the theory of electrodynamics. His point of departure was the discussion of the mutual action of two current elements. An expression for the potential of two such elements had been formulated by F. E. Neumann, which differed from those deduced from the theories of W. Weber and Clerk Maxwell respectively. All three gave identical results in the case of closed circuits. Taking the elder Neumann's formula as the groundwork of his investigations, Helmholtz sought to find the terms which must be added to it, so as to produce the most general expression consistent with the known behaviour of closed circuits. The result was an expression consisting of the sum of two terms, which were multiplied respectively by $\mathbf{I}+k$ and I - $k$, where $k$ is an undetermined constant. The expression is equivalent to that given by Weber when $k=-\mathrm{I}$, to that given by F. E. Neumann when $k=\mathrm{I}$, and is in accord with Maxwell's theory when $k=0$. It was then proved that if $k$ is negative the equilibrium of electricity at best must be unstable, so that motion, when once established, would increase of its own accord, and lead to infinite velocities and densities. The assumption was, in fact, a violation of the law of the conservation of energy

${ }^{1}$ Rücker, Obituary Notice of Helmholtz, Proc. Roy. Soc., vol. lix., No. 355, p. 27. 


\section{HERMANN vON HELMHOLTZ}

in the sense that two electrified particles starting with a finite velocity would, within a finite distance, acquire infinite speed, and therefore infinite energy. ... It remains, however, to discuss the case where $k$ was equal to or greater than zero. The most interesting part of this investigation was the application of the generalised formula to the propagation of electrical and magnetic disturbances through bodies capable of electrical or magnetic polarisation. These properties were treated independently.... Both longitudinal and transversal electric disturbances can be propagated in unmagnetisable dielectrics. The velocity of the transversal undulations in air depends on the absolute susceptibility of the medium. If this is very large the velocity is the same as that of light. The velocity of the longitudinal waves is equal to that of the transversal waves multiplied by the factor $\mathrm{I} / \sqrt{k}$, and by a constant which depends on the magnetic constitution of the air. In conductors the waves are rapidly damped. If the insulator is magnetisable, the magnetic longitudinal oscillations have an infinite velocity, the transversal magnetic oscillations are perpendicular to the transversal electrical oscillations, and are propagated with the same velocity. In the particular cases when $k=0$ the longitudinal waves of electricity have also an infinite velocity, and the theory is then in close accord with that of Maxwell, provided that the absolute specific inductive capacity 208 


\section{HELMHOLTZ IN BERLIN}

of the air is great enough to make the common velocity of the electrical and magnetic transversal undulations equal to that of light.'

Finding the notion of action at a distance inconsistent with dynamic principles and with experiment, he abandoned it and accepted Faraday's principle. Then followed, as the years went by, papers on the origin of electric currents and on their action in circuit, on galvanic polarisation of fluids free from gas, on the electrolysis of water, on galvanic currents due to differences of concentration of fluids, on electric border-plates, on currents on polarised platinum, on the galvanic polarisation of mercury, and on the capillary electrometer. In some of these papers the method followed is less mathematical and more that of experiment and induction; but in all the fundamental principle is the conservation of energy. In the tract on the conservation of energy he had shown long before that if the phenomena of Oersted and Ampère be assumed, that is, if a wire carrying an electric current is impelled across the lines of magnetic force, then the phenomenon discovered by Faraday follows necessarily, namely, a conductor moved across the lines of magnetic force shows an electromotive force whose intensity can be determined by the application of the equation of energy. ${ }^{x}$

Ampère had stated the laws of action between Tait, op. cit., p. 89. 
conductors carrying currents, and he showed that the action of a small closed current at a distance is the same as that of a small magnet placed in the centre of the closed circuit, provided that the axis of the magnet is at right angles to the plane of the closed circuit, and that its magnetic moment is equal to the product of the area of the closed circuit into the current. This subject was extended mathematically by Helmholtz.

Helmholtz introduced a new method of research into electrical questions by bringing in the idea of convection in the distribution of electricity, that is, the conveyance of electricity from one point to another by the movement of the material elements carrying it. It was important to determine whether or not the magnetic effects of an electric current were identical with those produced by the displacement of matter carrying an electrostatic charge. The experimental research on this subject was carried out in Helmholtz's laboratory by the well-known American physicist, H. A. Rowland, and the results were published in I876. Electricai convection currents throw some light on the movement of electricity in unclosed conductors; while in electrolysis the gases dissolved in the fluid may also carry charges of electricity by convection. It was proved that a revolving charged conductor behaves like a ring-shaped electric current.

With another American electrician, E. Root, Helmholtz, also in 1876 , examined the polarisation 


\section{HELMHOLTZ IN BERLIN}

effects of the occlusion of hydrogen on thin plates of palladium and platinum. They found that if a stream of hydrogen is directed to one side of a thin platinum plate by electrolysis, its presence is soon felt on the other side of the plate by the plate becoming more positive, and they showed that what was required by theory was fulfilled by experiment.

In these investigations Helmholtz made many subsidiary discoveries. Lord Kelvin and he independently established the reciprocal property of the electric charge of one conductor on another. Thus the potential of a body $\mathrm{A}$ due to a unit charge on $B$ is equal to the potential of $B$ due to a unit charge on $\mathrm{A}$. He also invented a double galvanometer, which was a modification of that of Gaugain. In the instrument of the latter the magnet was suspended, not at the centre of the coil, but at a point on the axis at a distance from the centre equal to half the radius of the coil. Helmholtz greatly improved the instrument, and made it more trustworthy by placing a second coil, equal to the first, at an equal distance on the other side of the magnet. ${ }^{I}$ $\mathrm{He}$ also constructed an electro-dynamic balance not affected by the magnetism of the earth.

On April 5, 1881, Helmholtz delivered the Faraday lecture to the Chemical Society On the Modern Development of Faraday's Conception of Electricity, in which he gave an interesting estimate of

I Jamin et Bouty, Cours de Physique, t. iv. 2, p. I33. Paris, 1883. 


\section{HERMANN vON HELMHOLTZ}

the great English physicist. ${ }^{\mathrm{I}}$ His words in opening the lecture are so characteristic of Helmholtz himself as to merit quotation: "The facts which he [Faraday] discovered are universally known. Every physicist, at present, is acquainted with the rotation of the plane of polarisation of light by magnetism, with dielectric tension and diamagnetism, and with the measurement of the intensity of galvanic currents by the voltameter, while induced currents act on the telephone, are applied to paralysed muscles, and nourish the electric light. Nevertheless, the fundamental conceptions by which Faraday was led to these much admired discoveries have not received an equal amount of consideration. They were very divergent from the trodden path of scientific theory, and appeared rather startling to his contemporaries. His principal aim was to express in his new conceptions only facts, with the least possible use of hypothetical substances and forces. This was really an advance on general scentific method, destined to purify science from the last remnants of metaphysics. Faraday was not the first, and not the only man, who has worked in this direction, but perhaps nobody else at his time did it so radically. But every reform of fundamental and leading principles introduces new kinds of abstract notions, the sense of which the reader does not catch in the first instance. Under such circumstances, it is often less difficult

I Trans. of the Chemical Society, p. 277. 


\section{HELMHOLTZ IN BERLIN}

for a man of original thought to discover new truth than to discover why other people do not understand and do not follow him. This difficulty must increase in Faraday's case, because he had not gone through the same common course of scientific education as the majority of his readers. Now that the mathematical interpretation of Faraday's conceptions regarding the nature of electric and magnetic forces has been given by Clerk Maxwell, we see how great a degree of exactness and precision was really hidden behind the words, which, to Faraday's contemporaries, appeared either vague or obscure; and it is in the highest degree astonishing to see what a large number of general theorems, the methodical deduction of which requires the highest powers of mathematical analysis, he found by a kind of intuition, with the security of instinct, without the help of a single mathematical formula. I have no intention of blaming his contemporaries, for I confess that many times I have myself sat hopelessly looking upon some paragraph of Faraday's description of lines of Force, or of the galvanic current being an axis of power, etc. A single remarkable discovery may, of course, be the result of a happy accident, and may not indicate the possession of any special gift on the part of the discoverer; but it is against all rules of probability, that the train of thought which has led to such a series of surprising and unexpected discoveries, as were those of Faraday, should be with. 
out a firm, although perhaps hidden, basis of truth. We must also in his case acquiesce in the fact, that the greatest benefactors of mankind usually do not obtain a full reward during their lifetime, and that new ideas need the more time for gaining general assent the more really original they are, and the more power they have to change the broad path of human knowledge.'

The lecture, however, was not merely a panegyric of Faraday. Helmholtz unfolded to the English chemists the theory of electrolysis, in its most modern form, as moulded by the law of the conservation of energy, and the laws of electrolysis discovered by Faraday himself. Electricity can pass from the fluid to the electrodes only under conditions of equivalent chemical decomposition, which is brought about by the electrical forces splitting up the chemical compounds present. Helmholtz proved by calculation that the electric forces are quite sufficient for this work, as shown by the unexpected magnitude of the electrical equivalents that change places during the process.

As already stated, p. 206, Helmholtz found that all the hypotheses of electrical action, such as those of Weber, the Neumanns, Riemann and others, explained certain of the facts. For example, he found that they all accounted for the phenomena of electrical currents in closed circuits, but they did not do so for conductors which end in insulating nonconductors, or what might be called open or 


\section{HELMHOLTZ IN BERLIN}

unclosed conductors. He was also of opinion that Wilhelm Weber's supposition that electrical quantities had inertia, like ponderable bodies, was highly improbable. In 1879, Helmholtz set as a prize research for his students this question of the inertia of electricity, and, in 1880, it was won by Heinrich Hertz, who showed that if it has inertia at all, the latter could only have an influence of the smallest degree conceivable. This was the beginning of the famous work of Hertz, which resulted in the experimental demonstration of Maxwell's magnetoelectric waves, and has led to the invention of wireless telegraphy.

The subject of electrical oscillations was investigated by Helmholtz in 1869 and 1871 . In 1869 he caused his pendulum myograph to close two circuits at short but measurable intervals of time. Oscillations were thus produced in a secondary circuit, the terminals of which were led off to a Leyden jar. The secondary circuit was then broken, and the electrical oscillation was transmitted to the sciatic nerve of a frog-muscle preparation. The number of twitches could thus be recorded. As the time between the completing of the primary and the breaking of the secondary current was increased in successive experiments, alternations in the violence of the twitchings of the muscle were noticed, and in all forty-five minima were observed. ${ }^{\mathrm{I}}$ In $187 \mathrm{I}$, 


\section{HERMANN vON HELMHOLTZ}

Helmholtz, by his pendulum methods, determined the velocity of the propagation of electro-magnetic induction at 314,400 metres per second.

Faraday had shown that the passage of electrical action involved time; but, what was of even greater importance, he also demonstrated that electrical phenomena are brought about by changes in intervening non-conductors, or dielectric substances. The seat of electrical action was to be sought in the tensions and strains that occur in the dielectric medium. Upon this basis Clerk Maxwell founded his theory of electrodynamics. This theory, carried out to its logical conclusion, required that any electric disturbance should be propagated through what had been till then called the 'luminiferous' ether. Suppose a current passing in a metallic conductor in which there is a minute break or gap filled up by a non-conductor, such as air, the current, if sufficiently strong, will pass across the gap as a spark. If this action cause a disturbance in the dielectric, this disturbance should be propagated into space by the ether? An imperfect analogy may help the mind at this point. What occurs at the gap may be like the effect of a stone dropped into still water, when a wave will be started and propagated from the centre of disturbance. Another disturbance will cause another wave, another a third wave, and so on. The shorter the interval of time between successive disturbances the shorter will be the waves. 


\section{HELMHOLTZ IN BERLIN}

Is there anything analogous in magneto-electric action? Fitzgerald was the first to suggest an attempt to measure the length of electric waves; and Helmholtz propounded the question for a prize essay to be awarded by the Berlin Academy.

It was reserved for Hertz, the favourite pupil of Helmholtz, to prove the correctness of Clerk Maxwell's theory, and actually to demonstrate the existence of electro-magnetic waves, or, as they are usually called, the Hertzian Waves. How he was led step by step to this great discovery, overcoming difficulties as they arose, and going into this unknown land in the firm belief that scientific theory would not lead him astray, has been fully described by Hertz himself. ${ }^{\mathrm{I}}$ He showed that waves of electric energy consist of displacements transverse to the direction of transmission, and are governed by the same laws of reflection, refraction, and polarisation as those of light. Their velocity of transmission is the same as that of light, 300,000 kilometres per second ( 186,380 miles per second, in vacuo; Michelson, 1879). As the electric oscillations produced by the Hertzian method are comparatively few in number per second, when the velocity of light is divided by this number, the resultant wave-length is still found to be im-

${ }^{1}$ Hertz. Electric Waves. Trans, by Jones, with preface by Lord Kelvin. London, 1893. See especially the Introduction, p. 1. See also a lecture by Hertz $O$ n the Relations between Light and Electricity, delivered on Sept. 20, 1889, and printed in his Miscellaneous Papers, trans. by Jones, p. 313. London, 1896. 


\section{HERMANN voN HELMHOLTZ}

mensely greater than that of light, varying from decimetres to kilometres, while the waves that fall on the retina, and constitute what we call light, have a wave-length of only from 0.3 to 0.7 thousandths of a millimetre.' Then, by the principle of 'resonance,' (using this word in a special sense), the waves may be detected as minute sparks, or by acting on an arrangement called a coherer. ${ }^{2}$ Hence wireless telegraphy!

Hertz always referred the inspiration to Helmholtz, and W. von Bezold gives his impression of the memorable occasion when Helmholtz reported to the Academy on the researches of his distinguished pupil. 'The impression will never be forgotten by anyone. ... The most intense and purest joy shone in the countenance of the great master, who explained in eloquent words, and with the freshness of youth, the importance and influence of this fundamental work.' This was in 1888. Six years later, on the 1st of January 1894, Hertz died before the completion of his thirty-seventh year. Helmholtz wrote of him these words:- 'The news of the death of this favourite of genius was a severe shock to all who

I Relation between British and metric units of length and mass :I yard $=0.91439179$ metre; I metre $=1{ }^{\circ} 093623$ I I yards $=39^{\circ} 370432$ inches; 1 pound $=0.453593$ kilogramme; 1 kilogramme $=2 \cdot 2046212$ pounds; also, 1 kilometre $=1000$ metres; I millimetre- $\frac{1}{1000}$ th $^{\text {th }}$ metre $=3_{3}^{2} \mathrm{th}^{\mathrm{t}}$ inch.

${ }^{2}$ Kerr. Wircless Telegraphy. London, 1898. Also, Andrew Gray's Treatise on Electricity and Magnetism, vol. i.. London, 1898, chap. xi., for a full description of the Hertzian Vibrator and Receiver. 


\section{HELMHOLTZ IN BERLIN}

recognise the development of the individual, both as regards mental capacity and the victory of the soul over the passions and opposing powers of nature. Endowed with the rarest gifts of mind and character, he has in his short life reaped a harvest in a field in which many of the most talented of his scientific brethren had laboured in vain. In classical times his death would have been regarded as a sacrifice to the envy of the gods. Nature and fate co-operated in his development. In him we found all the qualities required for the solution of the hardest problems in science. . . Heinrich Hertz appeared to be predestined to disclose new vistas into the unpenetrated depths of nature ; but all these hopes were crushed by the insidious disease which slowly and unceasingly crept on until it destroyed the life we esteemed so valuable. I myself deeply felt the loss, as I have always looked on Hertz as the one of all my students who had entered into the innermost circle of my scientific thoughts, and the one in whose ultimate development and success I dared to place my surest hopes.' In a few months the great master followed his pupil to the grave.

Among the last papers written by Helmholtz was one on Clerk Maxwell's theory of the movements in the free ether, in which he discussed profound questions as to whether it were free to move, to what extent and how it was associated with gross matter, and he shows that its incompressibility being assumed, 


\section{HERMANN voN HELMHOLTZ}

all its changes and movements can be deduced from the laws of electrodynamics, and the principle of least action.

\section{On Meteorological Physics.}

Like all brain workers, Helmholtz found it necessary to spend part of the year, mostly during the interval between the summer and winter sessions of academic work, in the country, and he was in the habit of going to the Alps, to the south of France, and occasionally to England. One can readily understand that a mind like his was always receptive, and that the sights and sounds of nature in the magnificent aspect of mountain and valley, in the green woodland and on the rocky coast by the sea, were a source of the purest enjoyment. But the intellect never slumbered. Accordingly, we find that he endeavoured, now and again, to explain natural phenomena, such as the formation of clouds, the mechanical conditions of the whirlpool or whirlwind, and the formation of glaciers. It would be wrong to suppose that this habit of the scientific analysis of one's impressions of natural effects diminishes the æsthetic enjoyment; we should rather conclude that æsthetic enjoyment may be of different kinds. The poet simply opens his mind to nature, receiving all her impressions, he has his imagination fired, and his heart touched by the feelings of beauty, while he 


\section{HELMHOLTZ IN BERLIN}

yearns to give expression to his feelings in adequate form. To him, possibly, an analysis of how these effects are produced might destroy the charm, and might even lead him to give a wrong interpretation of what was before his eyes, as was the case when Goethe attempted to explain colour by an utterly erroneous conception. But the man of science, who has in him a love of nature, and an imagination akin to that of the poet, and often more penetrating, must strive towards the intellectual satisfaction of understanding the methods by which nature works.

In one of his papers on hydrodynamics, Helmholtz refers shortly to the theory of tidal action. The tendency of tidal movements on the surface of a planet is to retard its rotation till at last it turns always the same face to the body that causes the tidal motion. Helmholtz was the first to point out that the reason why satellites generally turn the same face to their primary, is to be found in the tides produced by the primary on the satellite while it was yet in the molten state. $^{\mathrm{I}}$

The movements of glaciers and the formation of ice arrested his attention, and it so happened that at that time the observations of Rendu, Forbes and Tyndall were being discussed. Helmholtz's contributions to the ice theory were published in 1865 and 1866 , while he was in Heidelberg. Faraday had made the familiar observation that two pieces of ice pressed against

s Tait, Thermo-Dynamics, p. 104. 


\section{HERMANN vON HELMHOLTZ}

each other at zero (centigrade) freeze into one block. James Thomson, the brother of Lord Kelvin, had explained this by showing that pressure causes a lowering of the freezing point. James Thomson deduced this fact from the mechanical theory of heat. Lord Kelvin soon after gave the complete theory connecting melting point and pressure, and verified by experiment his brother's calculation that each increase of a pressure of one atmosphere causes a lowering of the freezing point to $\frac{1}{15}$ of a degree cent. A mixture of snow and ice becomes colder as pressure increases, just as theory requires. In Faraday's experiment mentioned above, some free heat becomes latent during pressure, a part of the ice along the side of the block melts and then freezes again, cementing the blocks into one piece. These facts, and also the remarkable phenomenon of the well-known movements of a hard, and, in popular belief, a brittle body, like ice in great glaciers, were originally accounted for by regarding ice as a viscous fluid, a suggestion due to Rendu, a Savoyard priest, and very fully developed by the celebrated natural philosopher, James Forbes. Helmholtz, by a large number of experiments, in which ice was submitted to varying degrees of pressure, succeeded in imitating the formation of glacial ice. Lord Kelvin also showed that cobbler's wax behaved like a viscous fluid. In the course of months or years, it will gradually flow down an inclined plane as a 


\section{HELMHOLTZ IN BERLIN}

glacier flows down a valley, showing the curves and stream lines as in the true glacier. It is a curious sight to watch corks, if left to themselves for a long time on the surface of the wax, ultimately float on it, just as bodies left on the surface of a glacier may by-and-by be found deeply embedded in the apparently brittle substance.

In one of his lectures Helmholtz gives an explanation of waterspouts. He shows that the whirling water forms a vertical tube full of air. Probably his most interesting contribution to meteorological physics is contained in two papers on the movements of the air published in I888 and I889. This was followed by one in 1890 on the Energy of Winds and Waves. ${ }^{\mathrm{I}}$ In these he develops the mathematical theory of the formation of cloud strata. It is said that in one of his Alpine excursions he saw, from the summit of the Rigi, the grand spectacle of a table-land of clouds below him, and the appearance suggested that of waves on the sea seen from the height of a rocky coast. The formation of cloud waves was suggested from the formation of water waves, the fundamental idea being that a plane surface of water over which a wind of uniform velocity is blowing is in a state of unstable equilibrium, and that waves thus originate. Here we have two fluids, air and water, of different densities, gliding over each other. While friction in the upper regions of the air must be very slight, it will

${ }^{2}$ Wissenschaftl. Abhandlungen, Bd. iii., s. 289 ; 8. 309 ; 8. 333. 


\section{HERMANN vON HELMHOLTZ}

be found at surfaces of separation between two layers and along the borders of rotating masses.

Helmholtz drew special attention to the manner in which, according to the kinetic theory of gases, viscosity and interchange of temperature take place across such surfaces of separation. We may suppose that in the upper regions of the atmosphere there are contiguous layers of air of different densities, temperatures and velocities. If no watery vapour condenses at the surfaces across which intermingling takes place nothing will be seen. But should there be condensation of vapour, clouds will be formed; and then, just as wind raises waves on the surface of the ocean, so cloud waves will be formed on the side of the less dense layer. The action will not take place in a quiet steady manner, but by fits and starts, being, indeed, a case of disturbed equilibrium. The effect is well seen in the beautiful wavy appearance of barred cirrhi clouds, in which the shining white bars correspond to the wavetroughs, and the thin translucent bars, through which the light of the blue sky penetrates, to the wave crests. Helmholtz, at Cap d'Antibes, measured the velocity of the wind with an anemometer, and counted the number of waves on a given surface of sea, and thus obtained data on which to base his calculations. He thus found the connection between the strength of the wind and the length of the waves. The water waves were compared as to length with cloud waves. A 


\section{HELMHOLTZ IN BERLIN}

moderate wind blowing over the surface of water will give rise to waves of about a metre in length (a little more than a yard); the same waves, in cloudland, at the border of two layers of air, differing in temperature by $10^{\circ} \mathrm{C}$. will have a length of two to five kilometres (about $2 \frac{1}{3}$ miles). Sea waves may reach a length of five to ten metres (say I2 yards), and as these would correspond to cloud waves of from fifteen to twenty kilometres (say over ro miles), we can grasp the notion that one of these long cloud waves may, at a particular time, cover all the sky above our head. That these views of Helmholtz on cloud formation are correct, has been supported by many observations since made in balloon voyages. It has always been found that in traversing regions in which there are great plains of cirrhi clouds, a sudden change of temperature is noticed in passing from one layer of air into the other.

\section{On Physical Optics.}

A slight sketch has already been given in Chapter VIII. of Helmholtz's researches in physiological optics, and the whole is narrated in full detail in a new edition of his great work, Handbuch der physiologischen Optik, published in 1894, the year of his death. In this work the dioptrics of the eye are fully discussed, with a wealth of illustration and mathematical power that is truly astonishing. The laws of refraction from 


\section{HERMANN vON HELMHOLTZ}

spherical surfaces, the properties of cardinal points, and the theorems of Gauss relative to the refractive powers of centred systems of spherical surfaces,-all matters relating to what may well be called physical optics,- -are discussed, so that, in forming an estimate of all that Helmholtz has accomplished in this department of science, the treatment of these subjects in a work mainly physiological must not be forgotten. Nine papers, however, are enumerated in his collected works as specially belonging to physical optics. Five of these relate to colour, and might well have been included in the list of fifteen works on physiological optics, so that only four remain. One of these, published in 1867 , is a mathematical essay dealing mainly with the action of lenses; two, issued in 1873 and 1874 , deal with the higher optical principles of the compound microscope and the limits of magnification; and the last, which was also issued in 1874, relates to the theory of anomalous dispersion. Finally, in 1892, there appeared a paper, important from a theoretical point of view, in which he applied Clerk Maxwell's electro-magnetic theory of light to explain the dispersion of colour. ${ }^{\mathrm{I}}$

In this connection, and as it is a matter of practical interest, it may be pointed out that Helmholtz was often in the habit of magnifying small movements by reflecting a beam of light from a small mirror

All the papers on light appear in Bd. ii. Wissenschafil. Abhandlungen; that on colour dispersion in Bd. iii., 8. 505 . 


\section{HELMHOLTZ IN BERLIN}

attached to a suitable part of the apparatus that was in motion. But he was not the inventor of this method, as has sometimes been erroneously stated. Poggendorff, in Vol. VII. of his Annalen, issued in 1826 , describes an experiment in which he attached a mirror to a magnetised bar, and from this mirror a beam of light was reflected into a theodolite. This was the first example of making a beam of light act as a weightless pointer, and thus to amplify and indicate movement upon a scale. The method has been of the greatest service to physical science, and is seen to perfection in the arrangements of Lord Kelvin's electrometer and galvanometer.

Newton established that white light consists of innumerable different homogeneous constituents which are dispersed by refraction. This is proved by passing white light through a prism, when a spectrum is produced. The index of refraction becomes greater and greater as we pass through red to orange, orange to yellow, yellow to green, green to blue, blue to indigo, and indigo to violet, the violet rays being often described as the most refrangible of visible rays. It is also known that if certain media are placed in the path of the beam of light, and the light is then passed through a prism, certain parts of the spectrum show dark bands, known as absorption bands. This is well seen when a layer of blood sufficiently diluted is examined with a spectroscope. Two absorption bands may then be detected, one next the Frauenhofer line $D$, 


\section{HERMANN vON HELMHOLTZ}

narrower than the other and blacker, while the broader band is more towards the right, that is, nearer E. The remaining part of the spectrum shows all the colours with beautiful clearness. The analysis of light by means of the spectroscope affords, then, a ready means of examining the phenomena of absorption, an example of which has already been given in treating of Helmholtz's explanation of the fact that the mixture of a yellow with a blue pigment produces green.

The peculiar phenomenon of anomalous dispersion is closely associated with that of absorption. It was first discovered by Fox Talbot about I870.' The experiment of Fox Talbot was as follows:-' I prepared some square pieces of window glass, about an inch square. Taking one of these, I placed upon it a drop of a strong solution of some salt of chromium, which, if I remember rightly, was the double oxalate of chromium and potash, but it may have been that substance more or less modified. By placing a second square of glass on the first, the drop was spread out in a thin film, but it was prevented from becoming too thin by four pellets of wax placed at the corners of the square, which likewise served to hold the two pieces of glass together. The glasses were then laid aside for some hours until crystals were formed in the liquid. These were necessarily thin, since their thick-

${ }^{1}$ Proc. Roy. Soc. Edin., 1870-71. See also Tait on Light, p. 156. Edinburgh, 1884 . 


\section{HELMHOLTZ IN BERLIN}

ness was limited by the interval between the glasses. Of course the central part of each crystal, except the smallest ones, was bounded by parallel planes, but the edges were bevilled at various angles, forming so many little prisms, the smallest of them floating in the liquid. When a distant candle was viewed through these glasses, having the little prisms interposed, a great number of spectra became visible, caused by the inclined edges. Most of these were no doubt very imperfect, but by trying the glass at various points, some very distinct spectra were met with, and these could, with some trouble, be isolated by covering the glass with a card pierced with a pin-hole. It was then seen that each prism (or oblique edge of the crystal) produced two spectra oppositely polarised and widely separated. One of these spectra was normal; there was nothing particular about it. The colours of the other were very anomalous, and, after many experiments, I came to the conclusion that they could only be explained by the supposition that the spectrum, after proceeding for a certain distance, stopped short and returned upon itself.'

The words italicised show that Fox Talbot discovered the real nature of this curious phenomenon. Le Roux, in 1860, had found that vapour of iodine, which allows only red and blue rays to pass, refracts the red more than the blue, the opposite of the effect of a glass prism. An alcoholic solution of fuchsine (an aniline colour) gives a dark absorption 


\section{HERMANN vON HELMHOLTZ}

band in the green, and it was found that the refractive index rises (as in normal bodies) for rays from the red to the yellow. But all the rest of the transmitted light, consisting of the more refrangible rays, is less refracted than the red. From some experiments of De Klecker, published in 1879 , it would appear that 'The addition of fuchsine to alcohol alters the speed of propagation of the (so-called) less refrangible rays, but not perceptibly that of the more refrangible.' ${ }^{\text {I }}$

The phenomenon had been examined by many physicists; but the explanations were unsatisfactory. Helmholtz's first solution was founded on the supposition that in transparent media certain ponderable molecules participate in the vibrations of the ether surrounding them. Mathematical difficulties arise if we suppose that there is discontinuity between the surfaces of these particles and that of the ether everywhere in contact with them, so he further assumes that there is continuity, that is, that there is no abrupt transition. Now, imagine light falling on such an arrangement. Part of the vibrations transmitted by the ponderable molecules is transformed into irregular vibrations, that is to say, into heat. Thus part of the light is absorbed or disappears. The ponderable medium opposes to the movement of the vibrating molecules a resistance like

x Tait, Light, p. 157. See also Jamin et Bouty, Cours de Physique, t. iii., p. 542 . 


\section{HELMHOLTZ IN BERLIN}

that of friction. Each molecule of the ether is thus affected by (I) an elastic reaction of the ether; and (2) a force due to the ponderable medium, which is supposed to be proportional to the relative displacements of a molecule of ether and a molecule of ponderable matter. The ponderable molecule, on the other hand, is acted upon (I) by a force equal to, and in the reverse direction of, the preceding; (2) a force due to the neighbouring ponderable molecules; and (3) a retarding frictional force proportional to the rapidity of displacement. These conditions mathematically expressed lead to the differential equations of motion. When there is no sensible absorption, the formulæ indicate a normal dispersion, but when great absorption takes place, theoretical results are obtained in accordance with those observed in anomalous dispersion. Thus, as expressed by Professor Tait, Helmholtz's explanation 'depends upon an assumption as to the nature of the mutual action between the luminiferous ether and the particles of the absorbing medium, coupled with a farther assumption connecting the absorption itself with a species of friction among the parts of each absorbing particle.' These assumptions were first suggested by Allenmeier, but they were fully applied by Helmholtz.

This explanation was offered in 1874 , but he returned to the subject in 1892 and 1893 , and endeavoured to account for the fact in accordance with Clerk Maxwell's electro-magnetic theory of light, by the 


\section{HERMANN vON HELMHOLTZ}

conception of pairs of oppositely charged particles (ions) of inert matter fixed in the ether. This paper probably contributed more to supporting the electromagnetic theory of light than to an adequate explanation of anomalous dispersion, which is an easily demonstrable fact still incapable of explanation.

It was in 1873 and 1874 that Helmholtz wrote two important papers on the Optical Principles of the Compound Microscope, and determined the limits of amplification. This was accomplished independently of similar and even more elaborate work, both mathematical and experimental-carried out by the greatest living authority on all such questions, Professor Abbe of Jena, to whose researches, especially in connection with the construction on correct principles of apochromatic lenses, science owes so much. Helmholtz, in the first place, established a formula by which we can express the ratio of the linear magnitudes of the object and its image, in terms of the divergence of the rays before and after refraction, which is independent of the distance of the focal lengths of the refracting surface. ${ }^{\mathrm{I}}$ $\mathrm{He}$ showed also how to measure and define the angle of aperture, and finally proved that in consequence of the dispersion of light at the edges of minute bodies, no objects can be seen that are smaller than the $\frac{1}{5000}$ th of a millimetre, that is, the $\frac{1}{125000}$ th of an inch. So far the microscope can go and no farther.

' Heath's Geometrical Optics, p. 56. 


\section{CHAPTER XVI}

HELMHOLTZ IN BERLIN-PHYSICAL RESEARCHES CONTINUED

6. On the Principles of Dynamics.

T $\mathrm{N}$ his later years, Helmholtz was much occupied 1 with the discussion of dynamical questions of the most abstruse nature. To him all physical phenomena were ultimately to be explained on dynamical principles, not merely those evident to the senses, but those in the greater world of molecular action. His mental vision penetrated below the surfaces of things, and to such a mind the mazy dances and whirls of atoms were ruled as rigidly by dynamical laws as were the movements of the planetary bodies. It was also characteristic of his mental capacities that they seemed to increase in power as time went on. In his old age he was not satisfied merely with the contemplation of what he had done, although that of itself must have been a source of supreme satisfaction, nor did he rest merely on his experience of men and things, but he was ever passing into higher regions of thought. Here he was engaged, not in the gathering 


\section{HERMANN vON HELMHOLTZ}

of facts, but in the establishment of great principles, which would be applicable to abstract dynamics, hydrodynamics, thermodynamics, electrodynamics, alike, and by which insight might be obtained into hidden processes. In 1884 we find three elaborate mathematical papers on what he termed monocyclic systems; in I886, a paper on the principle of least action ; in 1887 , another on the same subject ; and in 1892, a third paper on the principle of least action in electrodynamics.

Cyclic systems are those in which there are periodic or circulating motions. This is a somewhat vague description, but it may indicate what is meant. A motion definable by a single co-ordinate, like that of a circular disc spinning round its axis, he termed monocyclic, but he also conceived the more complicated case of a polycyclic system definable by a large number of co-ordinates, satisfying certain assumed conditions. The position of a disc in a monocyclic system depends on the angle which a plane containing the axis imakes with a plane fixed in space; but the energy depends on the angular velocity. The potential energy remains unaltered while the disc revolves. The broad lines of the methods by which such systems may be investigated were first laid down by Thomson (Lord Kelvin) and Tait. Helmholtz narrowed the discussion to certain types of such systems. He assumes for such that neither the kinetic nor the 


\section{HELMHOLTZ IN BERLIN}

potential energy depend on the uncontrollable coordinates themselves (that is, co-ordinates incapable of being affected by the action of any external system), but only on the velocities corresponding to them. Further, he assumes that the velocities corresponding to the controllable co-ordinates are always very small in comparison with the others, and further, that the accelerations of the uncontrollable or cyclic velocities are also small. These assumptions imply that no forces depend on the cyclic co-ordinates. Changes in the cyclic velocities may change the energy of the system, but changes in the cyclic co-ordinates cannot do so. ${ }^{\mathrm{I}}$ Helmholtz also studied the effects of one monocyclic system on a neighbouring one, and of two or more monocyclic systems held together by a common band. The chief interest of these investigations arises from the fact, that thermodynamic phenomena (more especially those related to the second law) show the peculiarities of monocyclic systems. One may also say that the value of the work of Helmholtz in this department is, that his conceptions of monocyclic and polycyclic systems have such general application.

Helmholtz showed that the principle of least action enunciated in 1744 by Maupertuis, and expanded by William Rowan Hamilton, the inventor of quaternions, is even a greater and more comprehensive generalisa-

${ }^{2}$ For a discussion of these difficult matters, see Gray, Treatise on Electricity and Magnet ism, vol. i., chap. 7, p. 180. 


\section{HERMANN vON HELMHOLTZ}

tion than that of the law of the conservation of energy. This law is not of itself sufficient to give a dynamical explanation of the mutual actions or relations of a system. The principle of least action, however, gives a dynamical process from which, with certain assumptions, those relations can be deduced. Maupertuis, who was a contemporary of Voltaire, and one of the brilliant group of men gathered around him by Frederick the Great, saw in his principle an indubitable proof of the existence of God, but he was not able to give it a mathematical form, nor could he have foreseen how important it was destined to become in general dynamics. For a long period it was only a metaphysical conception, even although mathematicians of the first rank endeavoured to express it in the language of dynamics.

The subject has been fully treated, without the aid of formulæ that are bewildering to the uninitiated, by Professor Leo Koenigsberger, in his admirable address on the Researches of Helmholtz in Mathematics and Mechanics, delivered in 1895, the year after the decease of Helmholtz. ${ }^{x}$

Descartes founded analytical geometry, which, by determining the distances of all points by fixed lines, or co-ordinates, reduced spatial relations to their arithmetical expression, and by the use of algebraic

1 Rede zum Geburtsfeste des höchstseligen Grossherzogs Karl Friedrich und zur akademischen Preisvertheilung, am 22 Nov. 1895, von Dr Leo Koenigsberger, Professor der Mathematik. Heidelberg, 1895. 


\section{HELMHOLTZ IN BERLIN}

equations solved geometrical problems, and demonstrated geometrical propositions. Descartes's error in theoretical physics was in conceiving matter as moved only by impulsion and pressure, and not by internal forces; but he recognised that the quantity of matter and motion in the universe remained unchanged. $\mathrm{He}$ also defined the quantity of motion as being equal to the product of mass and speed $(m v)$. The next great name in this arena of thought is Leibnitz, who, about the same time as Newton was engaged on establishing the differential calculus or calculus of fluxions. He argued that it was rather the quantity of vis that remained unchanged in the universe, and he defined this quantity as the product of the mass and the square of the speed $\left(m v^{2}\right)$. The two views led to a schism among thinkers, some supporting Descartes, among those Euler, while others were on the side of Leibnitz. Kant admitted the Leibnitzian view with a limitation. It is, however, wholly a question of definition and of nomenclature. If we mean by a force, a cause proportionate to the quantity of motion of a body, the Cartesian principle applies; but if we mean by force, the power of a body to overcome a continuous and uniform resistance, the formula of Leibnitz holds good, namely, that the work performed by the force is equal to the product of half the mass into the difference of the squares of the speeds at the commencement and at the end of the motion. Both principles were recog- 


\section{HERMANN vON HELMHOLTZ}

nised by Newton; and in the language of the present day $m v$ (mass into speed) is the quantity of motion or momentum, and $m v^{2}$ (mass into square of speed) is twice the kinetic energy.

From a consideration of the principles of the lever, the pulley and the inclined plane, came the definition of work as the product of the quantity of a force into the minute movement of a material point measured in the direction of the force. This led to the establishment of the principle of virtual velocities according to which any material system is in equilibrium only when for every virtual or infinitely small movement compatible with the connections of the points, the work of the entire system is equal to zero. From Galileo's doctrine of inertia, and the enunciation of Newton's three laws of motion, a basis was formed for theoretical dynamics. The more important of these laws in the present connection are the first and second. The first asserts that every body continues in a state of rest or of uniform motion in a straight line, unless compelled to change that state by the action of some external force; in other words, it expresses the principle of inertia. Force may be defined as that which changes or tends to change the state of rest or motion of a body, and force is measured by the change of momentum it produces in a unit of time. In the idea of momentum, the quantity of matter moved (mass) is taken into account as well as the rate at which it travels. This leads to the second law. Rate of $23^{8}$ 


\section{HELMHOLTZ IN BERLIN}

change of momentum is proportional to the impressed force, and takes place in the direction in which the force acts. Then we have the third law, that to every action there is always an equal and opposite reaction.

Greater precision is introduced by adopting the Gaussian notion of unit force. If a unit of force act for a unit of time upon a unit of mass, the velocity of the mass will be changed, and the total acceleration will be unity in the direction of the force. Further, in accordance with Newton's Second Law, the magnitude and direction of this total acceleration will be the same whether the body is originally at rest or in motion. Again, when any number of forces act on a body, the acceleration due to each force is the same in direction and magnitude as if the others had not been in action. ${ }^{x}$

It was about this stage that Huygens, Leibnitz, and the Bernoullis contributed to the discussion, but their arguments were often of a metaphysical character.

Half the product of the mass of a particle into the square of its speed is its kinetic energy. A material system may have any number of such particles, and the sum of the individual kinetic energies will become the kinetic energy of the system. Further, any increase in the kinetic energy of a material system in passing from one configuration

${ }^{1}$ Clerk Maxwell, Matter and Motion, p. 42. London, 1876 . 


\section{HERMANN VON HELMHOLTZ}

into another is equal to the work done on the system by the external forces. If these forces depend upon positions and mutual distances of the particles, the system, after a change from one configuration into another, and a return to its original condition, will suffer no change in kinetic energy. Such a system is described as conservative. When a conservative system, in its change from one configuration into another, does a certain amount of work, then its power of doing work in virtue of its configuration, or, in other words, its potential energy, is greater in the first position than in the second.

In this way we arrive at a statement of the law of the constancy of energy, which asserts that, in the motions of any conservative system, the sum of the potential and of the kinetic energy is unchangeable. This, of course, implies the impossibility of the perpetual motion, or the production of work from nothing, because if it (the perpetual motion) were possible, we might gain work by changing the system one way and then back again by a different route to its original condition. This principle of conservation was long recognised in a limited sense, but it did not seem to apply to all kinds of forces. Thus, if a system moves backwards and forwards on the same track, first without and afterwards with friction, then the friction in the latter case will diminish the velocity, and there will be a loss of 


\section{HELMHOLTZ IN BERLIN}

kinetic energy. Consequently we must extend the conception of energy from that of potential energy, or the energy of position, so as to include the energy of motion, which may appear as heat or other forces. The loss of kinetic energy in the above case will then be equal to the amount of heat produced. This idea led Mayer (see p. 47) to the fundamental conception of the equivalence of heat and mechanical work, and it no doubt also guided Helmholtz in writing his tract, Die Erhaltung der Kraft. The outcome of this discussion is that the work done by any conservative system in changing from one configuration into another, depends on the configurations at the beginning and the end of the process, and not on the intermediate stages. The tract was intended to show the theoretical and practical importance of the law of the constancy of energy, not from a priori considerations, but by induction from facts, and especially from vain attempts to discover or invent the perpetual motion. It does not tell us anything about the mode by which the configuration is changed, or, to put the matter in other words, it does not define the route followed by the system in passing from the first configuration into the last.

The publication of this tract, which has had so great an influence on science, was often referred to in later years by Helmholtz. It was therefore fitting that he should crown the edifice he had reared by the great papers of his later years, in which he re- 


\section{HERMANN voN HELMHOLTZ}

turned, with mature powers and with the enormous experience gained in many fields of physiological and physical research, to the problems of his early youth. As already explained, the notion of action at a distance was gradually but completely abandoned, and its place was taken by that of a medium connecting masses of matter with each other, and transmitting force. But if this new conception is still mechanical, if particles of matter are straining upon the invisible ties that bind them together, if all attractions and repulsions occur in the medium known as the ether, what is the simplest expression of the laws that control these dynamical operations? Can any general principle be established by which, and even without experiment, these dynamical operations can be deductively explained? It was felt by many that, even with the help of Galileo's notion of inertia and Newton's laws, some mechanical conceptions, such as statical equilibrium, or the theory of virtual velocities, were not fully proved; while, on the other hand, many phenomena, molecular, chemical, electrical, magnetical, were hidden from direct observation and immediate experience. The enunciation of the law of the conservation of energy changed the aspect of affairs, and gave a great impulse to the development of theoretical dynamics. The notion of force fell into the background, while mass and energy became recognised as indestructible quantities. Energy was twofold: kinetic energy depended in all 


\section{HELMHOLTZ IN BERLIN}

cases on the speeds of the moving masses; potential energy by the positions of the masses in any system. The discussion of the different modes of energy, and the conditions of the passage of one mode of energy into another, became the subject-matter of physics and chemistry. Helmholtz did not, as had hitherto been done, deduce the general principles of mechanics from equations of motion, but he started from a more general principle, that of least action. The papers on this subject are, according to Hertz, the high-water mark of modern physics.

Action, according to Leibnitz, was the product of the mass, the distance through which it was moved, and the speed. In other words, the product of the vis viva (twice the kinetic energy), and the time. According to this view, when a body passed from one configuration into another, the total amount of the action had a limit value, while the amount of the energy remained unchanged. The element of time came into the statement, so that the position of individual parts of the system at specific times during the whole time occupied by the change of configuration could also be taken into account. Lagrange and Hamilton also introduced the idea, that, while the relative amount of potential and kinetic energy were constantly changing, the amount of this change must also be considered; while Jacobi, assuming that the potential energy is independent of time, gave the kinetic energy a certain 


\section{HERMANN vON HELMHOLTZ}

value, and thus eliminated the increment of time from the action. Hamilton stated the principle of least action in yet another form. ${ }^{\mathrm{X}} \mathrm{He}$ showed that the complete solution of any kinetical problem, as regards the action of any conservative system of forces and constraint depending on the reaction of smooth surfaces or curves, is reducible to the determination of a single quantity, which he called the characteristic function of the motion. This quantity is found from a partial differential equation of the first order and second degree, and from the complete integral of this equation all the circumstances of the motion may be deduced by differentiation. This has been called the method or principle of varying action. ${ }^{2}$

The principle of least action may be thus briefly stated:-Given a conservative system in any configuration, and different paths by which it could be guided to any other definite configuration, under the condition that the sum of its potential and kinetic energies is constant, then the path for which the action is least is the one along which the system would move unguided if the proper initial velocities were given to it. The term action, as applied to a

W. R. Hamilton on a General Method of Dynamics. Phil. Trans. 1834,1835 .

2 Thomson and Tait's Natural Philosophy, vol. i., pt. i., sect. 333 ; also Tait on the Application of Hamilton's Characteristic Function to Special Cases of Constraint. Trans. Roy. Soc. Edin., vol. xxiv., and Scientific Papers, vol. i., p. 54. 


\section{HELMHOLTZ IN BERLIN}

moving system for a short interval of time, is usually defined as the product of double the average kinetic energy during that time, multiplied by the time; or, shortly, it is double the time-integral of the kinetic energy. Discussions based on this definition give the action in terms of the initial and final co-ordinates of the system and the time prescribed for the motion. Again, action may be expressed in another way, as the sum of the products of the average momentum for the spaces through which particles move, multiplied by the length of the spaces. For double the kinetic energy during a short interval of time multiplied by the time, is equal to the average momentum during that time multiplied by the space described. Investigations on the second definition of action give the action in terms of the initial and final co-ordinates of the system, and the constant sum of the potential and kinetic energies. ${ }^{1}$

It is not easy finding simple examples of the application of the principle; nor can it be said that the fundamental dynamic significance of the principle has been made clear. Quantities like velocity, momentum, kinetic energy, potential energy, are what might be called instantaneous properties of a system. Their values are definite at each instant, and can be assigned without reference to what has taken place previously. But the Action of a system at any instant depends on

I Thomson and Tait, Natural Philosophy, vol. i., part i., sec. 326 to 368, pp. 337-439. 


\section{HERMANN vON HELMHOLTZ}

the previous history, reckoning from some chosen instant, as epoch. If we take the simplest case of a particle moving with constant velocity, and therefore with constant kinetic energy in a straight line, the Action is simply the kinetic energy multiplied by the time, and increases at a steady rate. If the particle is guided between two positions by any other than the straight line connecting these positions, it must describe a longer course and, since the speed is constant, take a longer time. In this simplest of all cases the minimum property is obviously fulfilled when the path pursued is the natural path.

As already indicated, the principle of least action, taken in connection with the principle of the constancy of the sum of the potential and kinetic energies, leads to the equations of motion of the system under consideration. But it is only in problems of abstract dynamics that the sum of the potential and kinetic energies is constant. With the recognition of the true nature of heat came the great modern generalisation of the conservation of energy. Heat is a form of molecular and ethereal energy; and dynamically this great doctrine of the conservation of energy is the earlier principle of the constancy of the potential and kinetic energies, if cognisance be taken of the invisible motions of molecules and ether as well as of the visible mass motions.

The idea of Helmholtz was to apply the principle of action to these wider problems. In the general 


\section{HELMHOLTZ IN BERLIN}

dynamical system considered by him, the internal forces are assumed to be conservative, but the external forces depend on the time and work done by them and can be specially calculated.

Helmholtz based his investigations on two functions of the co-ordinates and the velocities, namely, Hamilton's Principal Function, and the total energy. The total energy is the sum of the potential and kinetic energies, while the Principal Function (called by Helmholtz the Kinetic Potential) is the difference of these two quantities. The principle of least action was then defined in these words:-If calculated for equal short intervals of time, the negative mean value of the kinetic potential, while the system passes by its natural path from one configuration to another, is a minimum as compared with its value by all other contiguous paths described in the same time from the initial to the final configuration. For cases of equilibrium, the kinetic potential becomes the potential energy; and the principle just enunciated becomes the well-known condition for stable equilibrium, namely, the potential energy must be a minimum. From the minimum theorem of the kinetic potential, Helmholtz then deduced the principle of the constancy of energy, and applied the principle to important general problems in thermodynamics and electrodynamics. He considered that the truth of the principle went far beyond the dynamics of ponderable masses, and that it was the general law for all reversible 


\section{HERMANN VON HELMHOLTZ}

processes in nature; while, in regard to irreversible processes-as, for example, in the generation and conduction of heat - the irreversibility appeared to depend, not upon the essential nature of things, but upon the limitation of our powers in reducing to order again haphazard motions of molcules, or in reversing the molecular movements associated with the transference of heat.

The outcome of this discussion is to show that in the mechanical operations of nature, there is simplicity and economy. The members of a system, free to move amongst each other, and unaffected by any external system, may have many paths along which they might pass from one position to another, so as to make a change from one configuration to another, but they always travel by the best possible route, and thus bring about the change in a simple way. What the real significance of this is we do not know, and we must eliminate from the conception the notion of choice. It may yet be shown why this must be so. This principle, apparently, has universal application, and it is the guide in many investigations.

In his paper on Maxwell's theory of movements in the free ether, already referred to (p. 219), Helmholtz plunges into questions of an extremely difficult nature, and on which all his powers of mathematical analysis and his capacity of wielding, like an intellectual Titan, the tremendous principles of the conservation of energy and of least action, are brought to bear. Ponderable 


\section{HELMHOLTZ IN BERLIN}

matter is everywhere bathed by ether and is permeated by it. If the ponderable matter and the ether are in close grip one with the other, one may reason from the movements of the former to those of the latter. But if we consider the spaces which are empty of ponderable bodies and filled with ether alone, then the question arises, has the ether any inertia? Again, suppose ponderable bodies move in the ether, can the latter get out of their way, or does it pass through the ponderable bodies like water through a sieve, or does the ether remain at rest or is it partly dragged along by the ponderable bodies? Helmholtz finds, on the assumption that ether is an incompressible frictionless fluid, having no inertia, that the electromagnetic law of Clerk Maxwell, experimentally proved by Hertz, holds good, and explains all the phenomena. He finally draws important conclusions as to the character of the discontinuity at the boundary of ether and ponderable matter, and the manner in which the electrical and magnetic forces originate. This paper was a fitting termination to the labours of Helmholtz in the lofty region of mathematical physics. 


\section{CHAPTER XVII}

THE PHILOSOPHICAL POSITION OF HELMHOLTZ

$\mathrm{O}$ understand the position of Helmholtz, with
regard to the great questions in philosophy, we must take into account the school in which he was trained and the path which he chose for himself in physiological investigation. No physiological principle influenced him so much as that of the specific energy of nerves, taught by Johannes Müller. The statement of this principle is, that in whatever way a terminal organ of sense may be stimulated, the result in consciousness is always of the same kind. Thus the vibrations of the ether that constitute physical light, or pressure, or electrical stimulation, all cause, when applied to the retina or to the optic nerve, sensations of luminosity. The same is true of all the sense organs. It is evident, therefore, that there is no correspondence between the sensation and the physical nature of the stimulus arousing it, seeing that the latter may be varied while the former remains unaltered. This principle was the guide to Helmholtz in all his physiological work on the senses, just as that 


\section{HIS PHILOSOPHICAL POSITION}

of the conservation of energy controlled and directed him in the sphere of physical research. Lotze has finely said, that philosophy is always a piece of life, and that a prolonged philosophical labour is nothing else but the attempt to justify, scientifically, a fundamental view of things which has been adopted in early life. ${ }^{\mathrm{I}}$ This is well illustrated in the case of Helmholtz.

He early adopted a system of empiricism, and was thus, in a modified sense, a follower of John Locke, the English philosopher who denied the existence of innate ideas. Nothing is in the intellect except what came by sensory impressions, and, to begin with, the mind was a tabula rasa, a blank tablet, ready to receive the inscriptions of the outer world. Knowledge was derived from sensuous perception, or sensation, and partly from internal perception or reflection. External objects were appreciated by the senses, while within there was the apprehension of psychical phenomena by a kind of internal sense. All spatial properties had objective reality, but sensible qualities, such as sound, colour, taste, were in the perceiver and not in the objects themselves. Sensations were signs or symbols, not copies of the external things. They are no more like the real thing than words are like the ideas they represent. In the inner world of mind reflection enables us to know the actions of our willing and thinking faculties. From the two

I Philosophy of the Last Forty Years. Contemporary Reviezv, Jan. I880. 


\section{HERMANN VON HELMHOLTZ}

sources of knowledge, the internal and external, we obtain ideas, which may be simple or complex, and ideas always deal with modes, substances or relations. It is clear, therefore, that our knowledge, according to these doctrines, must be mainly gained from experience.

Spinoza, Descartes and Leibnitz, on the other hand, held that the mind, by its own powers, could transcend the limits of experience and reach the truth. The pantheistic monism of Spinoza implied unity of substance, this substance having the fundamental qualities of thought and extension; God, ourselves, and the world were one. A mode of extension (an external object), and the idea of an object are, in the language of Spinoza, the same thing expressed in two different ways. To understand a sensory impression we must have an idea of the affected as well as of the affecting body.

Descartes conceived all external bodies to be extended substances, while the soul is a thinking substance without extension. External bodies are real, because we are conscious of the dependence of sensations on external causes. Soul and body interact, touching at one point, the pineal gland, and thus body and spirit constitute a dualism, but the mode of interaction is incomprehensible. Why did Descartes attach such importance to an obscure little organ, now known to be an abortive eye? Leibnitz introduced his strange system of monads, - a monad 


\section{HIS PHILOSOPHICAL POSITION}

being a simple unextended system, having power of action. Active force is the essence of substance. Monads are like the atoms of Democritus, they are centres of force, a notion not unlike the modern conception of Lord Kelvin, which describes atoms as rotational movements of the ether. But we part company with modern notions when we meet with the assertion of Leibnitz, that the active forces in monads are ideas. The soul is a monad, for it can act on itself, a proof of its substantiality. Every finite monad has a perception of those parts of the universe to which it is related ; to our sensory perceptions, the order of the monads appears as the temporal and spatial order of things, while time is the order of succession of phenomena. There is a pre-established harmony between the movement of the monad and the ideas of the mind, itself a monad. Mind and body work together like two clocks, set together and moving at the same rate.

Much controversy arose between the schools of Locke and Leibnitz, and the battle raged with varying fortunes until Kant threw his influence on the side of the latter. The origin, extent and limits of knowledge were examined in his Critique of the pure reason, by the latter meaning reason independent of experience. He established the twelve categories or original conceptions of the mind,- - unity, plurality, totality,reality, negation, limitation,--substantiality, causality, reciprocal action,-—possibility, necessity, existence,-as 


\section{HERMANN vON HELMHOLTZ}

the forms by which judgments are conditioned. He also made the important distinction between judgments $a$ posteriori and judgments a priori. A judgment a posteriori is founded on experience. On the other hand, a judgment a priori is one having the marks of universality and necessity. Thus the latter judgments are either absolutely independent of experience, or they are relatively independent, in the sense that the conceptions employed are deduced from other conceptions which had been previously derived from experience. $\mathrm{He}$ assumes that the necessity and universality of $a$ priori judgments cannot arise from any combination of experiences. Again, he draws a distinction between analytical and synthetical judgments. If by analysing the conception of the subject we find the predicate, or if the subject and the predicate are identical, the judgment is analytical; but if the conception of the subject does not contain the predicate, so that the latter must be added to it, the judgment is synthetical. Synthetic judgments fall into two classes: those synthetic a posteriori, in which the synthesis of subject and predicate is effected by experience; and those synthetic a priori, if the synthesis occurs apart from all experience. Some a priori judgments are thus synthetic, such as those of mathematics. The fundamental judgments of arithmetic, such as $6=6$, are analytic, but all those of geometry, such as the socalled axioms of Euclid, have the marks of strict universality and necessity, and are synthetic a priori. 


\section{HIS PHILOSOPHICAL POSITION}

He places in the same group even general physical conceptions, such as the indestructibility of matter. Such statements, according to Kant, are true apart from all experience. In like manner the law of causality, our conceptions of time and space, our conceptions of space in three dimensions, are of transcendental origin, we possess them a priori, they are born in us, or, to use the technical word, they are nativistic.

Helmholtz was early brought into collision with this aspect of Kant's philosophy. It seemed to him to imply that some conceptions came from without, or, rather, that they were placed in the mind by an external or supernatural power, an implication that conflicted with the scientific view of the universe. In the tract on the conservation of energy, Helmholtz asserts 'that Science, whose object is to understand nature, must start from the assumption of its intelligibility.' In other words, nature must explain herself, and she must hold all the contents necessary for an explanation of everything. His subsequent physiological studies, more especially those on the senses, led him to different notions as to the way, for example, in which an animal becomes cognisant of the outer world. It does so by the use of its sense organs and by the movements of its limbs. The latter are at first apparently purposeless, but, by a kind of education, they are brought into relation with sensory impressions.

$\mathrm{He}$ appears, however, to have felt the force of the 


\section{HERMANN VON HELMHOLTZ}

objection to the empiristic view of things that some animals, when newly ushered into the world, seem already to possess a large amount of knowledge. He remarks: 'The accuracy of movement of many new-born animals, or of those who have just escaped from the egg, is very striking; the less mentally endowed these are, the sooner do they learn all they can possibly learn. The newly-born human child, on the contrary, is very slow in acquiring visual perception; it takes several days to learn how to judge as to the way in which it has to turn its head to reach the mother's breast. Young animals seem to be more independent of individual experience. But what this instinct is which guides them may be .... those are matters of which as yet we know practically nothing (darüber wissen wir Bestimmtes noch so gut wi nichts).' ${ }^{\prime}$

This matter, however, does not seem so inexplicable in the light of the Darwinian hypothesis, with which Helmholtz often expressed his general agreement. If the origin of an eye or an ear can be so far explained by the Lamarckian principle of the adaptations of an organ to its environment, and if this be supplemented by the law of variation and survival of the fittest, it does not seem difficult to explain the gradual accumulation of experiences through countless generations leading to the forma-

${ }^{x}$ Quoted by Du Bois Reymond. Gedächtnissrede, 8. 39. Berlin, 1896. 


\section{HIS PHILOSOPHICAL POSITION}

tion of what are termed instinctive habits. Thus we may account for the origin of even a priori conceptions. These seem to be so universal, so true when stated, that the element of experience in their formation is overlooked. In this way the mind is not a clean tablet, as supposed by Locke, but it is a tablet already modified by the accumulated experiences of a pedigree. The great difficulty met with in such lines of thought, is the question of why modifications go on in a particular line and apparently with a determinate end? Why are organs modified in a particular direction? why has the physical subtratum of mind been gradually so built up that certain statements, and not others, are recognised as intuitive? The evolution hypothesis, while it may apparently reconcile the empiristic and nativistic views of the origin of certain conceptions, as held by Spencer and Du Bois Reymond, does not explain the whole matter. It is certainly difficult, as stated by $\mathrm{Du}$ Bois Reymond himself, to reconcile with the empirical theory the fact that a butterfly only just escaped from the larval state should, during its short existence as it flits from flower to flower, apparently recognise and know, as if from experience, space in its three dimensions, the resistance of the air, the feeling of falling, and be able to discriminate the colours of flowers. As it could not have gathered experience of these things during its lowly life as a caterpillar on a cabbage leaf, in what stage or stages 


\section{HERMANN vON HELMHOLTZ}

of its ancestral existence did it acquire this experience? We may be able to answer this question when we have full knowledge of the whole evolution of insect life, but at present it is a mystery. It is still more difficult to understand, on the empiristic theory, how the human infant, during the first three months of its life, learns to use its hands and eyes for a definite purpose. Does it begin to acquire knowledge by a series of more or less successful experiments, or is there something even here, acquired by long ancestral experience, that tells the child it need not try to grasp the moon, while it makes a mistake with the gaslight near it and burns its little fingers?

Helmholtz supported the empiristic point of view by questioning the correctness of Kant's ideas as to the nature of space, and the a priori truth of the axioms of geometry. As early as 1852 , while in Königsberg, at the very university in which Kant lectured for many years, Helmholtz published an important lecture on the nature of human sensations. Then he critically examined such questions, in the last section of his work on physiological optics, laying down the fundamental proposition, that sensations are for consciousness only signs, the interpretation of which is given by the intelligence. For vision, these signs give intensity, quality (colour), and, in relation to the part of the retina affected, what he terms the local sign, that is the apparent position.

I Wissenschaftl. Abhandlungen, Bd. ii., s. $59 \mathrm{I}$.

258 


\section{HIS PHILOSOPHICAL POSITION}

Notions of extent and of movement are not derived necessarily from visual perceptions, but from the feeling of movement due to muscular contractions, and even to the degree of innervation felt to be necessary for a particular movement. Other impressions are added to those of the visual organs; thus the eyes or head are moved so as to see the object in different positions; it is touched, etc., and the ensemble of all possible sensations gives rise to the representation of the object to the mind. This is perception, when applied to actual sensations, or it may be a representation due to memory. The psychical act is the association of the signs derived from the organs of sense, or the association of representations.

In 1866, two elaborate papers appeared on the axioms of geometry; a synopsis of these was placed before English readers in $1870 ;{ }^{1}$ there was a popular lecture on the same subject in 1876 ; in the same year, and in 1877 , two papers were published on the origin and meaning of geometrical axioms, ${ }^{2}$ and in 1894, the year of his death, a last paper on the accurate explanation of sensory impressions. 3

There can be no doubt the researches of Helmholtz into the phenomena of single vision with two

The Academy, vol. i., p. 128.

2 Mind, vol. i., p. 301 ; also vol. iii., p. 212.

3 Zeitsch. für Psychologie und Physiologie der Sinnesorgane, Bd. 7, s. 18. 


\section{HERMANN VON HELMHOLTZ}

eyes, the theory of corresponding points, and the mathematical investigation of the geometrical form of the horopter in different circumstances, led Helmholtz to question Kant's doctrine of space. The philosopher of Königsberg taught that space and time are forms of intuition. Space is the form of external sensibility, that is our sense of the relative positions of things in the outer world; while time is in the form of internal and external sensibility jointly, that is our sense of the relative sequences of events. On the a priori nature of space depends the validity of geometrical judgments. On the $a$ priori nature of time arithmetical judgments depend. Things in themselves related neither to space nor to time are unknowable to man. Co-existence and succession are only in phenomena and are only in the perceiving subject. Now Helmholtz found in the study of the horopter, that two different sensations arising from the picture on each retina are blended together in consciousness, that this blending cannot be anatomically explained, and, indeed, has no anatomical foundation, and that it is due to a mental act, which is the result of experience. We cannot separate the part due to the immediate sensation from the part due to experience. There is not a perfect agreement between the external object and the mental representation, except in a mathematical sense. The feeling of localisation in space is not inborn, but is the result of an act of reason 260 


\section{HIS PHILOSOPHICAL POSITION}

or intelligence. It is not necessary to establish a harmony between local visual signs and certain corresponding positions in space, but there is a harmony between the laws of representation and of thinking and those of the outer world.

Among the elementary propositions of geometry there are some that are held not to require proof. There are the axioms, such as, (I) if the shortest line drawn between two points is called straight, there can be only one straight line; (2) through any three points in space, not lying in a straight line, a plane may be drawn, that is, a surface which will include every straight line joining any two of its points; and (3) through a point lying without a straight line only one straight line can be drawn parallel to the first; so that two straight lines that lie in the same plane and never meet, however far they may be produced, are called parallel. Again there are such propositions as that a solid is bounded by a surface, a surface by a line, and a line by a point; that the point is indivisible, that by the movement of a point a line is described, by that of a line a line or a surface, by that of a surface a surface or a solid, and by the movement of a solid a solid and nothing else is described. $\bar{x}$ The question arises, how far results of experience have become mixed up with logical processes? Now, in problems of geometrical construction, these axioms are true in all

${ }^{x}$ Mind, vol. i., p. 302 . 


\section{HERMANN VON HELMHOLTZ}

conceivable circumstances. The Euclidean method of proof is to establish the congruence of lines, angles, plane figures, solids, etc., and this is done by applying the one figure to the other, without changing their form or dimensions. But the method of establishing congruence implies mechanical movements, and by mechanical movements we acquire experience. If so, every proof of congruence rests upon experience.

To illustrate this point of view, Helmholtz imagines beings with perceptions like our own living in worlds differing from our own. The mind can readily conceive beings of two dimensions living on a plane surface, and so confined to it, that they had no power of perceiving anything outside this surface. The geometry of such beings would show that the movement of a point described a line, and that of a line described a surface; but they could not even imagine the form produced by the surface moving out of itself, so as to describe say a sphere or a cone. Living on an infinite plane, their geometry would be like planimetry. Again, we can conceive of intelligent beings living not on a plane but on the surface of a sphere. Their shortest line would then be an arc of the great circle passing through its ends. On a plane there could be only one shortest line between any two points, and in general this is also true of two points on a spherical surface, except when the two points 262 


\section{HIS PHILOSOPHICAL POSITION}

are diametrically opposite one another, in which case an infinite number of shortest lines (i.e., great circles) can be drawn between them. Spheredwellers, as Helmholtz calls them, would know nothing of parallel lines; they would say that two 'straight' (portions of great circles) lines, sufficiently produced, must cut in two points, or form parts of the same 'straight' line. The sum of the angles of a triangle would always be greater than two right angles, increasing as the surface of the triangle became greater. Helmholtz also imagined the geometry of intelligent beings living on the surface of an eggshaped body, or rather we must think of egg-shaped space. They would find it impossible to construct two congruent triangles at different parts of the surface. A triangle constructed near the pole would not be congruent with one at the equator. The periphery of a circle described at the blunt end of the body would be greater than that at the narrower, although the radii were equal, the radii being always measured by shortest lines on the surface. He then discusses the geometry of what is called a pseudospherical surface (a curious surface, of which a strip may be represented by the inner surface-turned towards the axis - of a solid arch or ring, the curves of which are infinitely continued in all directions). Such a surface was first investigated by Beltrami. The straightest lines of the pseudo-sphere may be infinitely produced, but they do not, like those 263 
of a sphere, return on themselves. On such a surface, also, as on a plane, only one shortest line is possible between any two points, but the axiom as to parallels does not hold good. Like the plane and the sphere, it has its measure of curvature constant, so that figures constructed on one part of the surface can be transferred to any other place with perfect congruence of form and perfect equality of all dimensions lying on the surface.

It can also be shown, by a method devised by Riemann, that the space in which we live is threefold, a surface is two-fold, and a line is an aggregate of points. Time is also an aggregate of one dimension. Colour is an aggregate of three dimensions, because each colour may be represented by a mixture of three primary colours, taken in definite proportions, as may be shown by Clerk Maxwell's colour top. But Helmholtz goes still further. He shows that we can depict the appearance of a spheric or of a pseudospheric world, or such a world as we see in a convex mirror. Suppose we looked at things through specially-constructed convex glasses, we would at first be confused, more especially by illusions of comparative size and distance, but, by experience, the space would cease to be strange. It is clear, therefore, according to this argument, that the axioms of geometry do not all hold good in different varieties of space. Taken by themselves out of all connection 


\section{HIS PHILOSOPHICAL POSITION}

with mechanical propositions, they represent no relations of real things. 'When thus isolated, if we regard them with Kant as forms of intuition transcendentally given, they constitute a form into which any empirical content whatever will fit, and which therefore does not in any way limit or determine beforehand the nature of the content. This is true, however, not only of Euclid's axioms, but also of the axioms of spherical and pseudo-spherical geometry. As soon as certain principles of mechanics are conjoined with the axioms of geometry, we find a system of propositions which has real import, and which can be verified or overturned by empirical observation, or from experience it can be inferred. If such a system were to be taken as a transcendental form of intuition and thought, there must be assumed a pre-established harmony between form and reality.' $I$

In our space of three dimensions, we can give up, as it were, what we possess, and be able to imagine a space of two dimensions inhabited by creatures having no thickness, and living between two layers infinitely close together, so that they could move from side to side and backwards and forwards; or a space of one dimension, like a tunnel, in which creatures having no thickness and no breadth could move only backwards and forwards. We cannot, however, go the other way and conceive a space of 


\section{HERMANN vON HELMHOLTZ}

four dimensions, because we have no organs by which such a conception can be formed; but it does not follow that there may not exist space of four dimensions, or, indeed, of any number of dimensions. If anything we saw slipped into the fourth dimensional space it would vanish from our eyes, and we would be quite unable either to follow it or to imagine whither it had gone. The point, however, is, that intelligent creatures living in a two-dimensional or in a one-dimensional space could develop a geometry of their own, in which the axioms would be like our own Euclidean axioms. Further, such intelligent beings living on a spherical or a pseudospherical surface, in which Euclidean axioms do not hold good, might develop a spherical or a pseudospherical geometry. Such non-Euclidean geometries have actually been worked out in some detail by Lobatschewsky of Kasan, and Beltrami of Bologna. Helmholtz, from these mathematical speculations, concludes : (I) that Kant's assumption of the a priori nature of the axioms is not proved; (2) that it is unnecessary ; and (3) that it is useless for the explanation of the real world. Still he takes care not to deny that space may be transcendental, even although the axioms of geometry may not be so, but are ultimately founded on our experience of the state of things in the space in which we live. The axioms then are empirical and are derived, like other laws of nature, from observation and induction. Helmholtz, 


\section{HIS PHILOSOPHICAL POSITION}

however, admitted that the law of causality is transcendental. ${ }^{I}$

In a later paper, written in 1888 , dedicated to Eduard Zeller on the occasion of his jubilee, Helmholtz endeavoured to disprove that the axioms of arithmetic were also a priori truths.

I For a criticism of Helmholtz's papers on the axioms of geometry, the reader is referred to a paper by W. Stanley Jevons in Nature, vol. iv., p. 481, 1871. See also Helmholtz's lecture on The Origin and Significance of Geometrical Axioms. Lectures, 2nd series, p. 27. London, 1881 . 


\section{CHAPTER XVIII}

HELMHOLTZ ON FSTHETICS

CHERE is still one department of human His manifold studies in the physiology of vision and of hearing brought him into relationship with the principles of art, and with that branch of philosophy which we include under the name of æsthetics. He was a lover of art in all its forms, and the contemplation of works of art was one of his favourite recreations. The writings of Kant, Schelling, Hegel, and Schopenhauer on art were familiar to him, and although he did not agree with the metaphysical conceptions on which many of their notions were founded, his writings show that they exercised an important influence on his ideas. On the whole, his notions as to what constitutes the beautiful lean to those of Kant, namely, that the beautiful, through the harmony of its form with the faculty of knowledge, awakens a disinterested, universal, and necessary satisfaction. Art is not merely the pleasure of the senses; it has in view the feeling of pleasure, but it always implies judgment. It must be free from 268 


\section{HELMHOLTZ ON ÆSTHETICS}

the restraint of arbitrary rules, as if it came from nature.

'No doubt,' he says in summing up the results of the volume on Sensations of Tone, ' is now entertained that beauty is subject to laws and rules dependent on the nature of human intelligence. The difficulty consists in the fact that these laws and rules, on whose fulfilment beauty depends, and by which it must be judged, are not consciously present to the mind, either of the artist who creates the work, or the observer who contemplates it. Art works with design, but the work of art ought to have the appearance of being undesigned, and must be judged on that ground. Art creates as imagination pictures, regularly without conscious law, designedly without conscious aim. A work, known and acknowledged as the product of mere intelligence, will never be accepted as a work of art, however perfect be its adaptation to its end. ... And yet we require every work of art to be reasonable, and we show this by subjecting it to a critical examination. . . The more we succeed in revealing the harmony and beauty of all its parts, the richer we find it, and we even regard it as the principal characteristic of a great work of art that deeper thought, reiterated observation, and continued reflection show us more and more clearly the reasonableness of all its individual parts.' I

1 Sensations of Tone, p. 569 . 269 


\section{HERMANN VON HELMHOLTZ}

Helmholtz also recognised the ethical importance of art, or rather, as expressed by Herbart, that ethics constituted a, perhaps the most, important part of æsthetics. Kant also held that the beautiful claims the assent of all as a symbol of the morally good. Helmholtz writes, 'Remembering the poet's words-

Du gleichst dem Geist, den du begreifst, ${ }^{\mathrm{I}}$

we see that those intellectual powers which were at work in the artist are far above our conscious mental action, and that, were it even possible at all, infinite time, meditation, and labour would have been necessary to attain by conscious thought that degree of order, connection, and equilibrium of all parts and all internal relations, which the artist has accomplished under the sole guidance of tact and taste, and which we have in turn to appreciate and comprehend by our own tact and taste, long before we begin a critical analysis of the work. It is clear that all high appreciation of the artist and his work reposes essentially on this feeling. In the first we honour a genius, a spark of divine creative fire, which far transcends the limits of our intelligent and conscious forecast. . . Herein is manifestly the cause of that moral elevation and feeling of ecstatic satisfaction which is called forth by thorough absorption in genuine and lofty works of art. We learn from them

Thou art like the spirit thou conceivest. 


\section{HELMHOLTZ ON ÆSTHETICS}

to feel that even in the obscure depths of a healthy and harmoniously-developed human mind, which are at least for the present inaccessible to analysis by conscious thought, there slumbers a germ of order that is capable of rich intellectual cultivation, and we learn to recognise and admire in the work of art, though executed in unimportant material, the picture of a similar arrangement of the universe, governed by law and reason in all its parts. The contemplation of a real work of art awakens our confidence in the originally healthy nature of the human mind when uncribbed, unharassed, unobscured and unfalsified.' ${ }^{x}$

In a series of lectures delivered in Cologne, Berlin, and Bonn, and summarised in a paper on the relation of optics to painting, ${ }^{2}$ he demonstrates the limitations imposed on truth to nature in artistic representations. He shows how the painter finding that binocular vision shows the flatness of a picture, carefully selects, partly the perspective arrangement of his subject, its position, and its aspect, and partly the lighting and shading, in order to give an intelligible image of its magnitude, shape and distance. He illustrates the condition of securing a truthful representation of aërial light, and how to transform the scale of luminous intensity so as to secure proper shading of colour. He then writes, "The artist cannot transcribe nature; he must translate her; yet this

${ }^{x}$ Sensations of Tone, $\mathrm{p} \cdot \mathbf{5 7}$ r.

${ }^{3}$ Lectures, p. 73. London, 1881 . 


\section{HERMANN VON HELMHOLTZ}

translation may give us an impression in the highest degree distinct and forcible, not merely of the objects themselves, but even of the greatly altered intensities of light under which we view them.... If in these considerations, my having continually laid weight on the lightest, finest, and most accurate sensuous intelligibility of artistic representation, may seem to many of you as a very subordinate point, a point which, if mentioned at all by writers on æsthetics, is treated as quite accessory,-I think this is unjustly so. The sensuous distinctness is by no means a low or subordinate element in the action of works of art ; its importance has forced itself the more strongly upon me the more I have sought to discover the physiological elements in their action.'

This brief statement contains an expression of the main esthetical principles enforced by Helmholtz. The combination of qualities found in him was of the rarest kind, and it was fitting these qualities were brought to bear on such questions. Schelling wrote that science in its highest perfection has the same problem to solve as art, but the method of its solution is different. In science the method may be mechanical, and the possession of genius is not absolutely necessary, but genius alone can solve artistic problems. In Helmholtz we had all that science could teach, and all that genius could inspire. 


\section{CHAPTER XIX}

HELMHOLTZ AS A LECTURER

DURING his whole life Helmholtz was in the habit of giving occasional lectures of a popular character. He did not consider that it was a waste of his time or beyond his province, to lay before an intelligent audience of men and women in the middle ranks of life, the results of his own scientific enquiries. Lectures of this description were not common in Germany, and in this matter of popular exposition Helmholtz was one of the first to attempt the experiment. In a preface to a translation into German of the lectures of Tyndall, Helmholtz alludes to the fact that such lectures had long been given in England, and he defends the practice as being likely to stimulate thought and to awaken an interest in the work of scientific men. There can be no doubt that the so-called popular lectures of Helmholtz reach the high-water mark in this class of literature. Prepared with great care, fitly illustrated by experiment, delivered with dignity, they made a great impression in Germany, and indeed all over the world. The 


\section{HERMANN voN HELMHOLTZ}

fame of Helmholtz has been extended by these lectures, which have brought instruction to the learned and the unlearned alike. In the printed form, and even in the translations, they are literary productions of great completeness. They give one a feeling of thoroughness in the treatment of the subject. The matter is discussed by a master, who brings to bear upon it all his wealth of learning and research, while there is the ever-enduring interest that attaches to an exposition by one who is giving forth from his own treasury. The lectures of Helmholtz are the fruit of his own thought and labour. They do not amuse; they instruct, and they inspire. They are usually on difficult subjects, and they take a wide and comprehensive survey. In the popular exposition of the phenomena of vision, of hearing, of the qualities of musical tone, of colour and the art of painting, Helmholtz stands, in his own field, head and shoulders above all his contemporaries.

The lecture on Goethe, delivered in 1853 , is specially worthy of notice. ${ }^{I}$ It was supplemented by a paper dealing with some aspects of the same subject, read in 1892 to the Generalversammlung der Goethe-Gesellschaft at Weimar. In this lecture he describes and explains the great poet's researches on colour, and shows the mental bias that completely led him astray in his theory of colour. At the same time he extols Goethe's scientific insight as

Iectures, p. 33. London, 1873. 


\section{HELMHOLTZ AS A LECTURER}

shown in his speculations on the morphology of the skull and of the flower. Other great lectures are on sensory perceptions, on the eye and vision, on the relation of the natural sciences to knowledge, and on geometrical axioms.

Worthy of notice also are his speech in memory of his great teacher Magnus, and a rectorial address on the academic freedom of the German universities. In the latter lecture there are several admirable examples of his way of thinking that are well worth quotation :-

I. German Student Life.- 'The German student is the only one who tastes an unmingled joy at the time when, in the first delight of his young independence, yet free from the anxieties of mercenary work, he may consecrate his hours exclusively to all that is noblest and best in science and in the conceptions of humanity. United by a friendly rivalry with numerous comrades devoted to the same efforts, he finds himself daily in intellectual communication with masters from whom he learns what is the movement of thought among independent spirits. I appreciate at its full value this last advantage, when, looking back, I recall my student days and the impression made upon us by a man like Johannes Müller, the physiologist. When one feels himself in contact with a man of the first order, the entire scale of his intellectual conception is modified for life; contact with 


\section{HERMANN vON HELMHOLTZ}

such a man is perhaps the most interesting thing which life may have to offer.'

2. Freedom.- 'There is here for feeble characters a gift as calamitous as it is precious for the strong. . . . But the state and the nation have more to expect from those who are capable of supporting liberty, and whose efforts and work are the results of their own individual energy, of their dominion over themselves, and their love of science.'

3. Professorial Fitness. - 'The doing something for the progress of science is the best mark of a man's fitness to educate.'

4. Use of Lectures.- 'A good exposition demands from the listener much less sustained effort than a bad one; it enables the subject to be comprehended much more surely and much more completely, and with a well-ordered arrangement, bringing into strong relief the principal points and the divisions, much more can be overtaken in the same space of time.'

5. Teachers.- ' $\mathrm{He}$ who wishes to inspire his audience with a complete conviction of the truth of what he advances, ought, above all, to know from personal experience what produces conviction. It is necessary, then, that he should have known how to advance alone into a region where no one has ever broken ground; in other words, he must have worked upon the frontiers of human science and conquered for himself new domains. A master who presents only results acquired by others, suffices for scholars to whom 276 


\section{HELMHOLTZ AS A LECTURER}

authority is given as the source of their science, but not for those who desire to deepen their convictions to their final foundations.'

6. Judgment of Students.- 'All this system rests upon the idea that the general current of the opinion of the students cannot long be at fault. The majority among them come to us with a reason sufficiently formed by logic, with a sufficient habit of intellectual effort, with a judgment so considerably developed by a knowledge of the best models, as to be able to discern the truth from a phraseology which has only the appearance of truth.'

One of the greatest lectures given by Helmholtz is on Thought in Medicine, delivered on 2nd August 1877, on the Anniversary of the Foundation of the Institute for the Education of Army Surgeons. ${ }^{\text {I }}$ It opens with the following sentence: ' $I$ t is now thirty-five years since, on the 2nd of August, I stood on the rostrum in the hall of this institute, before such another audience as this, and read a paper on the operation for Venous Tumours. I was then a pupil of this institution, and was just at the end of my studies.' When he delivered the lecture on Thought in Medicine he was Professor of Mathematical Physics in the University of Berlin, and the foremost man of science in Germany. He adds: 'I rejoice, therefore, that I can once more address an assembly,

${ }^{1}$ Lectures, p. 199. $188 \mathrm{I}$. 


\section{HERMANN vON HELMHOLTZ}

consisting almost exclusively of medical men who have gone through the same school. Medicine was once the intellectual home in which I grew up; and even the emigrant best understands and is best understood by his native land.'

It would be well if every young medical graduate throughout the world were presented with a copy of this lecture on the day of his graduation. 


\section{CHAPTER XX}

HELMHOLTZ IN BERLIN-CLOSING YEARS AND

PERSONAL CHARACTERISTICS

ELMHOLTZ devoted much time and atten-
tion to the affairs of the Technical Institute during the last few years of his life. He was much esteemed and revered by the staff, whose reward was, as one of them said, a kind glance, or a pressure of the hand, or a word of appreciation from the master. His great mental gifts, his splendid record of work accomplished, and a certain nobility of nature impossible to describe, combined with a quiet, unobtrusive manner, brought tokens of regard for Helmholtz as the years passed onwards. The Emperor William I. often received Helmholtz in the domestic circle to discuss with him some of the more recent advances in science, and he was also in close intimacy with the Crown Prince Frederick (afterwards Emperor) and his Princess, both of whom took the deepest interest in everything relating to Art and Science. The Emperor William I. ennobled him, and in doing so conferred distinction not only on Helmholtz, but on the ranks of the peerage. Honours of many kinds flowed in upon 


\section{HERMANN vON HELMHOLTZ}

him from all parts of the world. The celebration of his seventieth birthday became a national event, and a tribute was then paid to his eminence as a man of science and as an inspiring teacher, only equalled a few years ago by the ceremonies at the jubilee of his friend Lord Kelvin. The Emperor William II. sent him an autograph letter in ackowledgment of his great services to science, and conferred special honours upon him. The Kings of Sweden and Italy, the Grand Duke of Baden, and the President of the French Republic, sent him the insignia of various orders. Representatives of academies, universities, and learned societies, sent representatives and addresses. A Helmholtz gold medal was struck in his honour, to be awarded from time to time for distinguished services to science, and was, at a banquet, handed to Helmholtz himself as its first recipient, after a brilliant speech by his life-long friend Du Bois Reymond. At the same time a marble bust by Hildebrand was unveiled. ${ }^{\mathrm{I}}$

At this banquet von Helmholtz delivered a speech, in which he uplifted the veil of his inner life and revealed some of the secret influences that contributed to his marvellous creativeness. His own words, in free translation, are better than any other. Referring to the medal, he said,-

'It is the greatest honour men of science could pay

I On the 6th of June 1899 , a marble statue of von Helmholtz was unveiled by the Emperor William II., in front of the University of Berlin. It has been fittingly placed near those of the brothers von Humboldt. See Daheim, 24th June 1899 , No. 39, p. I. 


\section{HELMHOLTZ IN BERLIN}

to me to connect my name with this medal, which will stamp the progress of science in future times. Science, to modern humanity, proclaims peace. The scientific man does not work for his own welfare, but for that of his nation, and for the whole of humanity, especially for those who are sufficiently educated to enjoy the fruits of science. You desire to associate my name with this medal, and to hold me up to coming generations as an example of an investigator. I waver between a feeling of joy and a feeling of grave responsibility. I have a proud joy that the result of my thoughts is to work on to future generations far beyond my individual life. You will also understand that as a father cares for his offspring, and endeavours to help them, so I have also a love for the children of my thoughts. These contain the best of my convictions; I lay upon them the utmost stress; and I rejoice if the further development of science is to be in their direction. But the doubt may arise, whether my own ideals are not too narrow, and my principles sometimes too imperfect, for the wants of humanity in all time. If so, I hope the awarders of this medal in the future will not confine themselves to what I have accomplished; but I should like to wave on high the one banner on which are inscribed the words, that the purpose of science is to comprehend reality and the play of phenomena as regulated by law.'

On the occasion of his seventieth birthday, his eye 28 I 


\section{HERMANN VON HELMHOLTZ}

was undimmed and his natural force was unabated, and it was hoped that he had yet many years before him to complete his life work by the publication of his lectures. He attended the meeting of the British Association for the Advancement of Science, in Edinburgh, in 1892, and while years were evidently gathering upon him, his noble appearance made a deep impression on all who saw him. In 1893 he visited the International Exhibition in Chicago, and afterwards saw something of the grand scenery of North America and Canada. He then started on the homeward journey. Shortly before the steamer reached Hamburg he had an attack of giddiness, and fell down the stair of the cabin. The injury was severe, causing concussion of the brain and great loss of blood from a scalp wound. He recovered so far, but those about him saw strength failing. Now easily tired, work became more and more difficult. At last the brain that had worked so well gave way, and, in July 1894, he had a stroke of apoplexy. For two months he lingered on, showing, as one would expect from so great a nature, patience and calmness in looking forward to the end. This came on the 8th of September 1894, when he had lived eight days beyond his seventy-third birthday. ${ }^{\mathrm{I}}$

I In the Zeitschrift für Psychologie of March 7 th, Professor David Hansemann, of Berlin, published a report of his examination of the brain of Helmholtz. The circumference of the head was 59 centimetres, that of the skull 55 centimetres. The breadth of the skull was $15^{\circ} 5$, and its length 18.3 centimetres. The cephalic index was 282 


\section{HELMHOLTZ IN BERLIN}

German artists have preserved for all time, in marble and on the canvas, Helmholtz's personal appearance. This appearance was an indication of his own inner strength. Rather above the middle stature, he had a firm, erect frame. His splendid head was well thrown back, so that his posture was always sure to command attention. The shape of the head was perfect, broad between the eyes but not out of proportion. The eyes-

'Such splendid purpose in his eyes'-

were full of intelligence, not so brilliant as deep and reflective. They often had that far-away look so conspicuous in thinkers, as if the soul were away on its own quest. His manner was dignified, almost to coldness, but it was at the same time courteous. It is said that he had occasionally a peculiar look that caused a shallow man to stop asking questions and to feel his own unworthiness. With those who were truly in earnest he would take infinite pains to explain, listen to suggestions, and remove difficulties. Reserve was his habitual attitude. To his favourite students, and in the circle of his own friends, there was always therefore $85^{\circ} 25$, showing a broad head. Helmholtz's head was about equal in size to that of Bismarck, and rather smaller than that of Wagner, both of whom had big heads. On the other hand, Darwin's head was only 56.3 centimetres in circumference. The weight of the brain, with its blood, was 1700 grams., without the blood, 1400 grams., being about 100 grams, heavier than the average human brain. The sulci were very deep and well marked, especially in those parts of the brain which Flechsig has shown to be concerned in associations. The frontal convolutions in particular were deeply cut by very numerous sulci. 


\section{HERMANN vON HELMHOLTZ}

the charm of a great personality. The first time the writer saw him was in 1872 , in the Gewandhaus, in Leipzig, during a performance of Mendelssohn's 'Midsummer Night's Dream.' Near the orchestra he saw a head of such splendid proportions, with the eyes having a rapt expression, as the sensuous music floated through the hall, and he thought 'that must be Helmholtz !' It could be no other. A few days later he saw the great physicist in his own laboratory, and received kindly advice regarding the ophthalmometer and acoustical apparatus.

Helmholtz was fond of mountaineering, and he was an excellent swimmer. Du Bois Reymond says that long walks, to which his father had accustomed him in the beautiful surroundings of Potsdam, had more than a hygienic value for him. Helmholtz himself tells us that it was often during walking that the solution of problems came before his mind.

Volkmann, in his masterly estimate of the work of Helmholtz, remarks that one of his chief merits was to establish a harmony between the vast accumulation of facts that characterised the period comprehending the middle of this century and the more theoretical studies. The necessity for so doing was early felt by Helmholtz himself, for in 1874 we find him saying,'It seems to me that it is not so much knowledge of the results of natural science which the wisest and best educated men seek, as an aspect of the mental activity of the investigator, a view of his scientific 284 


\section{HELMHOLTZ IN BERLIN}

system, and a statement of the goal towards which he strives. They wish to know what his work has done for the great problems of human life.'

Helmholtz indicates his position in the words he uses regarding his pupil Hertz. 'He takes his place among those who see the advancement of humanity in the greatest possible development of their spiritual talents and in the sovereignty of the spirit over the natural passions and the hostile powers of nature. To bring about this there must be a severe mental discipline. Thought, the will, and the power of action must be brought into subjection.' Helmholtz himself submitted to a life-long discipline. He says : - I have never considered a research complete until it stood before me perfect and without logical defects. It was always formulated in writing. My conscience stood before my mind and the wisest of my friends, and I asked myself if they approved of my work. They were the embodiment of the scientific spirit of an ideal humanity and gave me my measure.

'I do not mean to say that in the first half of my life, when I had still to work for my outward position, that higher ethical motives than those of the desire of knowledge, and a feeling of doing my duty as an officer of the state, influenced my life, at all events it was not easy to be sure of their existence while egoistic motives compelled me to work. Most investigators feel this. But later on, when one's position had been secured, at a time when some who, 


\section{HERMANN VON HELMHOLTZ}

having no inner propelling power towards science, cease to work, a higher aspect of one's relation to humanity came into the foreground. The thoughts that have found their way into literature, or into the minds of men by the teaching of pupils, continue to have an independent life ; these thoughts have further developments, and inspire teaching on newer lines. One's own thoughts are of course more in one's spiritual circle of vision than strange ones, and one feels satisfaction when he sees his own bearing fruit. Then a paternal feeling springs up in the mind of the thinker, and he cares and fights for the advancement of his offspring. Still, the whole world of civilised humanity is before him, the duration of whose life seems to be eternal in comparison with the short life of an individual. The investigator then sees himself, with his small contributions to the building up of science, in the service of an eternal sacred cause, to which he is bound by the closest bonds of affection. By this thought his own work is hallowed. To feel the full force of this, one must have had the experience.' Helmholtz, in a speech delivered at the banquet, tells us something of his mode of working. When a problem came before his mind he turned it round on all sides. He reflected upon it for several days, carefully thinking out the details of any experimental procedures that might be necessary. In the solution of more difficult questions, the light seldom came when he was at his desk, and never when the brain was fatigued. It was 


\section{HELMHOLTZ IN BERLIN}

usually in the morning, after the wearied brain had been refreshed by sleep, or while walking up a hillside, with pure air and bright sunny weather, that the truth flashed before his mental vision. Even the smallest amount of alcohol he found interfered with his mental work. He then reduced his views to writing, and took great pains in giving correct expression to what he wished to communicate. In literary composition he was extremely fastidious, often writing the manuscript six times over, and next day, even after this severe ordeal, he was never satisfied with what he had written.

It is not necessary to define the position of Helmholtz amongst scientific thinkers. His works bear their own evidence. There is a general consensus of opinion that he is one of the greatest men of the present century. To find one like him in mental power and width of range, we must go back to such intellectual giants as Descartes and Leibnitz, and even when he is compared with them, it must not be forgotten how enormously broader was the field of science in the time of Helmholtz than in the seventeenth century. The only English philosopher with whom he may be compared is Thomas Young. Both were remarkable for versatility and originality; both had the same wide range of knowledge; both were manifold men of science; both were physiologists and physicists; the researches of both were fundamental. But Helmholtz was, as a mathema- 


\section{HERMANN vON HELMHOLTZ}

tician of the first rank, even greater than Young. It will be admitted that, taking him all in all, Helmholtz is the greatest Master of Medicine the world has ever seen.

Of Helmholtz's opinions on religious questions, nothing can be stated with any degree of precision. Such topics were not with him subjects of conversation. But throughout his writings there breathes a spirit of reverence, while his noble and pure life is the highest testimony to his true worth. For such a man a time surely comes when

'That in us which thinks and that which feels Shall everlastingly be reconciled, And that which questioneth with that which kneels.' 


\section{HERMANN voN HELMHOLTZ}

Strong soul, whose calm and almost God-like mien, Eyes of unfathomable depth of thought, And broad and lofty intellectual brow, Betoken force and insight : Shall I try To tread the path you followed in the quest Of Nature's truth ? To live in your great thoughts Is like to breathing a pure atmosphere On lofty mountain peak, in azure blue, While all around are pure white fields of snow, And all below is veiled in cloud and mist. And when I find atomic mazy dance, The swift-winged lightning, colour's sun-born hues, The tones of music and harmonious chords, Fine movements and the throb of nervous thrills That course so swiftly through this mortal frame, The hidden work of wond'rous ear and eye, Are all made clear and plain; then comes the thought That $\mathrm{He}$ Who made all these did also send To this dull earth His own interpreter, A great and gifted intellect like thine, A child of genius, armed at every point For all the glorious work that thou hast done, Revealing Nature's plans; and thou hast shown Man's soul is tuned to Nature, and reflects All things, as does the surface of a lake Reflect the glories of the earth and sky. 



\section{B I B L I O G R A PH Y}

1. Hermann von Helmholtz. Ein Nachruf von Dr J. Pernet, Professor der Physik am Eidgenössischen Polytechnicum. Neujahrsblatt der naturforschenden Gesellschaft, in Zurich, 1895. Zürich, 1894 .

2. Hermann von Helmholtz. Gedächtnissrede gehalten in der Singakademie zu Berlin am I4 Dezember I894, von Wilhelm von Bezold, mit einem Porträt nach einem Olgemälde von Franz von Lenbach. Leipzig, 1895 .

3. H. de Helmholtz. Esquisse biographique par le Dr E. Landolt. Archives d'Ophtalmologie, Décembre, 1894 .

4. Gedächtnissrede auf Hermann von Helmholtz, gehalten am 28 September 1894 in der Aula der Universität Utrecht. Von Th. W. Engelmann. Leipzig, I 894 .

5. Hermann von Helmholtz. Gedächtnissrede von Emil du Bois Reymond. Leipzig, I 897.

6. Hermann von Helmholtz. A Biography in Commemoration of his 70 th Birthday, by Dr Hugo Kronecker, Professor of Physiology in the University of Berne. Translated from the German by Dr Arthur Gamgee; F.R.S., Emeritus Professor of Physiology in the Owens College, Victoria University, Manchester. Reprinted from The Electrician, August 2 Ist and 28th, I89I. London, I 891 . 


\section{HERMANN vON HELMHOLTZ}

7. Hermann von Helmholtz's Untersuchungen über die Grundlagen der Mathematik und Mechanik. Rede zum Geburtsfeste des höchstseligen Grossherzogs Karl Friedrich und zur akademischen Preisvertheilung am 22 November 1895, von Dr Leo Koenigsberger, Grössherzoglich Badischen Geheim-Rath und v. ö. Professor am Mathematik, d. z. Prorektor der Grossh. Bad. Universität Heidelberg. Heidelberg, 1895.

8. Ansprachen und Reden gehalten bei der am 2 November I891 zu ehren von Hermann von Helmholtz veranstalteten Feier, nebst einem Verzeichnisse der überreichten Diplome und Ernennungen sowie der Adressen und Glückwunschschreiben. Berlin, I892.

9. Hermann v. Helmholtz. Gedenkrede gehalten vor den v. Deutschen Mechanike lage zu Leipzig am 21 September 1894, von Dr Hugo Krüss. Vereinsblatt der Deutschen Gesellschaft für Mechanik und Optik, I Oktober 1894. No. 19. S. 146.

10. Hermann von Helmholtz, von Hermann Munk. Sonderabdruck aus der Berliner klinischer Wochenschrift, 1894 . No. 38 .

II. Hermann v. Helmholtz, von J. Hirschberg. Deutsche medicinische Wochenschrift, 20 September 1894. S. 733 .

12. Hermann von Helmholtz, von J. v. Kries, Professor der Physiologie zu Freiburg, i. B. Deutsche medicinische Wochenschrift. 27 August 1891. S. 1025.

13. Hermann von Helmholtz. Reden gehalten bei der von der physikalisch ökonomischen Gesellschaft zu Königsberg in Pr. Veranstalteten Gedächtnissfeier am 7 Dezember 1894, von Dr L. Hermann, ord. Professor der Physiologie, Geh. 


\section{BIBLIOGRAPHY}

Medicinalrath z. Z., Präsident der Gesellschaft, und Dr P. Volkmann, ord. Professor der Theoretischen Physik. Königsberg, I 894 .

14. Obituary Notice of Hermann von Helmholtz, by Professor A. W. Rücker. Proceedings of the Royal Society, vol. lix., No. 355 , p. 17.

I 5. Notice of Hermann von Helmholtz, by Lord Kelvin in his Presidential Address at the Anniversary Meeting of the Royal Society, Nov. 30, I894. Proceedings of the Royal Society, vol. Ivii., No. 340, p. 38 .

16. Ueber die Erhaltung der Kraft, eine physicalische Abhandlung. Berlin, 1847 .

17. Die Lehre von den Tonempfindungen physiologische Grundlage für die Theorie der Musik. Braunschweig, I 863-1 870.

18. Théorie physiologique de la musique fondée sur l'étude des sensations auditives. Traduit de l'Allemand par M. G. Guéroult. Paris, I868I 874 .

19. Sensations of Tone as a Physiological Basis for the Theory of Music. Translated by A. J. Ellis. London, I 875 .

20. Handbuch der physiologische Optik. Leipzig, 1867.

21. Optique physiologique. Traduit par Emile Javal et N. Th. Klein. Paris, 1867.

22. Popular Lectures on Scientific Subjects. Translated E. Atkinson. London, 1873. Second series, I 88 r.

23. Das Denken in der Medicin. Berlin, 1878 .

24. Wissenschaftliche Abhandlungen. 3 Bände. Leipzig, I $882-1895$. 


\section{HERMANN VON HELMHOLTZ}

25. Populäre Wissenschaftliche Vorträge. Braunschweig, $1865-1876$.

26. Handbuch der physiologischen Optik. Zweite ungearbeitete Auflage. Hamburg und Leipzig, 1896.

27. Die Mechanik der Gehörknöchelchen und des Trommelfels. Bonn, 1869 .

28. Titelverzeichniss sämmtlicher Veröffentlichungen von Hermann von Helmholtz. Leipzig, 1895 .

29. Heinrich Hertz. Gesammelte Werke. 3 Bände. Mit einem Vorwort von Hermann von Helmholtz. Leipzig, $18 \dot{9} 4-5$.

30. Hertz. Electric Waves, with preface by Lord Kelvin. London, 1893.

3I. Vorlesungen über theoretische Physik von $H$, von Helmholtz, herausgegeben von Arthur König, Otto Krigar-Menzel, Franz Richarz, Carl Runge. Band i.-vi. Leipzig. 


\section{N DEX}

Accommodation, mechanism of, 7, 92, 94.

Action, at a distance, 203 .

Action, definition of dynamical, 245.

Action, principle of least, 235, 240,243 .

Asthetics, Helmholtz on, 268.

Aguilonius, reference to, $x 80$.

After images, 177 .

Air, micro-organisms in, 29.

Airy, reference to, 9 I, II8.

Ampère, 210.

Andrews, Thomas, reference to, 91 .

Apparatus, electrical, for physiology, 36.

Arm, muscles of, Helmboltz on, 170 .

Art, ethical importance of, 270 ; nature of, 269 .

Axioms of geometry, Kant's opinions as to, 258 .

BABBAGE, Charles, use of silvered mirror by, 77 .

Bach, reference to, 167 .

Bacon, on heat, 46 .

Baconian philosophy in Germany, 12.

Baden, government of, 184 .

Baden, Grand Duke of, reference to, 280.

Balloons, steering of, and theory of, 203.

Beats, nature of, $156,158$.

Beethoven, reference to, 134 .

Behr, reference to, 77.

Bell, John and Charles, reference to, I52.

Beltrami, reference to, 266.

Bentley, reference to, 203 .

Perlin, Physical Society of, 24.

Berlin, University of, $183,239$.

Bernard, Claude, reference to, 14.

Bernoulli, Daniel, reference to, 40.

Bertrand, reference to, 195.

Bessel, reference to, 70, 202.

Bezold W. von, reference to, 218 .

Bibliography, $29 x$.

Binz, reference to, 182 .

Bismarck, head of, 283 .

Bones of the ear, $133,135$.
Bonn, Helmholtz on, 88.

Bonn, University of, 129.

Bowman, physiologist, reference to, 14.

Boyle, Robert, reference to, 116 .

Branco, Professor, reference to, 58.

Brewster, Sir David, reference to, $9 x$, 112 , 118 , 119.

British Association, Edinburgh meeting $1892,282$.

British Association meeting at Hull $1854,9 x$.

Brücke, early friendship with Helmholtz, 10, 11, 13, 24, 25, 74, 77, 111 .

Brücke, on ciliary muscle, ror.

Butterfly, life of a, considered empirically, 257.

Cagniard de la Tour, reference to, 26.

Cape d'Antibes, 192.

Carnot, Sadi, reference to, 50, 194 .

Carpenter, reference to, 14 .

Cayley, Arthur, reference to, 190 .

Chicago, International Exhibition at, 282.

Chladni, plates of, 20.

Ciliary muscle, I01, 102.

Clang tint, 143 .

Clapeyron, on heat, 50 .

Clausius, physicist, 10, 23, 43, 194, 205.

Clouds, Helmholtz on, 223 .

Coccius, ophthalmoscope of, 77 .

Cochlea, action of, 140, 141, 152.

Coil, induction, of Du Bois Reymond, 36

Colding, on energy, 50 .

Colour blindness, 125 .

Colour, Helmholtz's researches on, II2.

Colour, nature of, 116.

Combination tones, 159, 16r.

Conservation of energy, 193, 242.

Consonance, nature of, 156 .

Cooper, Dr, reference to, $9 \mathbf{~}$.

Copernicus, reference to, 19 .

Corresponding retinal points, 173,178 .

Corti, physiological action of the organ of, 151,154 .

Coulomb, reference to, 2x; law of electrical attraction, 204. 


\section{INDEX}

Cramer, on accommodation, 95.

Critique of pure reason, Kant's, 253.

Cumming, W., reference to, 77 .

Currents, electrical, effects of those of short duration, rrr.

Cuvier, reference to, $2 x$.

Cyclic systems, Hemholtz on, 234.

D'Alembert, reference to, 40, 52.

Darwin, head of, 283 .

Darwin, reference to, $x 9$.

Darwinian hypothesis and innate ideas, 256.

Davy, Humphry, on heat, 47.

De la Tour, Cagniard, reference to, 26.

Democritus, reference to, 253.

Descartes, 44, 46, 52, 96, 236, 252, 257.

Difference tones, $x 59$.

Dispersion, anomalous, 227.

Dissipation of energy, 193 .

Dissonance, nature of, 156 .

Donders, reference to, $14,82,85,97$; reference to Cramer by, 97 ; on vowel tones, 162 ; on movements of eyeballs, 177 .

Dove, reference to, $22,43, \mathrm{r} 8 \mathrm{r}$.

Draper, reference to, 1 r 8 .

Drumhead, action of, $x_{33}, x_{35}$.

Du Bois Reymond, reference to, $\mathbf{I r}$, $15,107,108,109,118, x_{33}, 135$.

Ductus cochlearis, action of, 152 .

Dusch, reference to, 29.

Dynamics, Helmholtz on principles of, 233.

EAR, bones of, 133,135 .

Ear, damping arrangements in, 150.

Ear, internal description of, $x_{3} 8$.

Edinburgh, reference to, 92 .

Electric interrupter, of Helmholtz, $x 65$.

Electricity, animal, 66, ro4.

Electricity, theories of, 203 ; Helm. holtz's researches in, 200 .

Electrodes, non-polarizable, ro5.

Electrodynamics, 203.

Empirical philosophy, 25r.

Encyclopædists, reference to, 21 .

Energy, conservation of, 39, 193 .

England, Helmholtz's impressions of,

Erlach, Von, reference to, 74 .

Essex, reference to, 76 .

Ether, theory of movements in, 248.

Euclid, anxioms of, 254, 262 .

Euler, reference to, 40, $11_{4}, x_{95}, 237$.

Eyeballs, movements of, $17 x, 176$.

Eyeball, muscles of, 175 .

Eye, changes in, in accommodation, roo; reflected light from, 73 .

Faraday, reference to, gr ; the lecture,
Helmholtz on, 2rr, 222; on specific inductive capacity, 205.

Fechner, reference to, $x_{3}$.

Fermentation, studies by Helmholtz on, 26.

Fingal's Cave, reference to, 92.

Fitness, professorial, Helmholtz on, 276 .

Fluid, nature of, 195 .

Fluids, discontinuity in, $20 r$.

Forbes, on ice, $22 \mathrm{x}$.

France, intellectual life in, $2 x$.

Frederick the Great, reference to, 236.

Frederick, Crown Prince, reference to, 279.

Freedom, Helmholtz on, 275.

French Republic, President of, reference to, 280.

Fresnel, reference to, II4.

Frictionless fluids, 196.

Friedrich Wilhelm Institute, reference to, 40 .

Fourier's theorem, 144, r67.

GaliLeo, reference to, $x 9,38,242 j$

Galvani, reference to, $3 x$.

Gaugain, galvanometer of, $2 \mathrm{rr}$.

Gauss, reference to, $22 \mathrm{r}$; on unit of force, 239 .

Gay-Lussac, reference to, 27.

Geometry, axioms of, 26r,

Geometry, non-Euclidean, 266.

German student life, Helmholtz on, 275.

Germany, science in, during early part of Igth century, 18 .

Goethe, reference to, 119,221 ; lecture by Helmholtz on, 274 .

Goodsir, John, anatomist, reference to, 14.

Graefe, Von, reference to, 83 .

Grassman, reference to, 205.

Grove, W. R., on condition of physical forces, 48 , $9 \mathrm{r}$.

Gruithuisen, reference to, 76 .

HALLER, reference to, $x_{2}$; on rate of nervous impulse, 64 .

Hamilton, William Rowan, 9r, rgo, 243 ; principle of varying action, $235,244$.

Hansemann, David, reference to, 282.

Harmonic tones, $147,1_{48} 8$.

Hartley, reference to, II4.

Hassenstein, on reflected light from eye, 74 .

Hay fever, Helmholtz on, $18 \mathrm{r}$.

Heat, animal, 33.

Heat, dynamical equivalent of, 49 .

Hegel, reference to, 20,268 .

Helmholtz, Ferdinand, $x$

Helmholtz, apparatus for phase relations, 149 ; anomalous dispersion, 


\section{INDEX}

230 ; as a lecturer, 273 ; as librarian, 40 ; as a mathematician, 188 ; as a teacher, 130 ; birth of, 1 ; brain of, 282 ; certificate from rector, 5 ; choice of medical profession, 9; closing years, 279 ; death of, 282 ; Director of Physico-Technical Institute, 185 ; early days as surgeon, 25; early friends, 6, ro ; ennobled, 279; essay on energy, 40 ; first marriage, 58 ; second marriage, 187 ; general sketch of career, 16 ; gold medal in honour of, 280 ; improvements on inductive coil, 37 ; inaugural thesis, 14 ; investigations on electricity, 206 ; letter to Ladwig, 90 ; on animal heat, 33,34 ; on art, 270 ; on conbination tones, 160; on conservation of energy, 39,53 ; on colours, I 19 , 124 ; on Du Bois Reymond's theory of muscle current, 108; on empirical philosophy, 256; on fermentation, 28 ; on hay fever, $18 \mathrm{x}$; on his own work, 286 ; on magnified movements, IIo; on muscular contraction, 33 ; on philosophy of Kant, 255 ; on physiological acoustics, r29, r31; on principle of least action, 246 ; on rate of nervous impulse, 59 ; on red and blue and green, $120 ;$ on relation of physics to physiology, 31 ; on superposition of spectra, 122; on vowel tones, I6 3 ; ophthalmoscope, 71 ; parentage, 1 ; personal appearance, 283 ; personal characteristics, 283,287 ; philosophical position of, 250 ; school days, 3 ; speech on receiving medal, 280 ; speech when presented with Von Graefe medal, 86 ; statue of, in Berlin, 280 ; student life, 8 ; surgeon to the Red Hussars, 25 ; and Robert Mayer, 50.

Helmholtz, Robert, reference to, 187 .

Herbart, reference to, 270.

Hermann, Ludwig, reference to, 89 .

Hermann, Ludwig, on muscle current, 109 ; on summation tones, 160.

Hering, reference to, $1_{3}, 1_{19}$; colour theory of, 127 .

Herschel, Sir John, reference to, 128.

Heintz, physicist, ro.

Hertz, Heinrich, reference to, Igo, $215,217,2$ I9.

Hertz, Heinrich, Helmholtz on, 285 ; reference to, 243, 249.

Hildebrand, crest of Helmboltz by, 280.

Hoffman, reference to, 29 .

Horopter, Helmholtz on the, I72; true form of, r79.

Horopter, the, 260 .

Humboldt, Alexander von, reference to, 2I, 25 .
Hunter, John, reference to, 12.

Huygens, reference to, II, 239. Hydrodynamics, r94.

ICE, 222.

Infant, human, experience gained by, 258.

Italy, King of, reference to, 280.

JACOBI, reference to, 43 ; on potential energy, 243.

Jaeger, Von, reference to, 82 .

Jones, Bence, reference to, $9 \mathbf{r}$.

Jones, Wharton, reference to, 77 .

Joule, on dynamical equivalent of heat, 49,51 ; reference to, 91 .

KANT, philosophy of, 253 ; on dynamics, 237 ; on nature of judgments, 254 ; doctrine of space, 260 ; on the beauti ful, 268.

Karsten, Gustav, physicist, Io.

Kelvin, Lord, on thermodynamics, 52 ; friendship with Helmholtz, 92 ; on phase, I50; reference to, I65; on electricity, 211 ; on ice, 222 ; on dissipation of energy, I93; on theory of constitution of matter, 196,198 ; on Faraday, 206; on rotational movements of ether, 253 .

Kinetic, potential, 247.

Kirchhoff, reference to, I0, $43,107,184$

Klangfarbe, $\mathrm{I}_{43}$

Klerker, De, reference to, 230.

Knots, Professor Tait on, 200.

Koenigsberger, Leo, reference to, 236

König, Arthur, reference to, r26.

Konigsberg, Ir2.

Königsberg, University of, 58,89 .

Kronecker, Hugo, reference to, 90.

Kussmaul, reference to, 78 .

LAGRANGE, reference to, I95, 243.

La Hire, reference to, 78 .

Lamarckian, principle of adaptation, 256.

Langenbeck, Max, reference to, 97.

Laplace, mathematician, reference to, 21, 191.

Lavoisier, chemist, reference to, 2 I, 34 , 41.

Lectures by Helmholtz, 274 .

Lectures, Helmholtz on, 276.

Leeuwenhoek, reference to, 26

Leibnitz, reference to, 40,44 ; on dynamics, $46,52,230,237,243,252$, 287.

Linnaus, reference to, rg.

Liebig, reference to, 21, 22, 28.

Light, theory of, $114,116$.

Lissajous, reference to, 166.

Listing, schematic eye of, 102, 178 .

Lobatschewsky, reference to, 266 . 


\section{INDEX}

Locomotion, animal, Helmholtz on, IIr.

Locke, John, on heat, 46 ; philosophy of, $251,257$.

Loxkman, fables of, 3 .

Lotze, reference to, 250 .

Lovering, reference to, $x 99$.

Ludwig, Carl, reference to, II ; letter from Helmholtz to, $g$ o.

MAGnus, Gustav, physicist, Io, 22 ; influence of teaching of, 22 ; death of, 184 ; lecture by Helmholtz on, 275.

Marey, E.J., reference to, $x \mathbf{x x}$.

Maskeleyne, reference to, 70.

Matteucci, reference to, 65 ; indnced contraction, 66, 104.

Maximilian, King of Bavaria, reference to, 149 .

Maxwell, Clerk, reference to, $4 \mathrm{I}, 122$, $185,299,207,249,264$; on colour, II2, II7; on dynamics, 48; on electro-dynamics, 213 ; on electromagnetic waves, $2 \times 6$; on Faraday, 205 ; verse on mathematicians, 190.

Maupertuis, reference to, 235 .

Mayer, Robert, reference to, 23,48 , $54,242$.

Medal, ophthalmological, presented to Helmboltz, 84.

Medicine, lecture by Helmholtz on thought in, 277.

Melloni, reference to, $x \times 8$.

Membrana tympani, action of, $x 33$.

Mendelssohn's 'Midsummer' Night's Dream' music, $134,284$.

Mery, reference to, 78 .

Meteorology, Helmboltz on, 232.

Microscope, Helmholtz on, 232.

Mirror, use of in physical experiment, IIo.

Mitscherlich, reference to, 2r, 22, 28.

Mohl, Anna von, reference to, 187 .

Monads, Leibnitz's system of, 253.

Montgolfier, on beat, 47 .

Montpellier, mathematicians of, $6 x$.

Müller, Johannes, anatomist, ro, 23 ; on eye, $24, x_{19}, x_{29}, x_{41}, x_{52}, x_{73}, x_{7}$, 250,275 ; influence of, $x \mathbf{x}$; specific energy of nerves, $x_{3}$; on rate of nervous impulse, $6_{5}, 18_{4}$.

Mursinna, Surgeon-General, 8.

Muscle, current, 105.

Music, r34.

Musicians, indifference to investigation, $x_{37}$.

Myograph, 36 .

NeEF, interrupter of, 37 .

Nerve cells, discovery regarding, 15 .

Nerves, specific energy of, $x_{3}$.

Nervous impulse, rate of, 59 .

Negative variation, 107 .
Newton, reference to, $19,44,52,44$, $45, x_{4}, x_{17}, 146$; on the aether, 199 ; on action at a distance, $203,242,238$, Neumann, F. C., reference to, 22, 204, 207.

Neumann, C., reference to, 205, 214 . Nobili, reference to, ro4.

OHM, referençe to, 22, I44, I45, 148.

Ophthalmological Congress at Heidel. berg, 84 .

Ophthalmometer, the, 92,98 .

Ophthalmoscope, invention of, $7 \mathbf{r}$; theory of, 80.

Optic nerves, course of fibres in, I74.

Optics, Helmholtz on physical, 225.

Organ pipes, Helmholtz on theory of, $x 66$.

Panntrag, Helmholtz's ideas as to, 27 r. Paionios, reference to, 86.

Pallas, reference to, 74 .

Partial tones, $x_{47}, x_{4} 8$.

Penn, William, x.

Phase, can the ear perceive, $r 48$.

Phidias, reference to, 85 .

Physical Society of Berlin, reference to, 4 I.

Physico-Technical Institute, 185.

Physiology, considered as a science, 20 ; methods of, 29.

Piotrowski, G. von, reference to, 202 .

Poggendorff, reference to, 22, 43, 227.

Poullet, reference to, $60,62,64$.

Praxiteles, reference to, 86.

Prevost, reference to, 76 .

Principle of least action, 244.

Pseudo-spherical surfaces, 263.

Psycho-physical investigations, 7o.

Purkinje, images of, 95 .

Pythagoras, reference to, $\mathbf{r}_{4} 8$.

QUINCKE, physicist, 10.

RANkine, Macquorne, reference to, $9 x$.

Rayleigh, Lord, on phase, 150,189 .

Reed pipes, 167.

Rekoss, reference to, 89 .

Reimer, G. E., reference to, 4 r.

Reiss, reference to, 43.

Rendu, reference to, $22 x$.

Resonators, $x 46$.

Reute, on ophthalmoscope, 78 .

Reymond, Du Bois, early friendship with Helmholtz, 10, 24, 35, 43, 60; on animal electricity, $65,94,104$; physical theory of as to muscle current, 106, 184, 257, 284.

Riemann, reference to, $x_{39}, 205,224$; notions as to space, 264 .

Riess, reference to, 22 .

Ritter, electrical experiments of, 20 .

Root, E., reference to, 210 . 


\section{INDEX}

Rowland, H. A., reference to, 2 ro.

Roux, Le, reference to, 229.

Royal Institution of Great Britain, 32, r83.

Rücker, reference to, 207.

Rudolphi, reference to, 76.

Rnmford, Count, reference to, 32, 47.

SABINE, General, reference to, $9 x$.

Saccharomycetes, 26.

Saccule, 138.

Schelling, reference to, 20, 268; on art and science, 272.

Schleiden, botanist, reference to, I2.

Schlemm, canal of, roo.

Schopenhauer, reference to, 268.

Schroeder, reference to, 29.

Schwann, reference to, 12 ; on fermentation, 26, 27

Scotch Highlands, reference to, 92.

Seebeck, on thermo-electricity, 20.

Seguin, on heat, 47.

Semi-circular canals, $x 42$.

Sensations of tone, work on, $89,13 r$.

Sharpey, physiologist, reference to, 14.

Siemens, Werner, electrician, ro, 185, r86.

Smaasen, reference to, Io7.

Somerville, reference to, 47.

Sound, physiological effect of, $\mathbf{r}_{33}$.

Sound shadows, 166.

Space, of various dimensions, $262,265$.

Spencer, Herbert, reference to, 257.

Spinoza, reference to, 252.

Stahl, reference to, 39 .

Steinway, Messrs, reference to, $x 67$.

Stokes, Sir G. G., reference to, $9 x$, I95; on vortex motion, 197.

Students, Helmholtz on judgment of, 277.

Summation tones, $\tau 60$.

Sweden, King of, reference to, 280 .

Sylvester, Joseph, reference to, rgo.

Syren, polyphonic, of Helmholtz, 140.

TAIr, reference to Prof. P. G., 44, $45,47,200$.

Talbot, Fox, reference to, 228.

Teachers, Helmholtz on, 276.

Telephone, Helmholtz on the, 167.

Telestereoscope of Helmholtz, 180.

Temperature, influence of, on fermen-

itation, 28.

Thomson, Allen, reference to, $\mathrm{r}_{4}$.

Thomson, James, reference to, 222.

Thomson, Sir William, reference to, (see Kelvin, Lord).
Thorax, Helmholtz on movements of, 169.

Tidal actions, 22 .

Tone, analysis of, ro4.

Tones, combination, $x_{59}$.

Tones, compound nature of, 147 .

Tongue pipes, r6r.

Tyndall, reference to, $\mathbf{x}$, 22I, 273.

UTRICLE, $x 38$.

VARIATION, negative, ro7.

Velten, Olga von, 58 .

Vibration microscope, $x 66$.

Violin, Helmholtz on strings of, $x 65$.

Virchow, early friend of Helmholtz, ro.

Viscous fluids, $\mathrm{rg6}$.

Vision, conditions of, 92 ; laws of, with one and with two eyes, $x 73$.

Volkmann, reference to, 284 .

Volta, reference to, 3 I.

Voltaire, reference to, $32,236$.

Vortex motion, r94.

Vortex rings, 197 .

Vortices, nature of, 197 .

Vowel tones, 162 .

Vulpian, physiologist, reference to, $x_{4}$.

WAGNER, reference to, $\mathrm{r} 34$; head of, 283.

Watersponts, Helmholtz on, 223.

Wave forms, 143 .

Weber, Wilhelm, reference to, 22; law of electrical attraction, 204, 207, 214, 215.

Weber, Ernst \& Heinrich, 23, 153.

Weber, C., on electrical irritation of the eye, roo.

Wheatstone, reference to, $9 \mathrm{I}$; stereo. scope, 178 .

Wiedemann, reference to, II, 22, 24, 76, 191.

William I., Emperor, reference to, 279.

William II., Emperor, reference to, 280.

YEAST, studies in, 27.

Young, Thomas, reference to, 36,122 , ${ }_{123}, 1_{24}, 1_{52}$; compared with Helmboltz, 287 ; on accommodation, 96 ; on lens, xoo; on light, $\mathrm{xI}_{4}$; theory of colour, Iry; use of rotating cylinder, 62; Helmholtz, theory of colour, 125 .

ZEHENDER, Von, reference to, 84. Zeller, Eduard, reference to, 267.

Zinn, zonule of, ror. 
E R R A T A

Page 233. Line 4. For 'on' read 'under.'

" " 5 . Before 'bodies' insert ' heavy.'

"237. "10. Insert comma afier 'Newton." 


\section{REBMAN'S NEW BOOKS.}

Just Published. In one handsome $8 v 0$ vol. of 848 pp., profusely illustrated, price 22s. 6 d.

A Text-Book of Pathology. By Alfred Stenger, M.D., Instructor in Clinical Medicine in the University of Pennsylvania; Physician to the Philadelphia Hospital; Professor of Clinical Medicine in the Women's Medical College; Physician to the Children's Hospital, Philadelphia, \&c.

Just Published.-In One demy $8 v 0$ Vol. of 404 pp., Illustrated, price gs.

The Care of the Baby. By J. P. Crozer Griffith, M.D., Clinical Professor of Diseases of Children, University of Pennsylvania ; Physician to the Children's Hospital, Philadelphia, \&c.

'The best book for the use of the young mother with which we are acquainted. There are very few general practitioners who could not read the work through with advantage.'-ARCHIvES OF Pediatrics.

In One handsome imperial $8 v 0$ Vol. of about 1200 pp., profusely Illustrated with Woodcuts and Half-tone and Coloured Plates, price $38 s$.

Gould's Year-Book of Medicine and Surgery for 1899 . (Fourth year of issue.) A Yearly Digest of Scientific Progress and Authoritative Opinion in all Branches of Medicine and Surgery, drawn from Journals, Monographs, and Text-books of the Leading American, British and Foreign Authors and Investigators. Under the general

Editorial Charge of GEORGE M. Gould, M.D., assisted by a distinguished staff of Collaborators.

The LANCET says :-' It is emphatically a book which should find a place IN EVERY MEDICAL LIBRARY.' ( 1896 issue.) 'Its value as a work of reference in every department of medicine and surgery is VERY GREAT.' (1898 issue.)

The British Medical Journal says of this 'Year-Book':- In form....it is all that could be desired; while in respect of its contents IT iS UNRIVALLED AMONG SIMILAR PRODUCTIONS IN THE ENGLISH LANGUAGE.'

Now Ready. In One demy $8 v 0$ Vol. of 276 pp., profusely Illustrated with over 100 Woodcuts and Sphygmograms of Cases, with 4 Plates exhibiting 48 Figures. Price Ios.

Cardiac Failure and its Treatment. With Especial Reference to the Use of Baths and Exercises in Failure of the Heart. By ALEXANDER MORIsON, M.D., Edin., F.R.C.P. Edin., \&c. With an Appendix by MEDizinalrath Dr GroedeL, of Bad Nauheim.

'A valuable work upon the nature and management of Heart Failure'-YEAR-BOOK or TREATMENT, I899.

\section{One of the most Important Literary Innovations of the Day.}

Now Ready. In One handsome imp. $8 v 0$ Vol. of 965 pp., with 295 Illustrations and 12 Half-tone and Coloured Plates. Price, cloth, 34 s.

Anomalies and Curiosities of Medicine. Being an Encyclopædic Collec-

tion of Rare and Extraordinary Cases, and of the most striking incidences of Abnormality in all branches of Medicine and Surgery, derived from an Exhaustive Research of Medical

Literature from its Origin to the Present Day, abstracted, classified, annotated and indexed

by Geo. M. Gould, A.M., M.D., and Walter L. Prle, A.M., M.D.

'The work of Drs Gould and Pyle is, we venture to predict, destined to become a classic in medical literature.'-British MEdical Journal.

Just Published. In One $8 v o$ Vol. of 400 pp., Illustrated. Price I7s.

The Surgical Complications and Sequels of Typhoid Fever. By

William W. Keen, M.D., LL.D., Professor of the Principles of Surgery and of Clinical

Surgery in the Jefferson Medical College, Philadelphia; Corresponding Member of the

Société de Chirurgie, Paris; Honorary Member of the Société Belge de Chirurgie, \&c.

The BRITISH MEdicAL JourNAL of March 25 th, in an important leading article on the subject dealt with by Prof. Keen in this book, states that- " The work deserves the attentive perusal of all practitioners."

The LANCET says :- This work must long remain a standard source of reference.....and cannot fail to be of the greatest value not only to surgeons but also to physicians.'

\section{LONDON : REBMAN, LIMITED,}

129 SHAFTESBURY AVENUE, CAMBRIDGE CIRCUS, W.C.

Reg. Tel. Address: 'Squama, London.' Telephone No. 2026, Gerrard. 


\section{REBMAN'}

\section{MEDICAL REFERENCE - ATLASES}

\section{(Lehmann's Medicinische Handatlanten.)}

In planning this series of Atlases, arrangements were made with representative publishers in the chief medical centres of the world for the publication of translations into nine different languages, the lithographic plates for all these editions being prepared in Germany, where work of this kind has been brought to the greatest perfection. In this way the enormous expense of producing the plates was shared by the various publishers, so the cost to each one was reduced to practically one-ninth. Thus it has been possible to secure for these Atlases the best artistic and professional talent, to produce them in the most elegant style, and yet to offer them at a price heretofore unapproached in cheapness.

(20) These Atlases offer a ready and satisfactory substitute for clinical observation.

New Volumes just Issued.

Atlas of External Diseases of the Eye ; including a Brief Treatise on the PATHology and TREATMENT. By Dr O. HAAB, of Zurich. Edited by G. E. DE Scrweinitz, M.D., Professor of Ophthalmology, Jefferson Medical College, Philadelphia. With 76 Coloured Plates and 6 Engravings. Price 12s, 6d, net.

Atlas of Skin Diseases. By Prof. Dr Franz Mracek, of Vienna. Edited by Henry W. Stelwagon, M.D.; Clinical Professor of Dermatology, Jefferson Medical College, Philadelphia. With 80 Coloured Plates from Original Water-Colours. Cloth $15 \mathrm{~S}$. net.

\section{Other Volumes in the Series Recently Published.}

Atlas of Internal Medicine and Clinical Dlagnosis. By $\mathrm{Dr}$ CHr. JAKoB, of Erlangen. Edited by Augustus A. Eshner, M.D., Professor of Clinical Medicine in the Philadelphia Polyclinic. 68 Coloured Plates and 64 Illustrations in the text. Cloth, r2s. 6d. net.

... Dr Jakob's work, which is to some extent a new departure, deserves nothing but praise. The information is accurate, and up to present day requirements.'-British Medical Journal.

Atlas of Legal Medicine. By Dr E. von Hoffmann, of Vienna. Edited by Frederick Peterson, M.D., Clinical Professor of Mental Diseases, Women's Medical College, New York. With 120 Coloured Figures on 56 Plates and 193 Half-tone Illustrations. Cloth, 15s. net.

'The plates are most beautifully executed. . . Their interest is greatly added to by a brief account of the cases from which the drawings were made.'-The Larcet.

Atlas of Diseases of the Larynx. By Dr L. Grunwald, of Munich. Edited by Charles P. GRAYson, M.D., Lecturer on Laryngology and Rhinology in the University of Pennsylvania; Physician-in-Charge of the Throat and Nose Department, Hospital of the University of Pennsylvania. With ro7 Coloured Figures on 44 Plates. Cloth, ros. 6d. net.

- We commend this Atlas to everyone embarking on the study of diseases of the throat . it will be invaluable.'-The Practitioner.

Atlas of Operative Surgery. By Dr O. ZuckerkandL, of Vienna. Edited by J. Chalmers DA Costa, M.D., Clinical Professor of Surgery, Jefferson Medical College, Philadelphia. With 24 Coloured Plates and 217 Illustrations in the text. Cloth, I2s. 6d, net.

'The work is certain to be a popular one with the medical profession.'-Liverpool Medico. Chi. Journal.

Atlas of Syphilis and the Venereal Diseases. By Professor Dr Franz MrACEK, of Vienna. Edited by L. Bolton BANGs, M.D., late Professor of GenitoUrinary and Venereal Diseases, New York Post-Graduate Medical School. With $7^{I}$ Coloured Plates. Cloth, r5s. net.

'We have no hesitation in recommending it to our readers. '-Glasgoze Medical Journal.

DESCRIPTIVE CIRCULAR AND SAMPLE PLATE POST FREE ON APPLICATION.

\section{LONDON : REBMAN, LIMITED,}

129 SHAFTESBURY AVENUE, CAMBRIDGE CIRCUS, W.C. 


\section{STANDARD MEDICAL WORKS}

For Specialists, General Practitioners, and Stadents.

Practical Diagnosis. - The Use of Symptoms in the Diagnosis of Disease. By Hobart A mory Hare, M.D., Professor of Therapeutics and Materia Medica in the Jefferson Medical College of Philadelphia, etc. New (4th) edition. 624 pages, with 204 engravings, and 14 full-page coloured plates. Cloth, 2Is. net. Just ready

We can thoroughly recommend this book to practitioners and students.'-Lancet.

A Text-Book of Practical Therapeutics; with Especial Reference to the Applications of Remedial Measures to Disease and their Employment upon a Rational Basis. By Hobart Amory Hare, M.D., Professor of Therapeutics and Materia Medica in the Jefferson Medical College of Philadelphia. With special chapters by Drs G. E. DE Schweinitz, Edward Martin, and Barton C. Hirst. New (7th) edition. In one octavo volume of 775 pages. Cloth, 21s, net. (Revised in accordance with the new edition (1898) British Pharmacopoia.)

'We may repeat the words of our last notice. We can thoroughly recommend this book to practitioners and students.'-Lancet.

\section{A Manual of Clinical Dlagnosis by Microscopical and Chemical}

METHODS. For Students, Hospital Physicians and Practitioners. By Charles R.

Simon, M.D., Late Assistant Resident Physician, Johns Hopkins Hospital, Baltimore.

New (2nd) edition. In one very handsome octavo volume of 565 pages, with 133 engrav-

ings and 14 full-page coloured plates. Cloth, 16s. net.

'One of the best and most compendious manuals for the clinical laboratory that has yet appeared.'-Lancet.

\section{Tillmanns' Surgery.-3 Vols. A Text-Book of General Surgery. By} Dr Hermann Tillmanns, Professor in the University of Leipzig. Edited by Lewis A. Stimson, M.D., Professor of Surgery in the New York University. Octavo, cloth, ŁI, IS., net, per vol.

Vol. I.-The Principles of Surgery and Surgical Pathology. General Rnles governing the Application of Dressings. Translated from the Third German Edition by John Rogers, M.D., and Benjamin T. Tilton, M.D. With 447 Illustrations.

Vol. II.-Regional Surgery. Translated from the Fourth German Edition by Benjamin T. Tilton, M.D., New York. With 417 Illustrations.

Vol. III.-Regional Surgery. With 517 Illustrations.

Complete work now ready, price $£_{3}, 3$ s. net.

'One of the best works on modern surgery available in the English language.'-Practitioner.

'There is no English text-book on the subject which can in any way be compared with it. . . . Indeed, there has been nothing issued at all comparable to this work. ${ }^{2}-$ Scottish Medical and Surgical Journal.

Manual of the Diseases of Children. By JoHn MAIISON TAYlor, A.M., M.D., Professor of Diseases of Children, Philadelphia Polyclinic, etc.; and William H. Werls, M.D., Adjunct Professor of Obstetrics and Diseases of Infancy in the Philadelphia Polyclinic, etc., etc. Complete in one illustrated volume of 743 pages, gilt top, price 16 s. net.

'One of the best books for the use of the student and the practitioner.'-Lancet.

A Manual of Modern Surgery, General and Operative. By JоHN Chalmers Da Costa, M.D., Demonstrator of Surgery, Jefferson Medical College, Philadelphia; Chief Assistant Surgeon, Jefferson Medical College Hospital; Surgical Registrar, Philadelphia Hospital, etc. and edition, revised and enlarged, with 386 Illustrations, nearly rooo pages. Royal octavo, cloth, price 2 IS., net.

'We regard Dr Da Costa's Manual as the most concise, reliable and up-to-date of the many works on surgery.'-Glasgow Medical Journal.

Operative Gynecology. By Howard A. Kelly, A.B,, M.D., Fellow of the American Gynecological Society; Professor of Gynecology and Obstetrics in the Johns Hopkins University, and Gynecologist and Obstetrician to the Johns Hopkins Hospital, Baltimore, etc. In two royal octavo volumes, with 24 plates and 590 Illustrations. Handsomely bound in half-morocco, gilt tops. Vol. I., 580 pages; Vol. II., 573 pages. Price $£_{3}, 3$ s. net.

'The volumes are of the highest merit, will long remain the standard wcrk upon the subject of which they treat, and should be in the hands of all gynecologists and surgeons performing pelvic operations.'-Lancet. 


\section{SOME INTERESTING BOOKS}

PUBLISHED BY

\section{THE SCIENTIFIC PRESS}

Demy 8vo, with Two Plates, cloth gilt, over 400 pp., I2s. 6 d. net.

Medical Fistory from the Earliest Times. By E. T. WITr INGTON, M.A., M.B., Oxon.

' One of the best attempts that has yet been made in the English languas to present the reader with a concise epitome of the history of medicine, and such we very cordially comımend it.'-Glasgow Medical Journal.

\section{Demy 8vo, with Portrait, cloth gilt, I6s.}

George Farley, F.R.S.; or, The Life of a London Physiciar By Mrs Alec Tweedie.

'Does a reader thirst for adventure? Let him study Dr Harley's experienc at the time of the Crimean War : his escape from prison was little short miraculous. In the matter of miscellaneous reminiscences Mrs Alec Tweedie book is a fruitful field.'-Liverpool Post.

Crown 8vo, with many quaint Illustrations in the Text, several of which have never before been reproduced, cloth extra, $5 \mathrm{~s}$.

The Mystery and Romance of Alchemy and Pharmacy By C. J. S. Thompson.

'A very entertaining book, bringing together an extensive body of curiou lore with regard to the curative art.'-Aberdeen Daily Free Press.

\section{Imperial I 6 mo, cloth extra, gilt, $6 s$.}

Poison Romance and Poison Mysteries. By C. J. S. Thompson Author of 'The Mystery and Romance of Alchemy an Pharmacy,' etc., etc.

'A great deal of curious information concerning the history of poisons an poisoning.'-Saturday Review.

'Will attract readers who may be interested in the subject of poisons gene ally. The matter is treated in the author's best manner; the book is extremel well printed, and it is also handsomely bound.'-Pharmaceutical Journal.

Complete Catalogue of the Company's Publications Post Free on Application

\section{Condon}

THE SCIENTIFIC PRESS, LTD.

28 and 29 Southampton Street, Strand, W.C. 


\section{An Interesting New Book}

PUBLISHED BY

MR T, FISHER UNWIN

\section{EXPERIMENTS ON ANIMALS}

BY

\section{S'TEPHEN PAGET}

Author of 'John Hunter' ('Masters of Medicine'), Etc.

WITH AN INTRODUCTION BY LORD LISTER

Illustrated. Crown 8vo, Cloth, $6 \mathrm{~s}$.

This book is a short account of the chief results that have been obtained, by the help of experiments on animals, in physiology, pathology, bacteriology, and therapeutics. It also gives a reprint of the Act, and of various official statements as to its administration. It neither gives a history of all experiments on animals, nor defends everything that was done in the past, nor isolates the experimental method from other ways of advancing the science and art of medicine. It does not touch ethics, it avoids controversy, and it is concerned not with any experiments that failed, but only with those that were successful. Its single purpose is to show what has been gained by this method, and what conditions are imposed on it by law in the United Kingdom. The book may be useful both to medical men and to all who desire assurance that experiments on animals are justified by the results that have come of them.

London: T. FISHER UNWIN, 11 Paternoster Buildings, E.C. 


\title{
STANDARD MEDICAL WORKS
}

\author{
PvuLserb By
}

\section{The Central Publishing Company}

I8 CATHERINE STREET, STRAND, LONDON, W.C.

\section{DR WALLACE'S \\ CONSTITUTION OF MAN}

SiDan in ibealth SIDan in Disease

By J. ROBERTSON WALLACE, M.B., C.M., Edin.

Gives the Symptoms of and Advises Practically upon every Ailment Man can possibly be subject to.

Complete in 420 pages, with Plates and Illustrations Bound in Cloth. Price 5s., of Booksellers, or Post Free, 5s. $3 d$.

By a Member of the Royal College of Surgeons, London

\section{THE DICTIONARY OF DISEASES AND THEIR TREATMENT}

Constituting, under about roo0 Headings and References, A Complete A B C of Domestic Medicine and Surgery

The Dictionary of Diseases, complete in 183 pages. This book will be found invaluable as a work of reference. Whatever the symptoms, reference can be made, and the most valuable advice immediately found as to Medicine, Diet, Drinks, Etc.

$$
\text { Of all Booksellers 3s. 6d., or Post Free, 3s. } 9 d \text {. }
$$

\section{HOW TO PROLONG LIFE}

An Inquiry into the cause of 'OLD AGE' and 'NATURAL DEATH,' showing the Diet and Agents best adapted for a Lengthened Prolongation of Existence.

By CHAS. W. De LACY EVANS, M.R.C.S.E.

This work gives many useful and valuable hints for the preservation and enjoyment of life.

Price 5s. through all Booksellers and at the Bookstalls, or sent direct on receipt of 5s. $3 d$., Post Free. 

DATE DUE

\begin{tabular}{l|l|l|l}
\hline JAN 31 1972 & & \\
\hline MAR 1 1972 \% & & \\
\hline & & & \\
\hline & & & \\
\hline & & & \\
\hline & & & \\
\hline & & & \\
\hline & & & \\
\hline & & & \\
\hline & & & \\
\hline & & & \\
\hline & & & \\
\hline & & & \\
\hline & & & \\
\hline & & & \\
\hline GAYLORD & & & PRINTED IN USS A.
\end{tabular}




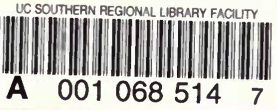


